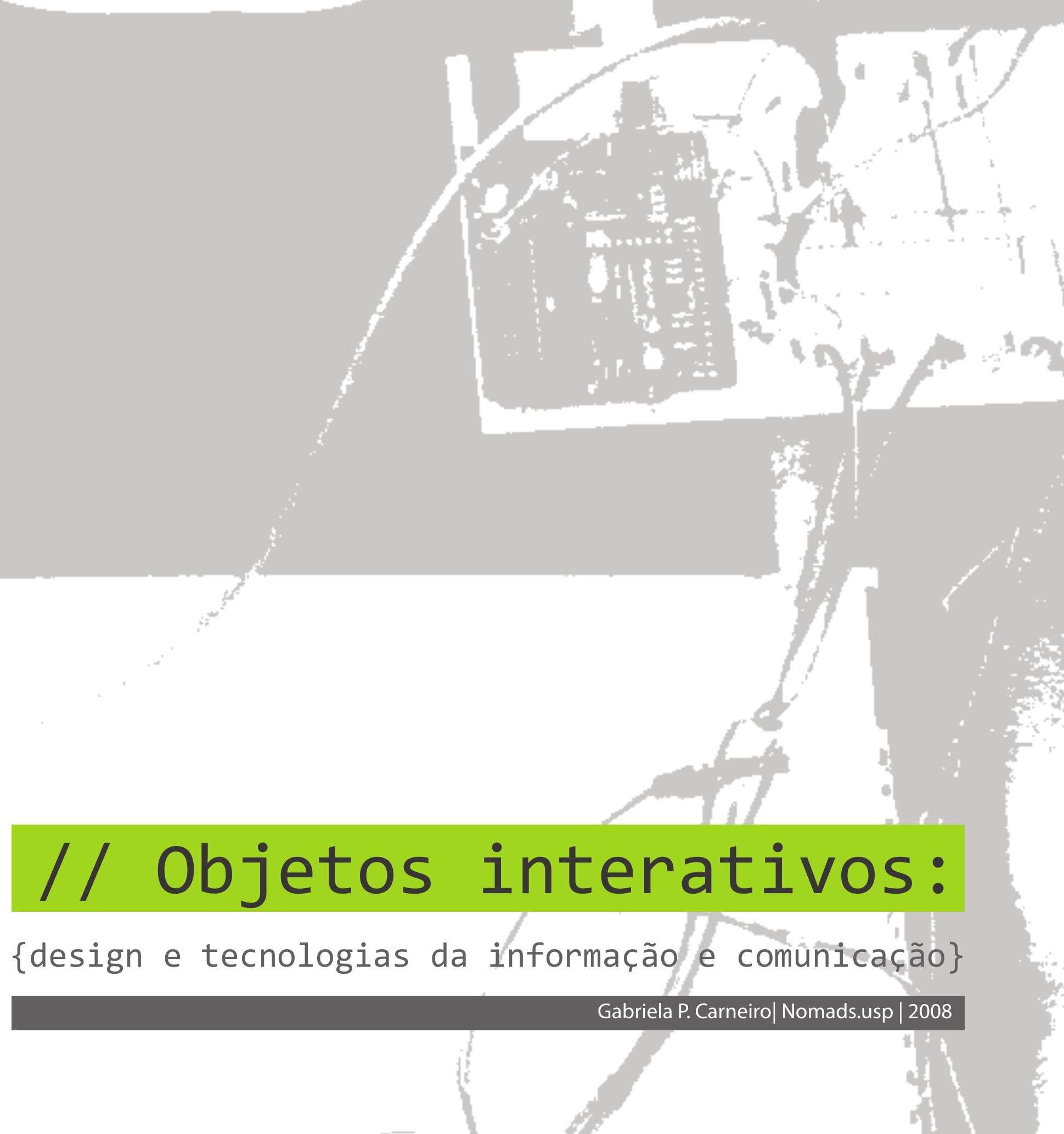





\section{// Objetos interativos: design e tecnologias da informação e comunicação}

Dissertação de mestrado

\section{Arq. Gabriela P. Carneiro}

Orientador: Prof. Assoc. Dr. Marcelo Tramontano Nomads.usp | São Carlos, 2008 
AUTORIZO A REPRODUÇÃO E DIVULGAÇÃO TOTAL OU PARCIAL DESTE TRABALHO, POR QUALQUER MEIO CONVENCIONAL OU ELETRÔNICO, PARA FINS DE ESTUDO E PESQUISA, DESDE

QUE CITADA A FONTE.

Ficha catalográfica preparada pela Seção de Tratamento da Informação do Serviço de Biblioteca - EESC/USP

\begin{tabular}{|c|c|}
\hline $\mathrm{C} 2890$ & $\begin{array}{l}\text { Carneiro, Gabriela P. } \\
\text { Objetos interativos : design e tecnologias da } \\
\text { informaçăo e comunicaçăo / Gabriela P. Carneiro; } \\
\text { orientador Marcelo Tramontano. -- São Carlos, } 2008 \text {. }\end{array}$ \\
\hline & $\begin{array}{l}\text { Dissertação (Mestrado-Programa de Pós-Graduação em } \\
\text { Arquitetura e Urbanismo e Area de Concentração em } \\
\text { Arquitetura, Urbanismo e Tecnologia -- Escola de } \\
\text { Engenharia de São Carlos da Universidade de São Paulo, } \\
\text { 2008. }\end{array}$ \\
\hline & $\begin{array}{l}\text { 1. Arquitetura. 2. Computação aplicada. 3. Arte } \\
\text { interativa. 4. Design. I. Título }\end{array}$ \\
\hline
\end{tabular}




\section{FOLHA DE JULGAMENTO}

Candidata: Arquiteta e Urbanista GABRIELA PEREIRA CARNEIRO

Dissertação defendida e julgada em 03/12/2008 perante a Comissão Julgadora:

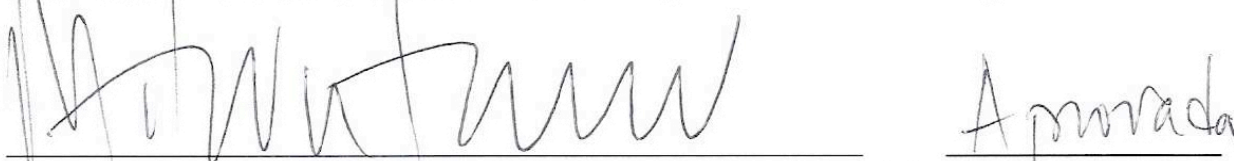

Prof. Associado MARCELO CLAUDIO TRAMONTANO (Orientador)

(Escola de Engenharia de São Carlos/USP)

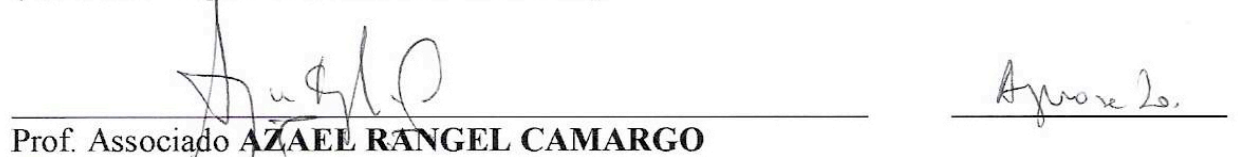

Prof Associado AZAEL RANGEL CAMARGO

(Escola de Engenharia de São Carlos/USP)

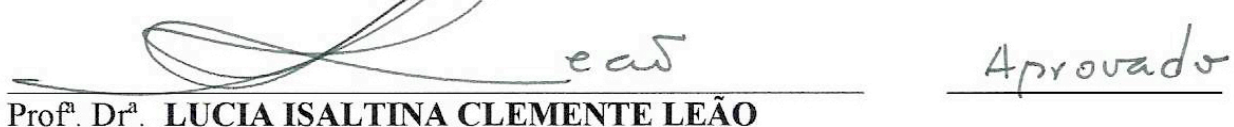

(Pontificia Universidade Católica/PUC/SP)

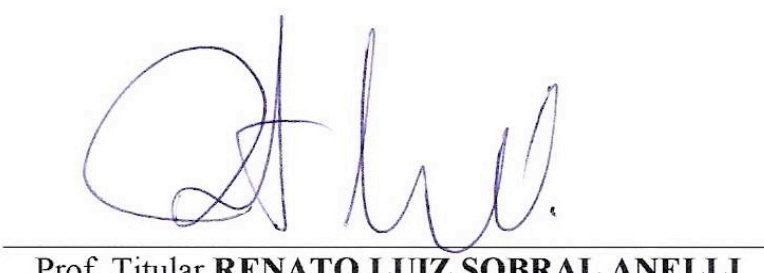

Prof. Titular RENATO LUIZ SOBRAL ANELL

Coordenador do Programa de Pós-Graduação em

Arquitetura e Urbanismo

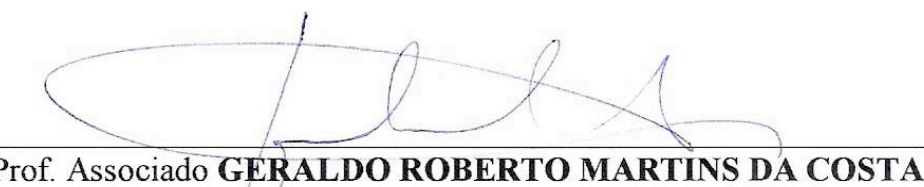

Presidente da Comissão da Pós-Graduação da EESC 

// aos meus pais, Marcos e Isa \{pelo amor incondicional e pela eterna confiança\} 

\{ao Marcelo, por me mostrar o caminho\}

\{à Christa e ao Laurent, pela oportunidade\}

\{ao Nomads, pelos momentos inspiradores, pelas pessoas incríveis\}

\{à equipe do projeto PIX, por torná-lo possível\}

\{ao Interface Culture Department, por ter feito parte\}

\{ao Programa de Pós-Graduação, pelo apoio\}

\{à FAPESP, pelo suporte

\{aos amigos, por sempre estarem lá, seja lá onde for\}

$\{$ ao Renato, pelo companheirismo\} 

// CARnEIRo, Gabriela. Objetos interativos: design e tecnologias da informação e comunicação. Dissertação de mestrado - Departamento de Arquitetura e Urbanismo, Escola de Engenharia de São Carlos, Universidade de São Paulo, 2008.

// palavras-chave: [arquitetura] [computação aplicada] [arte interativa] [design]

\{

Esta pesquisa busca delinear características do processo de criação de objetos interativos. Isso é feito a partir da verificação de possibilidades de interlocuções de saberes advindos de quatro áreas do conhecimento arquitetura, design, arte e computação - dentro do contexto das tecnologias digitais de informação e comunicação. Através desta perspectiva, acredita-se ser possível tanto uma compreensão mais fundamentada dos fenômenos tecnológicos do início de século XXI quanto a extração de direções para a ação no mundo contemporâneo.

\}

// CARNEIRO, Gabriela. Interactive objects: design and information communication technologies. Master Thesis - Departamento de Arquitetura e Urbanismo, Escola de Engenharia de São Carlos, Universidade de São Paulo, 2008.;

// key-words: [architecture] [applied computing] [interactive art] [design]

This research aims to delineate characteristics from the creation process of interactive objects. This is done through the verification of interlocution possibilities from four knowledge domains - Architecture, Design, Art and Computation - inside the information and communication digital technologies context. Via this perspective, it is believed that a more fundamental understanding of the technological phenomena from the beginning of the $20^{\text {th }}$ century is possible, as much as the extraction of directions for action in the contemporary world. 



\section{\{Sumário\}}

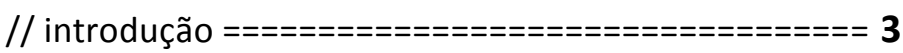

// capítulo 1 (design e comunicação) ============== 15

1.1 [design como ação de determinar relações] ====== 17

1.2 [a interação com o meio digital] =============== 25

1.3 [0 computador pessoal] $======================33$

1.4 [design do meio digital: $\mathrm{HCl}$ e interaction design] $=44$

// capítulo 2 (idéias e explorações) ===============- 57

2.1 [computação ubíqua e interfaces tangíveis] ====== 58

2.2 [interatividade na escala do corpo] ============= 71

2.3 [interatividade na escala do mobiliário] ========= 77

2.4 [interatividade na escala do edifício] ========== 86

2.5 [interatividade na escala da cidade] ============ 93

// capítulo 3 (experimentações:projetos interativos) = 101

3.1 [affective twins $\mathrm{P} \mathrm{PIX}$ ] ===================== 102

3.2 [objeto, processo, interação] ================ 111

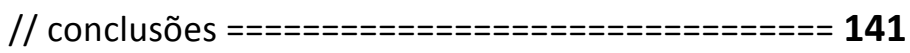

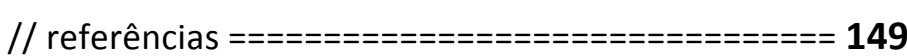

// índice remissivo =====================-======- 153 


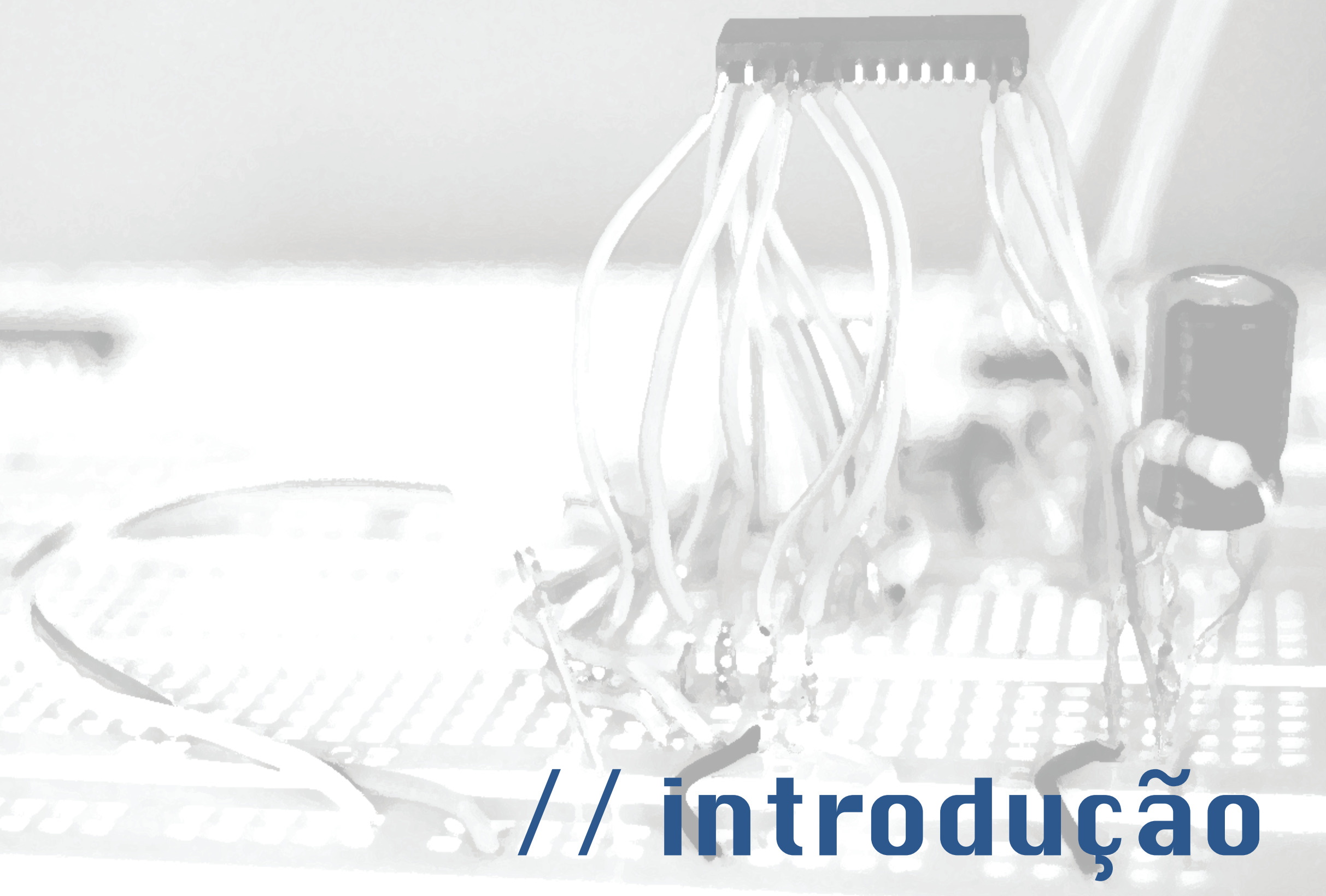
Esta pesquisa transita por diferentes conhecimentos, sendo que seu principal objetivo consiste em delinear características do processo de criação de objetos interativos informatizados. Isso é feito a partir da verificação de possibilidades de interlocuções de saberes advindos de quatro áreas - arquitetura, design, arte e computação - no contexto das possibilidades colocadas pelas tecnologias digitais de informação e comunicação. O estudo é composto pela combinação de elementos procedentes destes campos disciplinares sendo que os critérios de abordagem do objeto de estudo, caracterizado pelas possibilidades introduzidas pela interação mediada pela informação digital e por sua aplicação a partir das diferentes escalas de intervenção, introduzem os recortes impostos a cada uma das quatro áreas mencionadas. A partir desta perspectiva ampliada, acredita-se ser possível tanto uma compreensão mais fundamentada dos fenômenos tecnológicos do início de século XXI quanto a extração de direções para a ação no mundo contemporâneo. Contudo, é importante salientar que estas relações são resultados da aproximação da arquitetura com estes outros campos e, não, o contrário. Deste modo, acredita-se que, além das possibilidades de diálogo que se abrem com esta análise, um outro aspecto interessante é a possibilidade colocada, para os outros campos disciplinares, de se enxergarem a partir de uma perspectiva alternativa.

No contexto aqui colocado, por objetos interativos entendem-se as coisas materiais, passíveis de serem percebidas pelos sentidos, cujas propriedades são alteradas com a introdução da capacidade de 
processamentos digitais de informações. Faz-se importante ressaltar que o termo objeto é utilizado a partir de uma perspectiva mais ampla, que considera como tal uma grande variedade de artefatos físicos construídos. Sua abordagem é então definida a partir das escalas de intervenção. Neste caso, são considerados os objetos nas escalas do corpo, do mobiliário, do edifício e da cidade.

Esquematizado o quadro disciplinar e os aspectos do objeto de estudo desta pesquisa, é importante esclarecer algumas características do ponto de vista a partir do qual esta investigação é conduzida. 0 tema é explorado a partir de uma perspectiva segundo a qual, mais importante do que a justaposição de diferentes idéias são as relações que podem ser extraídas delas. Mais do que encontrar verdades resultantes de processos determinísticos, trata-se de esboçar possibilidades de diálogo, ou seja, de trabalhar com probabilidades. Essa abordagem possui forte influência da idéia de complexidade, sintetizada por Nelson Fiedler-Ferrara da seguinte maneira:

"A complexidade preocupa-se em refletir a respeito de fenômenos nos quais há muitos agentes e interagem muitos fatores, nos quais se combinam princípios de regulação e de desequilíbrio, nos quais comparecem contingência e determinismo, criação e destruição, ordem e desordem, e nos quais podem ser identificados níveis de organização e dinâmicas não-lineares marcadas por retroações entre esses níveis." (FIEDLER-FERRARA, 2005, p.325)

Apesar de englobar tanto os aspectos particulares dos fenômenos quanto suas características universais, a complexidade interessa-se principalmente pelas relações estabelecidas, em diferentes contextos, pelas partes. Garry William Flake a define como um ponto de vista intermediário capaz de conectar essas perspectivas holísticas e reducionistas. Segundo o autor: 
“Temos então, três diferentes maneiras de olhar para como as coisas funcionam. Podemos tomar uma abordagem puramente reducionista e tentar entender as coisas através da dissecação. Podemos também partir para uma visão mais ampla e tentar entender coleções completas de uma só vez observando como vários agentes, como por exemplo, os neurônios em um cérebro, formam um padrão global, tal como a inteligência humana. Ou podemos tomar uma visão intermediária e focar a atenção na interação entre os agentes. Através desse caminho intermediário, as interações dos agentes podem ser vistas como a cola que une um nível de entendimento ao próximo nível."1 (FLAKE, 1998, p.2)

Essa idéia de extrair uma 'outra coisa' da união das partes é fundamental para o pensamento complexo. Uma vez que às características particulares são somadas as possíveis relações que podem vir ou não a ser estabelecidas, os resultados alcançados podem então passar a extrapolar as expectativas iniciais. Essa perspectiva interessa particularmente a esta pesquisa pois descreve sua busca última de extrair, mais do que aspectos particulares ou generalizantes, o estudo de relações possíveis, sem a pretensão de esgotá-las ou tomá-las como categorias determinadas.

Contudo, é importante perceber que a maneira como a análise proposta é empreendida nesta pesquisa deriva, acima de tudo, de uma perspectiva particular, conforme admitido no primeiro parágrafo desta introdução, quando é dito que estas relações são resultados da aproximação da arquitetura com estes outros campos e, não, o contrário. Isso pressupõe que a organização do conhecimento aqui colocada é resultado de uma construção mental (relações), criada a partir de elementos mais simples (porções dos campos disciplinares), por um observador (que conduz as relações), para atingir um objetivo específico.

1 Do original: "We have, then, three different ways of looking at how things work. We can take a purely reductionist approach and attempt to understand things through dissection. We also can take a wider view and attempt to understand whole collections at once by observing how many agents, say the neurons in a brain, form a global pattern, such as human intelligence. Or we can take an intermediate view and focus attention on the interactions of agents. Through this middle path, the interactions of agents can be seen to form the glue that binds one level of understanding to the next level". (FLAKE, 1998, p.2) 
A relevância dessa colocação reside na necessidade de introdução de outra forte influência, também delineadora da perspectiva adotada por este trabalho, composta por idéias derivadas da cibernética. Teoria formulada nos anos 1940, na forma de estudos interdisciplinares, seu foco consiste na observação de sistemas complexos e nos auxilia na descrição e entendimento da estrutura de tais, em especial de processos de comunicação, mecanismos de controle e princípios de feedback. Segundo Paul Pangaro, renomado estudioso do tema, "praticantes da cibernética utilizam modelos de organizações, feedback, objetivos e conversação para entender as capacidades e os limites de qualquer sistema (tecnológico, biológico ou social); eles consideram ricas descrições como o resultado mais importante"2 (PANGARO, 1991-2006). Nesse sentido, da mesma maneira que a complexidade é abordada com o objetivo de delinear o ponto de vista empreendido nesta pesquisa, a cibernética também se configura como base para sua estruturação, uma vez que "oferece um vocabulário único e um conjunto de conceitos únicos próprios para representar vários tipos de sistemas"3 (ASHBY, 1957, p. 4). 0 termo "sistema" é entendido aqui, de acordo com a definição do ciberneticista Ross Ashby (1960), como um conjunto de variáveis selecionadas por um observador.

Desse ponto de vista, pode-se dizer que esta pesquisa consiste na delineação de relações entre diferentes sistemas, a partir de uma perspectiva complexa e de um entendimento cibernético. Neste caso, os sistemas são compostos pelos elementos trazidos de cada campo disciplinar, observados sob um ponto de vista a partir do qual a maior relevância reside nas relações que podem surgir (complexidade), sendo que para descrever estas relações são utilizados termos específicos (oriundos da cibernética).

\footnotetext{
2 Do original: "Practitioners of cybernetics use models of organizations, feedback, goals, and conversation to understand the capacity and limits of any system (technological, biological, or social); they consider powerful descriptions as the most important result." (PANGARO, 1991-2006)

3 Do original: "offers a single vocabulary and a single set of concepts suitable for representing the most diverse types of system." (ASHBY, 1957, p. 4)
} 
A introdução de alguns elementos derivados da complexidade e da cibernética são importantes de serem aqui colocados pois, por mais que não sejam o foco deste trabalho, muitas idéias trabalhadas no seu percurso remetem a estas bases. Mesmo que o objetivo aqui não seja o de definir estes campos e avaliar sua aplicabilidade, eles estão presentes tanto na maneira como o trabalho é redigido quanto nas análises que se propõe a fazer. Em cada parte, entrelaçam-se aspectos gerais, características particulares são apontadas e possibilidades de relações são esboçadas.

Estas preocupações estão presentes também em várias outras pesquisas do Nomads.usp, Núcleo de Estudos de Habitares Interativos, grupo no qual este trabalho foi desenvolvido. Os trabalhos do grupo concentram seus esforços no desenvolvimento de estudos e proposições sobre a participação das tecnologias de informação e comunicação (TIC) no cotidiano das pessoas. Mais especificamente, buscam entender como os processos de comunicação alteram usos, compreensões e proposições dos espaços pessoal, doméstico e urbano, acrescidos de uma instância virtual informatizada.

As dinâmicas do grupo partem de um constante movimento de aproximação com diferentes campos do conhecimento que abordam, em especial, teorias que buscam explicar a realidade a partir de perspectivas que ressaltem a importância de processos caracterizados pela dinamicidade do diálogo e da troca de informações. Teorias da Complexidade, da Informação, da Comunicação, dos Sistemas e da Cibernética4 têm embasado várias pesquisas e discussões do Nomads.usp de forma que são nitidamente refletidas no trabalho, sem contudo ser seu foco principal.

\footnotetext{
${ }^{4}$ No conjunto de autores constantemente referenciados no grupo, encontram-se aqueles que participaram diretamente das revoluções instauradas pelas tecnologias digitais, através das teorias e experimentos que desenvolveram, em especial a partir dos anos 1940. Entre outros podemos citar o matemático Norbert Wiener, autor de Cibernética (1948) e Cibernética e Sociedade (1950); o biólogo Ludwig Von Bertalanffy, autor da Teoria Geral dos Sistemas (1968); o sociólogo e psicólogo Edgar Morin, autor dos seis volumes de O Método (19772004); e o matemático e engenheiro Claude Shannon, autor do livro The Mathematical Theory of Communication (1948).
} 
Essa perspectiva dinâmica mostrou-se essencial para o alcance do objetivo principal desta pesquisa que consiste em delinear características do processo de criação de objetos interativos informatizados. Nestes, estão claramente colocadas relações entre o designer e a programabilidade de aspectos interativos, que alteram tanto as propriedades do objeto em questão quanto os processos que culminam na sua criação. A relevância desta investigação se justifica pela constatação da grande dispersão e influência das mídias digitais na sociedade contemporânea, somadas às possibilidades de ação colocadas pelo aumento da acessibilidade deste meio, no que concerne a busca de "fazer uma conexão mais interessante entre o mundo físico e o mundo do computador."5 (O'SULLIVAN; IGOE, 2004: p.xvii)

Para alcançar o objetivo principal da pesquisa, foram estabelecidos procedimentos de exploração dos assuntos baseados na convergência e alternância entre teoria e prática. Deste modo, todo o caminho percorrido reflete sua busca de constantemente transitar em diferentes campos do conhecimento. Para isso, a exploração teórica, iniciada com as disciplinas no primeiro ano de vigência da pesquisa, estendeu-se através das aulas freqüentadas em diferentes departamentos 6 . Por meio de leituras, seminários, monografias e discussões em sala de aula, foi possível obter um panorama de questões características do mundo contemporâneo e da prática do design.

A pesquisa teórica foi complementada pela constante atividade de revisão bibliográfica. Por meio desta, procurou-se ter acesso a publicações mais recentes e artigos cujos assuntos consistiram na descrição de

\footnotetext{
${ }^{5}$ Do original: "This book is designed to help you make a more interesting connection between the physical world and the computer world." (O'SULLIVAN; IGOE, 2004: p.xvii)

${ }^{6}$ Foram duas as disciplinas cursadas em departamentos além daquele no qual esta pesquisa foi desenvolvida: “CRP 5996 - Formas Comunicativas do Habitar" ministrada pelo Prof. Dr. Massimo di Felice no Departamento de Relações Públicas, Propaganda e Turismo da Escola de Comunicação e Artes (ECA) da USP; e a "CSo 103 Tópicos Especiais em Ciências Sociais : Sociologia (Tecnologia e Sociedade)" ministrada pelo Prof. Dr. Thales Haddad Novaes de Andrade no Programa de Pós-Graduação em Ciências Sociais, da Universidade Federal de São Carlos.
} 
projetos desenvolvidos nos principais centros de pesquisa e produção em mídia digital, tal como o Media Lab do MIT (Massachusetts Institute of Technology)7, o Georgia Institute of Technology ${ }^{8}$, o Royal College of Art $^{9}$, o Interactive Institute ${ }^{10}$, entre vários outros ${ }^{11}$. Isso foi importante, pois muitos dos assuntos abordados se referem a questões do desenvolvimento tecnológico, principalmente na forma como este tem sido trabalhado e pesquisado nos últimos dez anos.

A constante busca de diálogos com diferentes perspectivas dos assuntos fez com que parte da pesquisa fosse desenvolvida no Departamento de Cultura da Interface ${ }^{12}$, da instituição austríaca Universität für künstlerische und industrielle Gestaltung, localizada na cidade de Linz. Seu programa ensina e desenvolve tópicos relacionados às mídias interativas a partir de uma perspectiva artística/científica. Seu foco baseiase em uma combinação de arte, design e tecnologia com o objetivo de explorar formas inovadoras de interações entre seres humanos e máquinas, e entre arte e pesquisa aplicada. Este fato é relevante pois foi a partir dessa possibilidade de intercâmbio que se desenvolveram as explorações práticas desta pesquisa.

O contato com professores, profissionais e alunos de diferentes áreas forneceu subsídios importantes para as questões que permeiam esta pesquisa, em especial aquelas relacionadas aos processos de design que

\footnotetext{
${ }^{7}$ Mais informações disponíveis em: <http://www.media.mit.edu/>. (Acesso em 04/11/2008)

${ }^{8}$ Mais informações disponíveis em: <http://www.gatech.edu/>. (Acesso em 04/11/2008)

${ }^{9}$ Mais informações disponíveis em: <http://www.interaction.rca.ac.uk/>. (Acesso em 04/11/2008)

${ }^{10}$ Mais informações disponíveis em: <http://www.tii.se/>. (Acesso em 04/11/2008)

${ }^{11}$ Uma lista completa de referências pode ser acessada no web-site desta pesquisa, disponível em:

$<$ http://www.nomads.usp.br/site/objetos_interativos>. (Acesso em 04/11/2008)

${ }^{12}$ Durante o período de Março a Setembro de 2007 a pesquisadora freqüentou, como pesquisadora visitante, as aulas do curso de pósgraduação do Departamento de Cultura da Interface da Kunstuniversität em Linz, na Áustria, sob co-orientação da Profa. Dra. Christa Sommerer, pioneira no desenvolvimento da arte mídia. A viagem forneceu à pesquisadora uma oportunidade importante na medida em que pôde utilizar a infra-estrutura do Instituto, seus laboratórios e o aconselhamento dos professores para aprofundar o conhecimento sobre objetos, ambientes e arquiteturas interativas.
} 
transpassam o desenvolvimento de tais objetos. A participação em alguns dos cursos e workshops ${ }^{13}$ culminaram em exercícios que possibilitaram o contato com procedimentos e ferramentas utilizadas na produção de instalações interativas. Durante a estadia no exterior, foi desenvolvido o projeto Affective Twins, exposto no Festival Ars Electronica 200714, e, após o retorno ao Brasil, foi desenvolvido o projeto PIX, no grupo de pesquisa Nomads.usp, como um dos três experimentos do projeto de pesquisa D.O.S. Designers on Spot (proc.05/60724-6) ${ }^{15}$, financiado pela FAPESP - que também financiou esta pesquisa de mestrado16 - dentro da segunda fase do programa Tidia-Ae - Tecnologias da Informação no Desenvolvimento da Internet Avançada-Aprendizado Eletrônico17. No segundo ano do projeto D.O.S.

${ }^{13}$ Foram freqüentados os seguintes cursos e workshops: Arte Interativa, Microcontroladores, Arqueologia da Mídia, Screen Based Interaction, Fashionable Technologies, Robotic Workshop, Games Workshop e Stage Based Interaction Workshop.

${ }^{14}$ Durante o período de 6 a 11 de setembro o projeto Affective Twins foi exposto na iniciativa Campus 2.0 do Festival Ars Electronica 2007. O festival é uma iniciativa do Ars Electronica Museum que acontece anualmente na cidade de Linz, na Áustria e reúne os principais expoentes da arte eletrônica mundial. Simpósios, conferências, performances, exposições, animações atraem profissionais, artistas e público em geral para explorar tendências no espectro artístico das tecnologias digitais. O projeto foi exposto no espaço destinado aos trabalhos do Departamento de Cultura da Interface, dentro da iniciativa Campus 2.0 na qual universidades de diferentes países da Europa mostraram os trabalhos desenvolvidos por seus alunos. O interesse é mostrar aproximações experimentais resultantes das pesquisas desenvolvidas nas escolas. No ano em questão, a iniciativa foi coordenada pelo Instituto Hyperwerk, coordenado pelo Prof. Dr. Mischa Shaub, localizado na cidade de Basel, na Suíça, sob o tema Neoanalógico no qual objetos clássicos adquirem uma outra perspectiva no contexto dos materiais inteligentes e da necessidade de interfaces intuitivas.

${ }^{15}$ A estrutura do projeto D.O.S. encontra-se sub-dividida em duas partes, que ocorrem simultaneamente: Ações de Aprendizagem e Pesquisa Exploratória. A Pesquisa Exploratória proporciona a realização de experimentos práticos através das referidas sessões de projeto e prototipagem, as quais visam aplicar o conhecimento advindo das Ações de Aprendizagem, bem como adquirir experiência na materialização dos objetos. Os outros dois projetos consistem em experimentos na escala do corpo, um wearable computing que atende as características de portabilidade e conectividade a distância via internet, e na escala do mobiliário, o objeto Éos, que consiste em um anteparo capaz de bloquear ou filtrar a entrada de luz solar através de uma fachada translúcida de 7 metros de altura por 3 metros de largura na Unidade 001 (Sede do Nomads.usp).

${ }_{16}$ Para o desenvolvimento desta pesquisa foi concedida uma bolsa de mestrado pela FAPESP, proc. 06/53574-4, cuja vigência compreendeu o período de Setembro de 2006 a Agosto de 2008. Vale mencionar que este apoio foi fundamental para a pesquisa alcançar os resultados descritos nesta dissertação. Foi também através deste suporte e confiança que foi possível o intercâmbio da pesquisadora durante os seis meses que permaneceu na Áustria desenvolvendo sua pesquisa. Ressalta-se também a importância da disponibilização da reserva técnica, fundamental para a pesquisa uma vez que viabilizou a aquisição de bibliografia específica sobre o tema e também cobriu parte das despesas com o projeto PIX, essencial para a pesquisa como um todo.

17 Neste projeto maior, o Nomads.usp é um Laboratório Associado ligado ao cluster de São Carlos centralizado no Laboratório de Desenvolvimento Intermidia do ICMC - Instituto de Ciências Matemáticas e Computação. No total, são 16 laboratórios associados (LA) ou laboratórios de desenvolvimento associados (LDA) e 4 laboratórios de desenvolvimento (LD). 
priorizam-se análises mais detalhadas de processos de design de objetos interativos utilizando-se a Internet Avançada.

Todo esse caminho gerou insumos importantes para o entendimento teórico dessa prática e para a prática de questões teóricas. 0 resultado desse percurso é então apresentado nesta dissertação, organizada em três capítulos, além da introdução e das considerações finais. A elaboração dos capítulos reflete o percurso da pesquisa como um todo. Cada um se sustenta separadamente, pois possui os elementos essenciais para sua compreensão, porém é, na indicação de relações possíveis de serem estabelecidas entre eles, que se encontra uma das principais contribuições desta pesquisa. Como reflexo dessa abordagem os conteúdos são assim organizados:

O capítulo 1, “Design e Computação", aborda questões introdutórias do design e da computação. Inicialmente discute o entendimento do design como uma ação, a partir dos objetos que produz, de estabelecer, alterar e sugerir relações entre pessoas e ambiente. A seguir trata, a partir de uma perspectiva técnica, a maneira na qual os meios digitais alteraram a composição destes objetos e sua relação com as pessoas. Esse raciocínio é então utilizado para esclarecer aspectos históricos do desenvolvimento do principal objeto responsável por difundir essa tecnologia, o computador, e das suas interfaces. No final do capítulo são abordadas as diferenças entre duas abordagens que abarcam introdução das mídias digitais no cotidiano, o HCI (Human-Computer Interaction) e o Interaction Design.

0 capítulo 2, “Idéias e explorações”, explicita abordagens e explorações da mídia digital a partir do discurso da ubiqüidade da computação e das interfaces tangíveis, com o objetivo de fundamentar conceitualmente proposições que abordam a computação para além do computador pessoal. Proposições 
de objetos interativos na escala do corpo, do mobiliário, do edifício e da cidade são então analisadas como exemplos do que seria a aplicação da computação em vários elementos físicos do ambiente.

O capítulo 3, “Experimentações: projetos interativos”, descreve os projetos Affective Twins e PIX, desenvolvidos durante a pesquisa, e os analisa com o intuito de elucidar trocas ocorridas entre a teoria e prática. 0 objetivo é, além de embasar conceitualmente os projetos, apontar de que maneira sua execução auxilia no entendimento de questões mais amplas, respondendo perguntas mas também colocando novas.

Através desse caminho, o texto busca construir discussões sobre a introdução das tecnologias de informação e comunicação na criação de objetos, de forma a auxiliar no entendimento da maneira como a sociedade se relaciona com o mundo material mediada por aspectos digitais. A dissertação é então encerrada com as conclusões, onde está registrado o que realmente foi aprendido com a pesquisa empreendida. Com isso espera-se que este trabalho seja capaz de estimular, direcionar e fomentar discussões sobre o tema no âmbito brasileiro. 


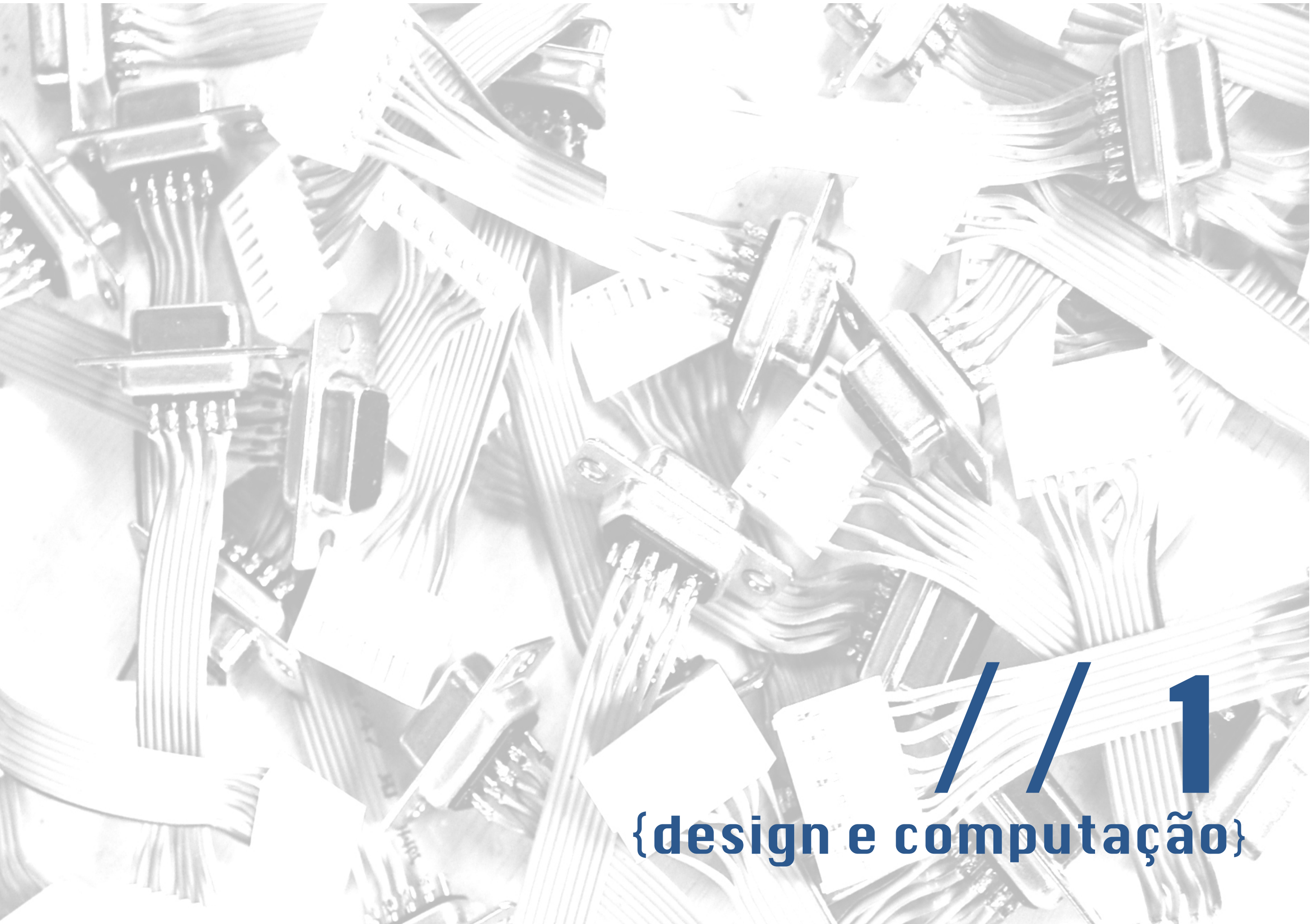


Este capítulo aborda aspectos da criação de objetos e arquiteturas acrescidos de instâncias interativas informatizadas. Na criação de tais objetos, algumas relações entre o designer e a programabilidade dos aspectos interativos diferem dos processos e ferramentas tradicionais do design. Propõe-se, aqui, uma leitura a partir da perspectiva da arquitetura, na qual se estabelecem relações estreitas entre os objetos e o espaço físico em que se inserem, compondo, assim, narrativas comuns. A interatividade de que se dotam os objetos, as arquiteturas e as instalações abordados refere-se à capacidade de captar informações dos usuários e dos aspectos do espaço em que estão inseridos, de transformá-las em dados computáveis, analisá-los e fornecer representações através das quais as pessoas envolvidas nesta interação possam perceber o resultado da computação.

Caixa-preta é um termo utilizado quando o sistema se configura de tal maneira que seu conteúdo não é totalmente acessível por meio da observação direta. Para possibilitar uma abordagem exploratória fundamentada e coerente das mídias digitais, é necessária a abertura de suas caixas- -pretas, ou seja, um entendimento básico das lógicas que regem seu funcionamento, sua história e seu desenvolvimento. A compreensão da história e de aspectos básicos envolvidos na computação digital pode abrir caminhos para a análise de perspectivas alternativas, como aquelas baseadas na dispersão das possibilidades computacionais pelos objetos e espaços, em lugar da concentração das atividades em uma só máquina, como acontece com o computador pessoal.

O computador pessoal é resultado de uma busca específica de tornar a computação digital acessível a todos. Sua popularização se deu graças ao caráter universal da máquina e aos desenvolvimentos de interfaces "amigáveis" 
que possibilitaram pessoas leigas a utilizarem o computador para as mais diversas tarefas. Ele é um dos principais símbolos da revolução informacional, porém está longe de se configurar como a única possibilidade de aplicação destas mídias.

Dentro do amplo processo do desenvolvimento tecnológico de uma sociedade, o campo do conhecimento das Ciências Humanas desempenha um papel importante na antecipação de cenários futuros. Os designers, arquitetos e mesmo artistas são profissionais aptos a oferecer perspectivas críticas e não-reducionistas que se contrapõem à tendência utilitarista dominante das possibilidades técnicas. Do ponto de vista do design, os conceitos abordados neste capítulo fazem parte daquilo que os designers Anthony Dunne e William Gaver (1997, p.2) definem como "design conceitual", em cujo processo a exploração de hipóteses e idéias constituem uma atividade em si. Essa perspectiva difere da maneira como a etapa de exploração é usualmente entendida, ou seja, como parte do estágio inicial do processo de design, visando sua aplicação prática e utilitária. Nesse sentido, a investigação aqui proposta desenvolve-se sobre um pano de fundo que considera menos os aspectos mercadológicos e de produção e mais o entendimento aprofundado das necessidades e dos modos de vida questionados por propostas experimentais.

A atual disponibilidade de uma grande variedade de recursos informatizados, passíveis de serem utilizados para capacitar objetos, espaços e edifícios com a aptidão de processar informações, exige dos designers a construção de novas práticas frente ao uso das chamadas tecnologias digitais. As análises que se seguem representam as principais referências que influenciaram esta pesquisa e definiram o entendimento do tema do ponto de vista da experimentação. 0 objetivo deste capítulo é, portanto, o de fornecer insumos para um entendimento focado nas idéias sobre o panorama técnico, no qual a interatividade dos objetos explorados por este estudo se desenvolve. 


\section{1 | Design como ação de determinar relações}

Imaginem-se pequenas garrafas de vidro, de diferentes formatos e tamanhos. Para tampá-las, diversas rolhas, cada uma especialmente desenhada para caber apenas no frasco correspondente. Em seguida, imagine-se que tipo de conteúdo seria possível colocar dentro de cada uma. Imediatamente cogita-se em água ou qualquer outro líquido, talvez também pedrinhas para enfeitá-las ou mesmo uma rosa. Em suma, alguma coisa material que passe pelo gargalo.

Esse não é o caso das garrafas do projeto MusicBottles, de Iroshi Ishii (Fig. 1-2). Ele ilustra um conjunto de fatores que permite acreditar que o complexo processo de desenvolvimento tecnológico, marcado pela forte influência das tecnologias de informação e comunicação, alterará ainda mais a interação das pessoas com os objetos que compõem seu cotidiano. 0 projeto consiste em uma série de pequenas garrafas de vidro cuja manipulação faz com que diferentes sons sejam emitidos. Ele compreende, também, uma mesa sobre a qual as garrafas são dispostas, dotada de um sistema de sensores e luzes capaz de identificar a garrafa manipulada e emitir padrões luminosos de acordo com o som emitido. Assim, pode-se ouvir uma performance de jazz ou de música clássica, dependendo de quais garrafas são abertas e dispostas sobre a mesa. Nesse projeto, objetos cotidianos são qualificados como interfaces por meio das quais é possível acessar informações digitais. 0 objetivo foi o de "conceber uma interface transparente que pode entrelaçar-se suavemente no tecido da vida cotidiana, provendo um acesso fácil, esteticamente agradável e emocionalmente engajado à informação digital."18 (ISHII, 2001, p.2) Uma interface transparente seria aquela que não se coloca diretamente entre a pessoa e a atividade realizada, ou seja, ela potencializa a capacidade do objeto mas não é percebida como algo separado.

\footnotetext{
${ }^{18}$ Do original: "design a transparent interface that could seamlessly weave itself into the fabric of everyday life by providing easy, aesthetically pleasing and emotionally engagnig access to digital information". (ISHII, 2001, p.2 )
} 

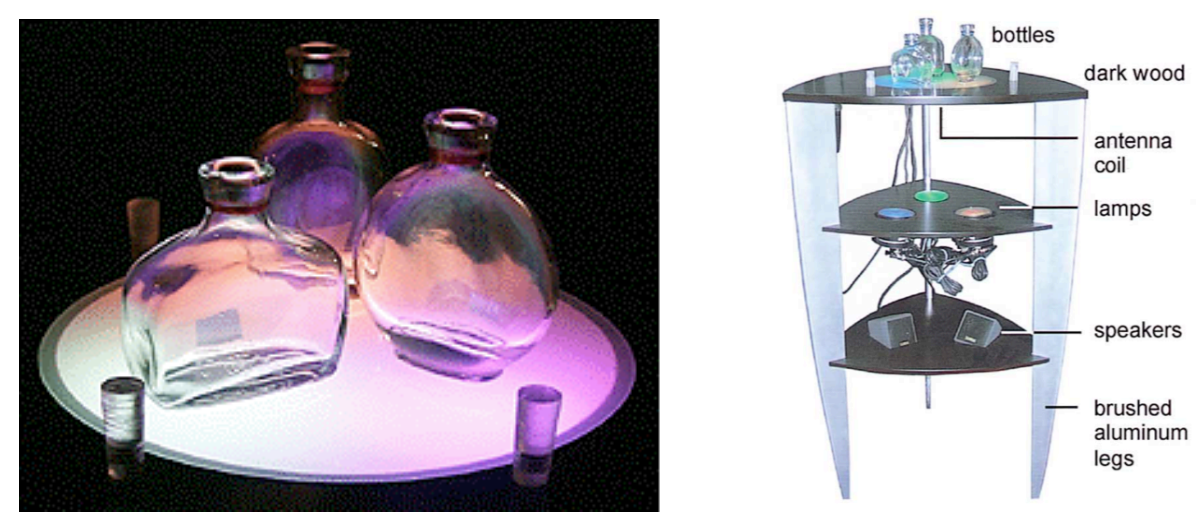

Fig. 1: Imagem da instalação MusicBottles (Tangible Media Group, 2001).

Fig. 2: Esquema da estrutura da instalação MusicBottles (Tangible Media Group, 2001).

Fonte: Ishii, H., Mazalek, A., Lee, J. (2001). Bottles as a minimal interface to access digital

information. p.2. In CHI 2001 Extended Abstracts, ACM Press.

Independentemente do contexto tecnológico, a capacidade de manipular e transformar a natureza e dar-lhe formas e funcionalidades específicas, de acordo com o arbítrio pessoal, é uma característica especificamente humana. $\mathrm{O}$ homem não apenas habita lugares e espaços mas o faz por meio dos artefatos que cria para tal fim. Entende-se aqui artefato a partir da definição formulada por Donald Norman como "qualquer coisa inventada pelos humanos com o objetivo de aperfeiçoar o pensamento ou a ação (...), tenha este uma presença física e seja construído ou manufaturado, ou seja mental e possa ser ensinado"19 (NORMAN, 1993, p.5). Isso reforça a abordagem do termo objeto nessa pesquisa, que abrange artefatos físicos presentes no cotidiano, , vestuários, arquiteturas, edifícios, espaços da cidade, entre outros. Os inúmeros objetos que permeiam o cotidiano existem por diversos motivos e podem ser entendidos como meios para se alcançarem fins maiores. Heskett corrobora a idéia de que o ato de conceber e usufruir de objetos pode adquirir diferentes significados, de acordo com as vontades e os contextos aos quais estão vinculados:

\footnotetext{
${ }^{19}$ Do original: "Anything invented by humans for the purpose of improving thought or action counts as an artifact, whether it has a physical presence and is constructed or manufactured, or whether it is mental and is taught". (NORMAN, 1993, p.5)
} 
"Quando fabricado um design [objeto] torna-se, como artefato tangível, parte da realidade física de seu tempo aplicado para finalidades específicas numa sociedade que condiciona a maneira pela qual sua forma é percebida e avaliada. Essa avaliação pode se basear em premissas diferentes daquelas do designer e produtor, e haverá quem argumente que os valores atribuídos aos designs em sua função social não são fixos e absolutos, mas flutuantes e condicionados.” (HESKETT, 1997, p.9)

Esse pensamento é importante para que se perceba que a relação entre homem, objeto e natureza é mais complexa do que pode parecer à primeira vista. As análises dos objetos que permeiam a vida cotidiana não deveriam restringir-se à sua funcionalidade e materialidade, ou mesmo a quão eficaz determinada configuração se mostra.

Os objetos representam uma pequena fração das relações estabelecidas pelas pessoas com o mundo natural e artificial que, juntos, conformam um sistema maior e infinitamente complexo. Nesse conjunto de partes e elementos interdependentes, não apenas o homem transforma a natureza e materializa suas vontades como também, segundo Baudrillard (1968, p.10), "todo objeto transforma alguma coisa”, ou seja, as relações humanas também são afetadas com a introdução dos objetos. Arquitetá-los significa pensar tanto seus componentes físicos, enquanto materialização de uma idéia, quanto seus aspectos imateriais, os quais englobam, entre outras instâncias, as sociais, interativas e virtuais, o que se aplica a qualquer objeto, independente da sua forma e materialidade. Baudrillard escreveu que

“Cada um de nossos objetos práticos se associa a um ou vários elementos estruturais, mas por outro lado escapa continuamente da estruturalidade técnica para as significações segundas, do sistema tecnológico dentro de um sistema cultural." (BAUDRILLARD, 1968, p.14) 
Dessa forma, ao mesmo tempo em que o homem materializa seus conceitos por meio da construção e produção de objetos e espaços, estes também são responsáveis pela mudança da maneira como o homem habita o mundo e como entende esse habitar.

Segundo Csikszentmihaly (1981, p.91), experiências sensoriais vivenciadas por uma pessoa ao longo de sua existência se combinam e conformam padrões que se tornam previsíveis com o tempo. Esses padrões, por sua vez, são os responsáveis por fazer emergir as delineações e os entendimentos dos meios com os quais os diversos indivíduos, classes e sociedades se identificam. Assim, os objetos que permeiam o cotidiano desempenham um papel fundamental na determinação da vida e da sua coexistência com o meio natural e material. Podem tanto estimular as relações quanto também restringir o alcance de ações e pensamentos.

“Os objetos afetam o que uma pessoa é capaz de fazer, tanto expandindo quanto restringindo o escopo das ações e pensamentos dessa pessoa. E porque o que a pessoa faz é em grande parte o que ele ou ela é, os objetos têm um efeito determinante no desenvolvimento do ser, motivo pelo qual o entendimento do tipo de relação que existe entre pessoas e coisas é tão crucial." 20 (CSIKSZENTMIHALY, 1981, p.53)

Com o objetivo de propor uma leitura da relação entre homem e objetos de maneira que seu aspecto dinâmico fosse ressaltado, o autor estipulo o homem e os objetos como elementos de uma transação. 0 termo é emprestado de John Dewey, que entende que os elementos nunca são independentes, ou seja, apenas adquirem seu significado no contexto da própria transação (CSIKSZENTMIHALY, 1981, p.175). Essa visão faz parte de um

\footnotetext{
${ }^{20}$ Do original: "Objects affect what a person can do, either by expanding or restricting the scope of that person's actions and thoughts. And because what a person does is largely what He or she is, objects have a determining effect on the development of the self, which is why understanding the type of relationship that exists between people and things is so crucial". (CSIKSZENTMIHALY, 1981, p.53)
} 
entendimento de que a cultura é um processo dinâmico no qual a atribuição de significados é entendida como uma transação. A partir dessa visão, os objetos:

“... não são entidades estáticas cujo significado é projetado nos mesmos a partir de funções cognitivas do cérebro ou de sistemas conceituais abstratos de cultura. Seja através da ação ou contemplação, os objetos no ambiente doméstico têm significado apenas como uma parte de um processo sinalizador comunicativo e são ingredientes ativos de tal processo."21 (CSIKSZENTMIHALY, 1981, p.173)

Ao se acrescentar aos objetos instâncias interativas, viabilizadas com o emprego das TIC, potencializam-se e influenciam-se as transações entre homem e objeto. Nas MusicBotlles, por exemplo, as mídias digitais foram utilizadas para expandir a capacidade e o significado de um objeto corriqueiro, ao mesmo tempo em que este se coloca como plataforma alternativa para inserção da computação. Nelas, segundo Ishii relata em entrevista concedida a Bill Moggridge, o importante não é a música, mas a possibilidade de se poder colocar informações dentro de qualquer garrafa de vidro existente na casa das pessoas (ISHII in MOGGRIDGE, 2007, p.527). Percebese, então, que as mídias digitais podem acrescentar aos objetos certas propriedades capazes de expandir suas características comunicativas e significativas. Assim, o pensamento que permeia o presente trabalho se nutre especificamente dessa possibilidade de utilização das TICs levadas em consideração durante o processo de criação, como instância a ser adicionada aos objetos cotidianos.

É então a partir desse princípio de ação idealizadora que o termo design é utilizado ao longo do presente texto. Nesse contexto de trocas constantes entre o homem, a natureza e os objetos de sua própria criação, o designer

${ }^{21}$ Do original: "Objects are not static entities whose meaning is projected on them from cognitive functions of the brain or from abstract conceptual systems of culture. (...) Whether through action or contemplation, objects in the domestic environment are meaningful only as a part of a communicative sign process and are active ingredients of that process". (CSIKSZENTMIHALY, 1981, p.173) 
enquadra-se na categoria de profissionais responsáveis por antever, dar forma e significado a esse mundo material. Nessa perspectiva, o design configura-se como um meio poderoso de atuação, como constata Thackara ao dizer que:

"Muitas das situações problemáticas no nosso mundo são resultado de decisões de design. (...) As decisões de design modelam os processos por trás dos produtos que usamos, dos materiais e energia necessários para fazê-los, da forma como os utilizamos no dia-a-dia e do que acontece a eles quando nós não mais precisamos deles."22 (THACKARA, 2005, p.1)

Sua atribuição profissional (do designer) baseia-se nas vontades das pessoas de criar objetos que auxiliem a transformação de idéias em ações, dentro de contextos específicos, antecipando e propondo necessidades e experiências. Mais do que desenho de produtos, o design trata da relação entre o homem e o meio material, sendo que ambos são aspectos de um universo complexo. Esse universo é entendido aqui como um sistema, ou seja, "um complexo de elementos em interação" (BERTALANFFY, 1977, p.84), no qual tão importante quanto as características particulares dos elementos que o compõem, são as relações estabelecidas entre as partes. A partir dessa compreensão sistêmica de mundo, o designer é, em última instância, um gerenciador de informações. Ele é capaz de desenvolver conhecimento servindo-se de sua capacidade crítica e criativa ao reunir ou produzir informações, organizando-as e apresentando-as de maneiras inovadoras, constituindo diferentes objetos.

Os princípios que visam dar forma e sublinhar relações por meio da materialização de idéias regem também o trabalho de diversos outros campos do conhecimento, tal como o das artes, o da engenharia e o da arquitetura,

\footnotetext{
22 Do original: "Many of the troubling situations in our world are the result of design decisions. (...) Design decisions shape the processes behind the products we use, the materials and energy required to make them, the ways we operate them on a daily basis, and what happens to them when we no longer need them". (THACKARA, 2005, p.1)
} 
cada qual com seus parâmetros e interesses próprios. Além disso, as diversas disciplinas relacionam-se estabelecendo trocas constantes nas quais uma altera e engloba características da outra. Desse modo, é importante ser ressaltado que os produtos de cada campo disciplinar são decorrências de estratégias de aproximação e interpretação específicas de um profissional, resultante de sua interação com o meio no qual se insere e das ferramentas de que dispõe para agir.

Situada na área da Arquitetura, mas lançando também um olhar sobre a área do Design, esta pesquisa baseia suas análises nas relações percebidas entre os diferentes objetos e o espaço habitado. Diferentemente do Desenho Industrial, cujo foco são os processos produtivos e o papel do objeto como produto, com a adição de questões simbólicas e emocionais, o interesse da Arquitetura reside mais nas contribuições que sua potencial mobilidade, portabilidade, flexibilidade e interatividade podem trazer ao espaço, ampliando modos de percebê-lo e experimentá-lo. Os diferentes tipos de objeto são, então, tratados como partes de um sistema cujo significado emerge das interações e relações entre as partes.

Um bom exemplo é a unidade Turn-on - urban sushi, concebida pelo grupo de design AWG_Alles Wird Gut (Fig. 35). Nela, atividades como comer, dormir, trabalhar, estocar e cozinhar são condensadas em nove configurações que partem do princípio da condensação de diferentes funções em um mesmo objeto na forma de grandes anéis. Segundo a análise de Smith e Tophan, o conceito trabalha a possibilidade de comprimir múltiplas funções do habitar em um único disco que permite o acesso às funções por meio do uso dos equipamentos, de acordo com a vontade do usuário. 0 ato de rotacionar a peça possibilita que diferentes partes da superfície interna dos anéis sejam habitadas. 


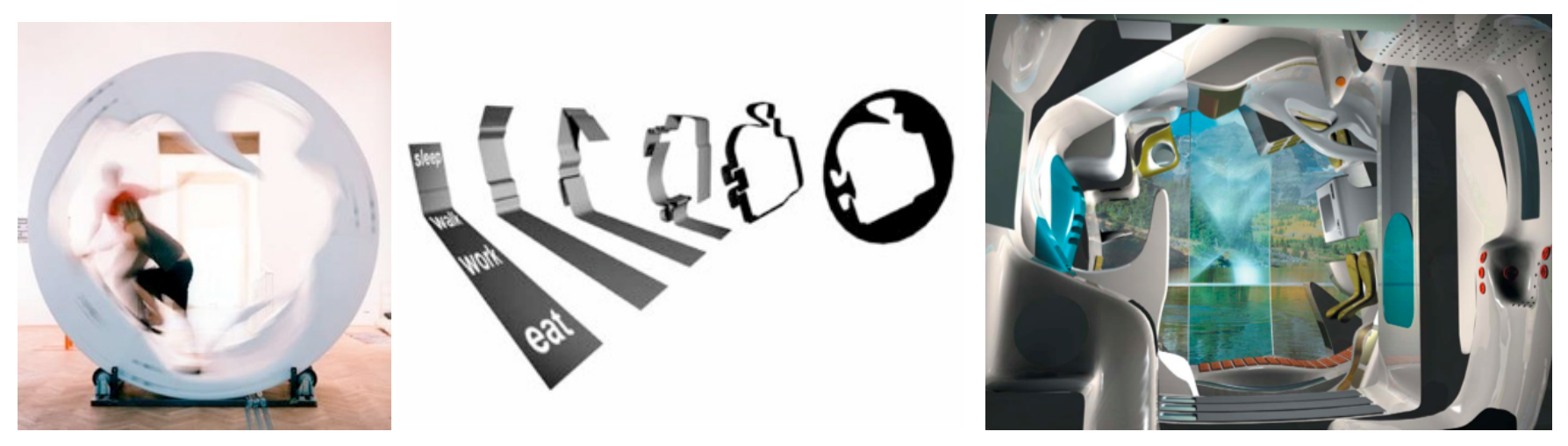

Fig. 3-5: Turn-on (AWG_Alles Wird Gut, 1999)

Fonte: Alles Wird Gut. Infosheet: turnOn. p. 2-4. Disponível em: <http://www.alleswirdgut.cc/awg.php?go=TURNON>.

Quando os módulos são justapostos, o resultado é um tubo que contém numerosas possibilidades de uso, fazendo referência à variedade de modos de vida socialmente aceitos na contemporaneidade (SMITH \& TOPHAN, 2002, p.124). A flexibilidade oferecida pelo Turn-on, ou seja, as possibilidades de usá-lo em diferentes atividades através da justaposição dos anéis , é estendida ao espaço no qual ele se insere, acrescentando ou alterando usos de acordo com os equipamentos escolhidos. Dessa forma, mais do que um objeto passível de ser comercializado nas suas diferentes configurações, o anel pode ser uma maneira de diversificar as qualidades do espaço em um pequeno apartamento. (SMITH \& TOPHAN, 2002, p.124) Além disso, 0 Turn-on faz refletir sobre a autonomia dos objetos que, à primeira vista, servem apenas de apoio ou complementação ao espaço existente. Não se trata apenas de equipamentos utilitários: seu desenho possui uma grande importância e configura-se como um exemplo que ilustra a capacidade do designer de organizar e apresentar informações de maneira inovadora, conforme já comentado anteriormente.

Vistos pelo prisma das estratégias para a materialização de objetos e, em especial, aqueles que possuem instâncias interativas informatizadas, os processos que permeiam o desenvolvimento e a produção das MusicBottles e do Turn-on diferem significativamente um do outro. 0 Turn-on caracteriza-se como um objeto 
tradicional do design, no qual função e materialidade determinam sua estrutura como objeto. Sua flexibilidade é alcançada pela incorporação de características físicas que remetem às atividades das pessoas, ao mesmo tempo em que diversas unidades podem ser montadas a partir de estruturas pré-concebidas para serem encaixadas umas nas outras. Já as MusicBottles incorporam a possibilidade de se colocar qualquer som dentro de uma mesma garrafa, o que pressupõe uma diferenciação entre estrutura e conteúdo. Além disso, o entendimento de aspectos de programação dos meios digitais não fazia parte do saber tradicionalmente ensinado ao designer.

\section{2 | A interação com o meio digital}

Interagir23 é algo que as pessoas sempre souberam fazer, com outras pessoas, com a natureza ou com artefatos. Segundo Paul Dourish (2004, p.03), "nossa natureza, como seres sociais, é baseada nas maneiras pelas quais nós agimos e interagimos, em tempo real, o tempo todo"24. Ao se inserirem mídias digitais no cotidiano, está-se, entre outras coisas, interferindo nas interações que ocorrem entre as pessoas e os objetos informatizados e, para isso, é necessário perceber e decifrar algumas características específicas dessa relação. 0 entendimento dos processos envolvidos na relação entre o homem e o computador ajuda a esclarecer de que maneira a interação entre eles se diferencia dos outros tipos de troca estabelecidos pelo homem. Essa diferença é bem explicada por Edmond Couchot na seguinte passagem:

"O modo dialógico, que governa as trocas com o computador, instaura uma relação sem precedentes entre o homem e a máquina. Jamais pode ser confundido com as outras formas de interatividade e delas se distingue pelo fato de colocar obrigatoriamente em jogo processos

\footnotetext{
${ }^{23}$ Segundo o dicionário Houaiss da Língua Portuguesa: INTERAÇÃO = [1] influência mútua de órgãos ou organismos inter-relacionados. Ex.: <interação do coração e dos pulmões> <interação do indivíduo com a sociedade a que pertence> [2] ação recíproca de dois ou mais corpos [3] atividade ou trabalho compartilhado, em que existem trocas e influências recíprocas [4] comunicação entre pessoas que convivem; diálogo, trato, contato. [5] intervenção e controle, feitos pelo usuário, do curso das atividades num programa de computador, num CD-ROM etc. Disponível em: <http://houaiss.uol.com.br/busca.jhtm?verbete=intera\%E7\%E3o\&stype=k>. (Acesso em 18/10/2008)

${ }^{24}$ Do original: "Our nature as social beings is based on the ways in which we act and Interact, in real time, all the time." (DOURISH, 2004, p.03)
} 
computacionais que se interpõem entre a ação do usuário e a resposta do computador."

(COUCHOT, 2003, p.170)

As possibilidades introduzidas pela computação deram lugar a modos complexos de interação de pessoas e máquinas. Isso ocorre pois os artefatos dotados da capacidade de processamento de dados são capazes de interpretar estímulos vindos do meio, de acordo com o conjunto de procedimentos implementados na sua programação.

Atrás das imagens animadas de vídeos e de gráficos 3-D exibidos na tela do computador, existe uma linguagem simples, uma lógica única responsável por articular desde as atividades mais singelas, tal como interpretar o clique de um mouse, até a execução de tarefas complexas, como a visualização de formas e gráficos a partir da simulação das suas múltiplas dimensões. 0 entendimento dos princípios regentes dessa lógica permite sua manipulação direta e possibilita a ampliação das possibilidades de trabalho com o meio digital. Assim, antes de qualquer discussão mais aprofundada sobre os impactos produzidos pelo computador nos objetos tratados nessa pesquisa, é importante ter contato com alguns aspectos de seu funcionamento interno, em especial aqueles referentes à linguagem binária e às rotinas de realização de tarefas.

0 código binário é a linguagem utilizada pelas máquinas computadoras digitais. Steven Johnson explica que "um computador pensa - se pensar é a palavra correta no caso - através de minúsculos pulsos de eletricidade, que representam um estado 'ligado' ou um estado 'desligado', um 0 ou um 1. Os seres humanos pensam através de palavras, conceitos, imagens, sons, associações” (S. JOHNSON, 2001, p. 17). Atualmente, os usuários comuns não possuem acesso a essa linguagem, sendo que os programas computacionais atuam como tradutores e tornam possível o diálogo entre homem e computador. 
Assim como o sistema decimal, a lógica binária nada mais é do que um sistema de contagem. Enquanto um possui dez valores, de 0 a 9, o outro sistema, utilizado pelos computadores, possui apenas dois, 0 e 1 . Como exemplo mencionaremos que o número vinte, em um sistema decimal, é representado por 20, enquanto em um sistema de contagem binário ele é representado por 10100. No caso da presente pesquisa, não é o caso entender como são definidos os números na lógica binária e sim que todos os números decimais possuem um equivalente no sistema binário. A utilização da lógica binária nos computadores deve-se principalmente à sua facilidade de manipulação e ao baixo custo de produção das máquinas que utilizam essa linguagem.

“A expressão binária das mensagens (...) facilitava consideravelmente seu tratamento matemático e lógico, uma vez que a quantidade de informação medida por um bit ${ }^{25}$ ( 0 ou 1 ) corresponde exatamente aos dois estados que prendem um relé telefônico (ou um tubo eletrônico) utilizado nas calculadoras (deixando ou não passar corrente).“ (COUCHOT, 2003, p.99)

Os computadores representam a evolução das antigas máquinas de calcular, como, por exemplo, o ábaco. 0 desenvolvimento de componentes elétricos, tal como as válvulas, possibilitou que essas máquinas se tornassem capazes de efetuar cálculos mais complexos. A principal característica desses elementos elétricos reside na sua capacidade de controlar quantidades consideráveis de energia, utilizando quantidades muito pequenas.

"De uma maneira geral, dispunha-se de um sistema capaz, a partir de uma "ordem" - ou de uma "informação" - e necessitando uma energia muito reduzida na entrada, de obter na sua saída um efeito, ou mais precisamente uma "ação" desenvolvendo uma energia muito mais forte." (COUHOT, 2003, p.94)

\footnotetext{
${ }^{25}$ A palavra BIT é uma abreviação de seu significado em inglês BInary digiT (em português: dígito binário).
} 
O desenvolvimento do transistor, capaz de exercer a mesma função sendo, porém, mais fácil e barato de ser produzido, foi o responsável por potencializar essa capacidade de controle. 0 transistor possibilitou a criação de circuitos integrados e se tornou um componente universal para tarefas não-mecânicas, ligadas ao controle e à computação de informações. Na medida em que seu tamanho diminuiu, a capacidade de processamento das máquinas aumentou e continua aumentando muito rapidamente 26 . Porém, é sempre importante lembrar que a lógica que rege seus programas e aplicativos continua a mesma.

0 que toda máquina digital faz é transformar ações físicas em pulsos de eletricidade, interpretadas como 0 ou 1. "De um ponto de vista geral, a quantificação e a medida de informação tornavam possível a transformação de qualquer mensagem, escrita, sonora ou visual, em uma seqüência de símbolos elementares tratáveis pelo computador, e vice-versa" (COUCHOT, 2003, p.99). Esse registro e processamento das informações providas do meio físico pelas máquinas computadoras é chamado, por Edmond Couchot, de digitalização das ações.

A transformação das ações em 0 ou 1 possibilita sua manipulação por meio de uma lógica específica, a lógica binária, baseada na álgebra booleana, criada pelo matemático inglês George Boole em meados do século XIX. Não cabe aqui aprofundar considerações sobre a álgebra booleana, mas lembrar que ela captura a essência das operações lógicas, passíveis de serem implementadas com a linguagem binária. “Aqueles pulsos de eletricidade são símbolos que representam zeros e uns, que por sua vez representam simples conjuntos de instrução matemática, que por sua vez representam palavras ou imagens, planilhas e mensagens de e-mail" (S. JOHNSON, 2001, p.18). Os conjuntos de instruções matemáticas são implementados de uma forma específica, utilizando algoritmos para sua construção.

\footnotetext{
${ }^{26}$ O Intel 8080, primeiro microprocessador, lançado em 1974, possuía 6.000 transistores enquanto um Pentium 4, lançado em 2004 , possuía 125.000 .000 de unidades.
} 
Outra característica da linguagem digital é sua forma de implementação. Os computadores são equipados para tratar de problemas de forma serial, ou seja, um cálculo após o outro, a partir de combinações lógicas. "Tradicionalmente, o componente central de qualquer cálculo da computação tem sido os algoritmos ou procedimentos - modelos passo-a-passo que especificam o comportamento seqüencial de um sistema computador"27 (DOURISH, 2004:03). Algoritmos consistem em seqüências não-ambíguas de instruções, executadas até que determinada condição pré-estabelecida se verifique.

“Um programa tradicional compõe-se de uma série de instruções que dizem ao computador o que fazer: pintar a tela com pixels vermelhos, multiplicar um conjunto de números, apagar um arquivo. Normalmente, essas instruções são codificadas como séries de caminhos que se bifurcam: faça primeiro isto; se obtiver resultado A, faça uma dada coisa; se obtiver B, faça outra coisa." (S. JOHNSON, 2001, p.42)

Milhares de transistores fisicamente conectados atuam como portais que direcionam a informação de acordo com a programação, ou seja, de acordo com o conjunto de instruções implementadas no computador. "A arte da programação baseia-se na construção de uma seqüência de instrução mais eficiente, a seqüência que fará o maior número de operações com a menor quantidade de códigos- e com a menor probabilidade de erro."(S. JOHNSON, 2001:42)

Para ilustrar o caminho da informação e elucidar o papel desempenhado pelos elementos apresentados até o momento, é possível esboçar um ciclo. Nele, uma ação física é desempenhada e a grande energia despendida na ação é transformada em um pulso discreto de energia, por meio da utilização de um transistor. Esse pulso

\footnotetext{
27 Do original: "Traditionally, the central component of any account of computation has been algorithms or procedures - step-by-step models that specify the sequential behaviour of a computer system." (DOURISH, 2004, p.03)
} 
discreto (um 1, por exemplo) é então utilizado (juntamente com outros conjuntos de 0 e 1) para a efetuação de uma série de operações lógicas. As operações lógicas efetuadas consistem na implementação física da álgebra booleana, possibilitada pela utilização de transistores. Os transistores funcionam, nesse momento, não para amplificar a energia e sim para encontrar e ordenar rapidamente a informação. Transistores são colocados de forma a conduzir a informação de acordo com os resultados obtidos nas operações de álgebras booleanas. A informação discreta (pulso de eletricidade; 0 ou 1; sim ou não), após sua computação, é então finalmente convertida em alguma outra ação física. Para que essa nova ação ocorra, novamente o transistor é utilizado, agora para transformar a informação discreta em uma ação de grande energia (como amplificador de energia).

A breve descrição apresentada acima tem o objetivo de ilustrar como os elementos apresentados até o momento se relacionam. 0 importante é perceber que, basicamente, o que as máquinas de computar fazem é implementar fisicamente uma lógica de raciocínio. Desse modo, com os computadores, atividades antes restritas aos humanos tornam-se também passíveis de serem praticadas por meio da conexão de elementos físicos, em especial dos transistores.

O computador moderno precede a revolução instaurada pelos transistores, já que, na primeira metade do século XX, já existiam os computadores analógicos. Uma vez entendido que o computador digital efetua suas operações a partir de uma informação discreta, ou seja, de um pequeno pulso de energia interpretado como 0 ou 1 , fica mais fácil entender o que é chamado de computador analógico. Este utilizava variações contínuas de variáveis físicas, tais como voltagem, corrente ou mesmo a velocidade de rotação de um dispositivo, para representar as quantidades sendo processadas. Em nenhum momento havia a transformação da ação em uma informação discreta, tal como ocorre nos computadores digitais. Na versão analógica, a computação de tarefas ocorria então a partir da utilização de fenômenos elétricos, mecânicos ou hidráulicos, para modelar o problema a ser resolvido. As máquinas analógicas eram então capazes de realizar uma quantidade limitada de operações, sendo que, para cada mudança de problema, todas as conexões precisavam ser reconfiguradas por pessoas especializadas. 
Quando o computador digital foi desenvolvido, na década de 1940, seu desempenho era ainda inferior aos analógicos, ainda capazes de efetuar cálculos mais complexos do que os digitais. Sendo assim, a grande revolução em termos computacionais digitais deu-se a partir da introdução da memória. Segundo Paul Dourish aponta:

“O que é normalmente aceito é que o desenvolvimento crítico na computação digital foi o computador de programas armazenados. Em contraste com projetos anteriores, tal computador é uma máquina cuja operação não é diretamente codificada em seus circuitos, mas é ao contrário determinada por uma seqüência de instruções carregadas em sua memória - instruções que podem claramente ser modificadas ou substituídas, com muito mais facilidade do que a reconfiguração de circuitos elétricos." 28 (DOURISH, 2004, p.06)

Um dos responsáveis por essa criação foi o matemático John Von Neumann, integrante da equipe que desenvolveu, entre 1949 e 1951, o EDVAC (Electronic Discrete Variable Automatic Calculator), um computador com uma estrutura simples e fixa, mas com controle programável. A máquina era capaz de executar qualquer comando sem haver necessidade de alterar fisicamente seus componentes.

“O matemático Von Neumann teve então a idéia de registrar na memória da calculadora o próprio programa, assim como os outros dados a tratar, na forma de instruções codificadas. Números e letras substituíam as conexões e os cabos, símbolos abstratos, constituindo uma espécie de linguagem - o programa (software) -, que substituíam matérias físicas e quinquilharias

\footnotetext{
${ }^{28}$ Do original: "What is generally accepted is that the critical development in digital computing was that of the stored program computer. Is contrast to earlier designs, a stored program computer is a machine whose operation is not directly encoded is its circuits, but rather is determined by a sequence of instructions held in its memory - instructions that can, clearly, be changed or replaced much more easily that the electrical circuits could be reconfigured". (DOURISH, 2004, p.06)
} 
(hardware). Assim nasceu o computador moderno e com ele a informática que podemos considerar globalmente como a ciência das linguagens de programação." (COUCHOT, 2003, p. 98)

Os avanços implementados por Von Neumann e toda a equipe envolvida na construção dessa máquina sugeriam também a implementação de uma instrução (conditional control transfer) que permitia a interrupção e reinício do programa em qualquer ponto da computação. Essa capacidade implantou outra grande mudança possibilitada pelas tecnologias digitais, caracterizada pela quebra de linearidade em se tratando do armazenamento e acesso à informação. A diferença entre o acesso linear e o randômico às informações é assim descrita por Dan O’Sullivan e Tom Igoe:

“Com filmes e fitas magnéticas, informações e imagens devem ser acessadas seqüencialmente, de acordo com sua localização física na fita ou filme, na medida que estes são rodados. As idéias apenas podem ser ligadas diretamente às idéias imediatamente anteriores e seguintes, na seqüência. Por este motivo, são chamadas de mídias lineares. Com as 'mídias de acesso aleatório', partes não-seqüenciais da memória de um computador podem ser ativadas como se estivessem uma ao lado da outra. Isto permite que qualquer idéia gravada na memória apareça como se estivesse próxima de qualquer outra idéia. Quando o acesso randômico é combinado com comunicação em rede, pode-se visualizar informações e imagens armazenadas em continentes diferentes como se estivessem armazenadas próximas umas das outras. Reordenar e fazer múltiplas versões torna-se então muito mais fácil; como por exemplo, as funções copiar e colar de um computador que são facilmente compreendidas por qualquer pessoa que já as utilizou. Computadores reduzem as barreiras de tempo e espaço ao brincar e rearranjar idéias. Como resultado, representam melhor as múltiplas e inter-conectadas relações entre as idéias no 
pensamento humano e podem ser mais igualitários ao dar voz às múltiplas versões destes relacionamentos ."29 (O'SULLIVAN \& IGOE, 2004, p.XVIII)

É importante ressaltar essa passagem da linearidade para o randômico pois ela configura um dos pilares da chamada Sociedade da Informação e da mudança de paradigmas que a acompanha. Segundo Edmond Couchot "as redes numéricas ${ }^{30}$ controladas por computador não funcionam mais como as redes de telecomunicações radiofônicas e audiovisuais, e introduzem importantes modificações na transmissão de informações" (COUCHOT, 2003, p.67). Sendo assim, o digital não rompe as relações e sim as recoloca diferentemente. A mídia digital, por sua capacidade de implementar raciocínios, possibilita a criação de interações mais parecidas com as relações interpessoais, mesmo que essas relações envolvam pessoas, artefatos e a participação de engenharia computacional.

\section{3 | 0 computador pessoal: interfaces físicas e gráficas}

A memória, introduzida nas máquinas computadoras na década de 1950, fez com que elas adquirissem um caráter genérico, uma das características responsáveis por sua posterior popularização. "Reservados até então à execução de certos tipos de cálculo muito especializados, eles adquiriram, ao mesmo tempo em que a programação era gravada em sua memória, a capacidade de resolver operações lógicas e aritméticas de toda natureza. 0 que os transformou em, mais do que calculadoras, máquinas universais" (COUCHOT, 2003, p.98). 0

\footnotetext{
${ }^{29}$ Do original: "With film and magnetic tape, information and images must be called up sequentially, according to their physical location on the tape or film as it rolls along. Ideas can only be directly linked with the previous and next idea in the sequence. Because of this, these are called linear media. With 'random access media', non-sequential parts of a computer's memory can be called up as if they were next to each other. This allows any idea recorded in memory to appear as if it's next to any other idea. When you combine random access with networked communication, you can display information and images stored on different continents as if they were stored next to each other. Reordering and making multiple versions are all made much easier, as anyone who has used a computer's copy and paste functions understands. Computers reduce the barriers of time and space when playing with and rearranging ideas. As a result, they better depict the changing and manifold relationships between ideas in human thought, and they can be more egalitarian in giving voice to multiple versions of those relationships." (O'SULLIVAN \& IGOE, 2004, p. XVIII)

${ }^{30} \mathrm{O}$ francês 'numérique' que em português, hoje, significa 'digital', foi traduzido, no livro de Couchot por 'numérico'.
} 
próximo passo, também contribuidor para a disseminação mundial dos computadores, deu-se então com a miniaturização de seus componentes.

Apesar dos primeiros computadores terem surgido já na primeira metade do século XX, foi no início dos anos 1970 que começaram a ser difundidos os microprocessadores, descritos hoje como o "coração do computador". Antes disso, os computadores eram máquinas enormes e de custo elevado, capazes de efetuar digitalmente cálculos avançados, cujo uso era restrito a técnicos especialistas, sendo que apenas grandes corporações, universidades e agências do governo possuíam as máquinas. Um dos fatores contribuintes para a dificuldade de uso era a necessidade de preparação prévia das tarefas a serem executadas por meio de cartões perfurados, pedaços de papel que continham informação digital representada pela presença ou ausência de buracos em lugares predeterminados das folhas. Os resultados levavam horas e até dias para poderem ser coletados. Os pesquisadores Asa Briggs e Peter Burke afirmam que o microprocessador:

“...tornou possível, não somente um enorme aumento da potência do computador, mas também uma descentralização do seu uso. (...) Centenas de milhares de componentes podiam ser colocados em um [único] microprocessador e, quando sua versatilidade tornou-se reconhecida, injetou um estímulo à tecnologia digital, em detrimento da analógica, em toda mídia, que logo seria uma de suas principais usuárias - impressos, filmes, gravações, rádio, televisão e todas as formas de telecomunicações agora sendo pensadas, cada vez mais, como parte de um complexo." (BRIGGS \& BURKE, 2004, p.289)

Durante a década de 1980, após a viabilização dos microprocessadores, foram disseminados os computadores pessoais. Os profissionais das mais diversas áreas passaram a utilizá-los e contribuir para seu desenvolvimento. Na década seguinte, esse mercado gozou de verdadeira prosperidade e cresceu rapidamente. Na medida em que 
aumentava o número de seus usuários, sua influência como instrumento de negócios, a forma como afetou as mídias tradicionais e a facilitação no surgimento de novas atividades, tornaram-se mais notáveis no dia-a-dia.

Segundo Steven Johnson aponta, "para que a mágica da revolução digital ocorra, um computador deve também 'representar-se a si mesmo' ao usuário, numa linguagem que este compreenda” (S. JOHNSON, 2001, p.17). É então neste contexto de busca de representação que vão surgindo as diferentes interfaces computacionais. "A interface atua como uma espécie de tradutor, mediando entre as duas partes, tornando uma sensível para a outra" (S. JOHNSON, 2001, p.17). Edmond Couchot assim complementa esse entendimento de interfaces:

“O usuário, que não poderia compreender a linguagem do computador em estado bruto, precisa que essas cifras sejam traduzidas em formas compreensíveis, particularmente em imagens, mas também em sons ou estímulos dirigidos a outras percepções além da audição ou da visão. Todas essas trocas acontecem através das interfaces diversas de entrada ou de saída, e o acoplamento toma a forma de um anel, sob controle computacional." (COUCHOT, 2003, p.171)

Em uma análise mais detida, pode-se dizer que o computador pessoal agrupa dois tipos distintos de interface que foram desenvolvidos e atuam conjuntamente: as interfaces físicas, responsáveis por traduzir as ações do usuário em dados computáveis, e as interfaces gráficas, que se concentram na tradução dos pulsos de energia em textos e imagens, passíveis de serem compreendidos pelas pessoas. Desse modo, ao estudar a evolução do computador pessoal é importante entender o desenvolvimento dessas partes.

É interessante notar que "por mais que os computadores [atuais] sejam radicalmente diferentes dos computadores de vinte anos atrás, e suas capacidades amplamente diferentes, interagimos com eles da mesma 
forma; nos sentamos em uma mesa, olhando para a tela e digitando no teclado"31 (DOURISH, 2004, p.27). 0 fato de ainda se interagir com os computadores pessoais da mesma maneira não descarta o desenvolvimento de outras possibilidades de inserção da computação no cotidiano, porém ressalta a importância de entender aspetos-chave da evolução de suas interfaces.

0 trio tela-teclado-mouse conforma as três interfaces físicas mais populares do computador pessoal. No caso do teclado e do mouse, são eles os responsáveis em traduzir os estímulos físicos dos usuários - toque e movimentação da mão - em pulsos de energia interpretados como comandos pelos microprocessadores. A semelhança com as já tradicionais máquinas de escrever auxiliou na consolidação do modelo de teclado tal como é difundido hoje. Com a invenção do mouse, "em vez de teclar comandos obscuros, o usuário podia simplesmente apontar para alguma coisa e expandir seus conteúdos, ou arrastá-la pela tela” (S. JOHNSON, 2001, p.21). 0 dispositivo foi primeiro apresentado por Doug Engelbart, em1968, e "permitia ao usuário entrar naquele mundo e manipular realmente as coisas dentro dele, sendo por isso muito mais que um mero dispositivo apontador." (S. JOHNSON, 2001, p.22)

As telas permitem a visualização de certos processos internos do computador e dos resultados das computações, sendo que sua vinculação com as máquinas possibilitou o início de uma espécie de diálogo entre o computador e seus usuários. É importante perceber que os desenvolvimentos dos diferentes tipos de interfaces são interdependentes. A potencialização do uso das telas se deu com o desenvolvimento das interfaces gráficas sendo que estas foram fortemente influenciadas pela invenção do mouse e das diferentes possibilidades de acesso à informação trazidas por ele. Com o mouse:

\footnotetext{
${ }^{31}$ Do original: "Despite the fact that computers are so radically different from the computers of twenty years ago, and that their capabilities are so vastly different, we interact with them in just the same way; we sit at a desk, watching the screen and typing on the keyboard." (DOURISH, 2004, p.27)
} 
“... ao invés de utilizar uma linguagem de comandos para instruir o computador, os dados sendo processados são expostos e acessados de forma mais representativa graficamente, sendo que um feedback visual imediato é fornecido após cada ação." 32 (WARDRIP-FRUIN; MONTFORT, 2003, p.485)

Dessa forma, com a diminuição dos componentes, em especial a partir da invenção dos microprocessadores, e com o desenvolvimento de diferentes tipos de interfaces, tanto a máquina quanto seu uso passaram a ser um problema não mais puramente tecnológico, mas também de design. É importante apontar que o movimento que culminou e culmina até hoje nas diferentes interfaces não é uma transição repentina e clara, e sim uma tendência geral que emerge de inúmeras maneiras. A elaboração do design das suas partes físicas (hardware) e digitais (software) foi fundamental para popularização dos computadores e para sua introdução em muitos aspectos da vida cotidiana de populações urbanas de várias partes do mundo.

As interfaces gráficas (GUI, Graphical User Interface) e o aumento da capacidade do computador de processá-las possibilitaram um grande progresso. Se, em um primeiro momento, os designers se preocupavam com o desenho de janelas, ícones, menus e ponteiros (WIMP - Windows, Icons, Menus and Pointers) ${ }^{33}$, a introdução de gráficos avançados, tais como multimídia e realidade virtual, ampliou suas possibilidades de experimentação. Puderam assim, explorar profundamente a não-linearidade das mídias digitais no sentido de "permitir ao usuário obter uma visão panorâmica do conteúdo, navegar na massa de dados sem perder a orientação e, por fim, mover-se no espaço informacional de acordo com seus desejos" (BONSIEPE, 1997, p.59).

\footnotetext{
${ }^{32}$ Do original: "The idea of direct manipulation, though less foolish, is an analogous one: instead of employing a command language to instruct the computer, the data being processed is exposed and accessed in a more graphically representational way, an immediate visual feedback is provided after every action." (WARDRIP-FRUIN; MONTFORT, 2003, p.485)

33 Segundo Bill Moggridge (2007, p. 20-22), a primeira geração de interfaces gráficas foi marcada pelo lançamento, em 1981, da Xerox Star, já com uma interface baseada na metáfora do desktop, com a utilização de mouse, janelas, ícones e menus. Os princípios de "ver e apontar" e "o que você vê é o que você tem" ("what you see is what you get, WYSIWYG"), deram forma a um novo caminho até hoje, início do século XXI, utilizado nas interfaces gráficas dos computadores.
} 
Como comentado anteriormente, as interfaces gráficas foram precedidas pela utilização das telas para mostrar um conteúdo puramente textual. Antes da tela e do texto, as tarefas a serem executadas pelo computador eram preparadas com antecedência por meio da perfuração de cartões e os resultados demoravam horas ou até dias para serem gerados. Com a utilização da tela e o desenvolvimento de uma interface textual, um outro tipo de relação estabeleceu-se, descrita por alguns autores como a primeira forma de interação efetiva entre máquina e homem.

"Quando esta transição ocorreu (simbólico para o textual), a interação textual não era mais um meio de descrever operações computacionais, mas se tornou a forma primária de interação. Discutivelmente, esta é a origem da computação "interativa”, pois as interfaces textuais significaram também o surgimento do "loop interativo" no qual a interação se tornou interminável entre o usuário e o sistema, caracterizando a ida e vinda de instruções e respostas. Mesmo naqueles dias das interfaces gráficas e de realidade virtual, este modelo muitas vezes ainda é o único recurso para algumas operações." 34 (DOURISH, 2004, p. 10)

Importantes também são as linguagens utilizadas para a programação. "Junto com as interações textuais veio uma 'gramática' de interação, que fragmentou o input de texto em comandos, parâmetros, argumentos e opções"35 (DOURSISH, 2004, p.10). Segundo o autor, foi a partir do diálogo textual que as pessoas construíram a idéia de interação com a máquina, e sobre isso complementa:

\footnotetext{
${ }^{34}$ Do original: "When this transition took place (simbolic to textual), textual interaction was no longer a means to describe computer operations, but became the primary form of interaction. Arguably, this is the origin of "interactive" computing, because textual interfaces also meant the appearance of "interactive loop", in which interaction became and endless back-and-forth of instruction and response between user and system. Even in these days of graphical and virtual reality interfaces, this model is still often the only recourse for some operations." (DOURISH, 2004, p. 10)

35 Do original: "Along with textual interaction came a "Grammar" of interaction, one that broke input text into commands, parameters, arguments, and options."(DOURSISH, 2004, p.10)
} 
"[A interação textual] posicionou relevantemente a idéia de interação. Esta abordagem baseou-se na linguagem muito mais explicitamente do que antes e ao mesmo tempo foi acompanhada por uma transição para um novo modelo de computação, no qual o usuário realmente senta-se na frente do terminal de computador, digita comandos e lê as respostas. Com esta combinação do uso da linguagem e interação direta, tornou-se natural olhar para o resultado como uma 'conversação' ou 'diálogo'."36(DOURSISH, 2004, p.10)

A tradução do código binário em textos ou imagens ainda segue uma lógica única, baseada no mapeamento da tela. "Cada pixel na tela do computador era referido a um pequeno naco da memória do computador: numa tela simples, preto-e-branco, esse naco seria um único bit, um 0 ou um 1; se o pixel fosse iluminado, o valor do bit seria 1; se ficasse escuro, seu valor era 0" (S. JOHNSON, 2001, p.21). 0 desenvolvimento das interfaces gráficas é então baseado nessa idéia de espacialização da informação, e cada dia mais "a tarefa de manejar a informação se torna a de manejar o espaço"37 (DOURISH, 2004, p.11), um mapa composto por bits que deu origem à nomenclatura "imagens bitmaps". Conforme comenta Steven Johnson, "pela primeira vez, uma máquina era imaginada não como um apêndice aos nossos corpos, mas como um ambiente, um espaço a ser explorado. Podíamos nos projetar nesse mundo, perder o rumo, tropeçar em coisas. Parecia mais uma paisagem do que uma máquina" (S. JOHNSON, 2001, p.23).

\footnotetext{
${ }^{36}$ Do original: "It brought the idea of interaction to the fore. Textual interaction drew upon language much more explicitly than before, and at the same time it was accompanied by a transition to a new model of computing, in which a user would actually sit in front of a computer terminal, entering commands and reading responses. With this combination of language use and direct interaction, it was natural to look on the result as a 'conversation' or 'dialogue'."(DOURSISH, 2004, p.10)

${ }^{37}$ Do original: "The task of managing information becomes one of managing space." (DOURISH, 2004, p.11)
} 
O primeiro sistema de elementos gráficos amplamente difundido foi baseado em janelas, ícones, menus e ponteiros, denominado WIMP (Winp, Icons, Menus and Pointers). Sobre o impacto que estas interfaces exerceram na maneira de as pessoas se relacionarem com o computador, Paul Dourish diz que:

“A mudança da interação textual para uma gráfica não simplesmente substituiu as palavras por ícones, mas ao contrário, abriu completas novas dimensões para a interação; muito literalmente, de fato, transformando a interação em algo que acontecia em um espaço bi-dimensional ao invés de uma corrente uni-dimensional de caracteres."38 (DOURISH, 2004, p.11)

Depois das grandes corporações, agências do governo e universidades, o computador ocupou escritórios, comércios e serviços de pequeno porte. E como as pessoas parecem ter um "talento natural para pensamento associativo, graças às formidáveis habilidades da rede distribuída do cérebro em comparar padrões" (S. JOHNSON, 2001, p.47), foi a partir das metáforas visuais do mundo do trabalho que as primeiras interfaces gráficas orientadas aos usuários foram desenvolvidas. "Uma seqüência de zeros e uns - ela própria um tipo de linguagem, embora ininteligível para a maior parte dos seres humanos - é substituída pela metáfora de uma pasta virtual que reside num desktop virtual” (S. JOHNSON, 2001, p.18). Áreas de trabalho, pastas e arquivos, lixeiras passam a fazer parte do vocabulário das pessoas não apenas para se referir aos objetos físicos como também para designar representações imagéticas dos zeros e uns responsáveis pela computação dos dados. Segundo Steven Johnson:

“Parte da solução era simplesmente funcional. Era possível usar como fundamento o potencial e as aptidões que o usuário já possuía. Saber alguma coisa sobre organização de fichários nos ajudaria na organização de nossos arquivos digitais, assim como conhecer o funcionamento de

\footnotetext{
${ }^{38}$ Do original: "The move from textual to graphical interaction did not simply replace words with icons, but instead opened up whole new dimensions for interaction - quite literally, in fact, by turning interaction into something that happened in a two-dimensional space rather that a one-dimensional stream of characters." (DOURISH, 2004, p.11)
} 
lixeiras nos ajudaria a excluir arquivos. As metáforas tornariam a experiência do usuário mais intuitiva, e metáforas gráficas divertidas, animadas, tornariam a idéia de usar um computador menos intimidante. Se você sabia se sentar a uma escrivaninha e revisar papéis, podia usar a máquina." (S. JOHNSON, 2001, p. 40)

Com o constante aumento da capacidade de armazenamento e processamento das informações somado ao barateamento dessas tecnologias, as interfaces gráficas puderam evoluir de maneira surpreendente. Segundo Helen Sharp “os conjuntos básicos da [interface] WINP ainda fazem parte das GUI modernas [atuais], mas evoluíram em várias outras formas e tipos." 39 (H. SHARP et al, 2007, p.225). As interfaces WINP e GUI, características dos anos 1980, foram aos poucos incrementadas e deram forma ao que a autora chama de interfaces gráficas avançadas.

Os anos 1990 foram marcados pela ampliação das possibilidades de manejo da informação. Algoritmos e técnicas de interação complexas ajudaram a inovar a visualização e exploração de dados. Aliado às interfaces multimídia - ou multimeios -, passou a ser possível o raciocínio sobre grande quantidade de informação cujo entendimento seria muito mais demorado caso se tratasse apenas de números e textos. Segundo Brenda Laurel (1993, p. 178), “a multimídia (...) agora refere-se a sistemas que entregam mais que texto e gráficos na sua tela visual e que caracteristicamente utiliza algum tipo de computador e algum tipo de mídia de armazenamento óptico”40. Ela combina várias mídias, entre elas, vídeo, gráficos, sons, animações, em uma mesma interface.

\footnotetext{
${ }^{39}$ Do original: "the basic building blocks of the WINP are still part of the modern GUI, but have evolved into a number of different forms and types." (SHARP et al., 2007, p.225)

${ }^{40}$ Do original: "Multimedia (...) now refers to systems that deliver more that text and graphics in their visual displays and which characteristically utilize some kind of computer and some kind of optical storage medium" (LAUREL, 1993, p. 178)
} 
A convergência de diversas formas de visualização de dados dentro de uma tela, somada à possibilidade de acesso randômico a elas, fez com que a multimídia se tornasse um dos grandes avanços da computação, altamente explorado até os dias de hoje. Sua importância parte da proposição de que "a combinação de mídias e interatividade pode fornecer melhores formas de apresentação de informação do que qualquer uma sozinha." 41 (H. SHARP et al., 2007, p.241)

A multimídia também abriu caminho para avanços no desenvolvimento de web-sites. Antes da possibilidade de combinação de diversas mídias, eles eram basicamente compostos por textos ligados uns aos outros, os hipertextos, de forma tão eficiente quanto possível, garantindo a navegação pelas informações. Conteúdos para $c d$-roms, filmes e navegação em DVD e web-sites são atualmente importantes territórios de atuação do designer na computação, mas estão longe de ser os únicos.

O avanço tecnológico permitiu também que espacialidades virtuais fossem criadas com alto grau de realismo por meio dos chamados gráficos 3-D. Como conseqüência dessa realização, as tecnologias chamadas de realidade virtual (Virtual Reality, VR) e de ambientes virtuais (Virtual Environments, VE). Os gráficos 3D representaram uma grande evolução em termos representacionais. Na arquitetura e no design, além da visualização prévia das espacialidades e objetos projetados, possibilitaram também a criação e manipulação de formas antes não imaginadas. Nos jogos, gráficos com alto grau de complexidade passaram a ser explorados e a movimentação dos personagens e objetos tornou-se mais dinâmica e próxima da realidade.

Tão logo se deu a implementação desses gráficos avançados, pesquisas foram feitas para ampliar a sensação de imersão nessas imagens. A projeção de imagens nas paredes e no piso de uma CAVE (Cave Automatic Virtual Environment) ou mesmo em grandes displays múltiplos (como nas telas IMAX) possibilitaram a experimentação

${ }^{41}$ Do original: " a combination of media and interactivity can provide better ways of presenting information that can either one alone." (SHARP, 2007, p.241) 
do conceito de realidade virtual, ou seja, "a experiência de interação com um ambiente artificial, que o faz sentir virtualmente real"42 (SHARP, 2007, p.244). Assim, pode-se identificar essa realidade virtual imersiva como um dos momentos no qual o desenvolvimento de interfaces tende a se afastar do trio mouse-teclado-tela.

“A realidade virtual mergulha o usuário em uma realidade gerada computacionalmente. Os usuários utilizam capacetes que mostram imagens levemente diferentes geradas pelo computador para cada olho, dando a ilusão de um espaço tri-dimensional. Pela monitoração dos movimentos da cabeça do usuário e ajuste apropriado da imagem, este espaço tri-dimensional pode ser estendido para além do campo de visão imediato; o usuário pode movimentar a cabeça e a imagem acompanha o movimento. Com tecnologias de sensoriamento adequadas, o usuário pode entrar no espaço virtual e agir nele. Uma 'luva de dados' é uma luva provida com sensores que transmitem a posição e orientações da mão e dos dedos para um computador; a mão do usuário que veste a luva é projetada como uma mão virtual no mesmo espaço tri-dimensional construído pelo computador e gerado pelo sistema de realidade virtual. Assim o usuário pode pegar objetos virtuais, examiná-los, movê-los ao redor e agir no espaço."43(DOURISH, 2004, p.37)

A realidade virtual imersiva demanda pesquisas sobre reconhecimento de voz, gestos e toque, porém, segundo Mark Weiser aponta, ela "concentra um enorme instrumental sobre a simulação do mundo, ao invés de melhorar invisivelmente o mundo já existente."44 (WEISER, 1990, sp). Ao longo dos anos 1990, as possibilidades vão

\footnotetext{
${ }^{42}$ Do original: "the experience of interacting with an artificial environment, which makes it feel virtually real." (SHARP, 2007, p.244)

${ }^{43}$ Do original: "Virtual Reality immerses the user in a computationally generated reality. Users don head-mounted displays, which present slightly different computer-generated images to each eye, giving the illusion of a three-dimensional space. By monitoring the user's head movements and adjusting the image appropriately, this three-dimensional space can be extended beyond the immediate field of view; the user can move his head around, and the image moves to match. With appropriating sensing technologies, the use can enter the virtual space and act within it. A 'dataglove' is a glove augmented with sensors that report the position and orientations of the hand and fingers to a computer; the hand of the user wearing the glove is projected as a virtual hand into the same computer-generated three dimensional space that the virtual reality system generates, so that the user can pick up virtual objects, examine them, move them around, and act in the space." (DOURISH, 2004, p.37)

${ }^{44}$ Do original: "Virtual reality focuses an enormous apparatus on simulating the world rather than on invisibly enhancing the world that already exists." (WEISER, 1990, sp)
} 
sendo prioritariamente pensadas para desempenhar as mesmas funções do mouse e do teclado, ou seja, a de manipulação direta da informação e da sua visualização em interfaces gráficas. Nesses aparatos de controle já tradicionais, as relações entre o usuário e o espaço à sua volta quase não são exploradas, da mesma forma que, no caso da Realidade Virtual, a tela bidimensional não é abandonada. Pode-se dizer que, durante um grande período, o desenvolvimento de possibilidades técnicas visou muito prioritariamente o computador pessoal e suas interfaces, apesar de sinais de outros caminhos passíveis de serem explorados já emergirem.

\section{4 | Design do meio digital: HCI e Interaction Design}

Entender a ligação entre desenvolvimento tecnológico e design é essencial para a determinação de novos campos de atuação, processos de criação e a formulação de objetos que respondam às diferentes realidades e necessidades. Nesse sentido, o desenvolvimento acelerado das tecnologias digitais tem influenciado diretamente as possibilidades de relação do homem com o meio no qual habita, sobretudo por meio dos artefatos que cria para tal finalidade. A respeito dos produtos tecnológicos dessa época, caracterizada pela disseminação dos objetos eletrônicos, Briggs e Burke, em seu estudo da história social das mídias, ressaltam que:

“Os computadores devem vir em primeiro lugar em qualquer análise histórica, pois logo que deixaram de ser considerados simples máquinas de calcular - e isso só aconteceu no começo da década de 70 - , eles passaram a fazer com que todos os tipos de serviços, e não somente os de comunicações, tomassem novas formas." (BRIGGS ; BURKE, 2004, p.283)

No caso do computador, se a tecnologia foi responsável pela miniaturização e barateamento de seus componentes, o design foi logo reconhecido como uma ferramenta importante para torná-lo capaz de ser utilizado por pessoas leigas, por meio do desenvolvimento de programas computacionais e interfaces 
“amigáveis". Esses usuários leigos são, em outras palavras, pessoas não especializadas no entendimento dos diversos processos que ocorrem dentro da máquina .

Esse interior desconhecido consiste em uma característica importante em termos de composição e arranjo do objeto. A diferenciação que existe na sua composição entre conteúdo (software) e estrutura (hardware), constitui um aspecto peculiar que o diferencia de todos os objetos produzidos até então e faz dele uma ferramenta versátil capaz de agenciar e executar infinitas tarefas. Esta diferenciação pode ser melhor explicada a partir da seguinte comparação:

“Um objeto eletromecânico, como um rádio, conecta seus componentes físicos mecânicos aos seus elementos eletrônicos de uma maneira completamente direta. Quando giramos o sintonizador, as pontas dos dedos e os músculos podem quase 'sentir' as estações sendo sintonizadas. Entretanto, com os computadores, a distância é normalmente muito menos direta entre as teclas e a imagem na tela em relação ao que está acontecendo dentro do computador. Nosso mundo físico e o mundo digital do computador parecem estar separados por milhas de distância." 45 (SMITH in MOGGRIDGE, 2007, p.XV)

Essa fragmentação do objeto trouxe conseqüências significativas ao processo de design que abarca sua concepção e desenvolvimento. Tom Mitchell (in THACKARA, 1988, p.208), ao afirmar que "os métodos tradicionais de design de produto mostraram-se pouco adequados na aplicação em tarefas do design de novas tecnologias da informação tais como a produção de programas"46, sugere uma obsolescência dos processos de

\footnotetext{
${ }^{45}$ Do original: "An electromechanical object, a radio say, links its physical mechanical components to its electronic elements in a fairly direct way. When we turn the dial, our fingertips and muscles can almost "feel" the stations being scanned. With computers, however, the distance between, on one hand, keystrokes and screen image, and, on the other, what's happening inside the computer, is usually much less direct. Our physical world and the computer's digital world seem miles apart." (SMITH, in MOGGRIDGE, 2007, p.XV)

${ }^{46}$ Do original: "Traditional methods of product design have proved unsuitable in application to new information technology design tasks such as the making of computer software." (MITCHELL in TACKARA, 1988, p.208)
} 
design da Era Industrial e aponta a conformação de métodos de design pós-mecanicistas. Assim sendo, o autor identifica diferentes estratégias de formulação e desenvolvimento empregadas para esse novo objeto, de forma que a visão e o entendimento de design passam a ser diretamente influenciados por elas.

Os computadores configuram-se como um meio universal e adaptável cuja especificidade é atribuída por sua programação e pelo conteúdo de seu software. O processo de design desse conteúdo é caracterizado pela sobreposição das etapas de planejamento e execução, de forma que, "ao realmente fazer, no lugar de simplesmente planejar os produtos, os designers são capazes de experimentar diretamente se seus produtos funcionam bem."47 (T. MITCHELL in THACKARA, 1988, p.211) Ao mesmo tempo, tradicionalmente, as necessidades dos usuários conformam o principal fator que determina a aplicação e as capacidades do produto.

Nesse contexto, o campo de conhecimento do $\mathrm{HCI}^{48}$ configura uma importante sub-área das Ciências da Computação, que cuida diretamente do design do computador e de seus sistemas (software) a partir da perspectiva do usuário, uma aproximação denominada “design centrado no usuário” (user-centered design). Nesse sentido, segundo Faulkner compara, "um bom sistema de computador, como um bom par de sapatos deve ser natural, confortável e servir sem que o usuário tenha consciência dele."49 (FAULKNER, 1998, p.7) Especificamente, o HCI foca-se no design de programas computacionais e na ergonomia e usabilidade da máquina, extremamente importantes na história do computador, atenuando e ocultando muitas de suas complexidades, tornando-o acessível a uma gama maior de usuários.

\footnotetext{
${ }^{47}$ Do original: "By actually making, rather than simply planning products, designers are able directly to experience how well their products work." (T. MITCHELL in TACKARA, 1988, p.211).

${ }^{48}$ Interação Humano-Computador ou Human Computer Interaction.

49 Do original: "A good computer system, like a good pair of shoes, should feel natural, comfortable and fit without the user being aware of it." (FAULKNER, 1998, p.7)
} 
"Hoje, os computadores são amplamente utilizados por pessoas que mesmo sendo peritos no seu campo específico, como por exemplo medicina, bancário ou aviação, não são necessariamente peritos em computadores. Em outras palavras, eles devem saber bastante sobre as tarefas que querem realizar, mas nada ou muito pouco sobre o computador que usam." ${ }^{50}$ (FAULKNER, 1998, p.6)

Peter Johnson, ao definir o campo de atuação do HCI, diz que seu processo de design trata de "identificar requisitos e assegurar que esses requisitos foram alcançados."51 (P. JOHNSON, 1992, p.3) A partir desta visão funcionalista, na qual a eficácia de uma solução garante um bom resultado, o HCI focaliza os três principais aspectos em jogo quando se faz uso de computadores: o usuário, o sistema e as tarefas a serem realizadas. Para alcançar a otimização do cumprimento de tarefas, aspectos físicos relacionados à memória, visão, cognição, audição, toque e coordenação motoras são combinados com características da organização pela qual será executada a tarefa.

Em relação a esta visão funcionalista, devem-se tomar cuidados no sentido de que cumprir tarefas não resume toda a potencialidade trazida por esse objeto. Ao computador seguiram-se diversos outros objetos digitais tais como palmtops e aparelhos celulares, nos quais notou-se uma elevação nos graus de interatividade. Isso fez com que outras preocupações fossem somadas ao desenvolvimento de artefatos eletrônicos, tendência descrita por Gillian Crampton Smith, no prefácio do livro Designing Interactions de Bill Moggridge. Smith lembra que

\footnotetext{
${ }^{50}$ Do original: "Today, computers are widely used by people who although they may be experts in their particular field, for example medicine, banking or flying aircraft, are not necessarily computer experts. In other words, they might know a great deal about the task they want to perform but nothing or very little about the computer they use." (FAULKNER, 1998, p.6)

${ }^{51}$ Do original: "Designing is very much about identifying requirements and ensuring that those requirements have been met." (JOHNSON, 1992, p.3)
} 
"Ao design focado na operacionalização, utilidade, satisfação e qualidades comunicativas, devemos adicionar um quinto imperativo: o design para a sociabilidade. Quando os sistemas de tecnologias da informação (IT) falham em auxiliar aspectos sociais do trabalho e do lazer, causam a desumanização e de-civilizam nosso relacionamento com os outros, empobrecem a rica rede social na qual vivemos e operamos, essencial tanto para o bem-estar quanto para a eficiência"52 (SMITH, in MOGGRIDGE, 2007, p. XIV)

Nesse âmbito, emergiu um novo campo de atuação denominado Interaction Design, cujo objetivo principal é colocar as pessoas e suas interações com o mundo acima do desenvolvimento tecnológico. Para além do envolvimento dos usuários no cumprimento de tarefas, trata-se de uma visão holística através da qual todo aparato tecnológico faz parte de um complexo e emaranhado sistema de relações e interações. A contribuição do design "visa aos fenômenos de uso e da funcionalidade de uso [sendo que] no centro de seu interesse se encontra a eficiência sociocultural na vida cotidiana. As categorias de engenharia, porém, não captam os fenômenos de uso, ou seja, a integração dos artefatos à cultura cotidiana."(BONSIEPE,1997, p.17)

A convergência desses dois princípios de pensamento aparentemente distintos é importante pois "quando concebemos um sistema ou dispositivo baseado no computador, estamos concebendo não apenas sua aparência mas também como ele se comporta. Estamos concebendo a qualidade de como nós e o sistema interagimos. Esta é a destreza do interaction designer." 53 (SMITH, in MOGGRIDGE, 2007, p.XVI) Esse profissional busca desenvolver tecnologias apropriadas a situações específicas, colocando sempre o contexto como foco principal na atividade de desenvolvimento de aparatos tecnológicos. Em um momento no qual as atividades cotidianas são

\footnotetext{
52 Do original: "To designing for usability, utility, satisfaction, and communicative qualities, we should add a fifth imperative: designing for sociability. When IT systems fail to support the social aspect of work and leisure, when they dehumanize and de-civilize our relationship with each other, they impoverish the rich social web in which we live and operate, essential for both well-being and efficiency." (SMITH, in MOGGRIDGE, 2007, p.XIV)

53 Do original: "When we design a computer-based system or device, we're designing not just what it looks like but how it behaves. We're designing the quality of how it and we interact. This is the skill of the interaction designer." (G. SMITH, in MOGGRIDGE, 2007, p.XVI)
} 
constantemente influenciadas e dependentes desses sistemas e aparatos, é imprescindível que seu desenvolvimento seja acompanhado da consciência de seu impacto no âmbito social. "Se você vai criar bons designs, primeiramente é necessário entender as pessoas - o que elas precisam, querem e gostam, e também a maneira como pensam e se comportam."54 (MOGGRIDGE, 2007, p.725)

Analisando a diferença entre o HCI e o Interaction Design, pode-se dizer que o primeiro possui uma aproximação centrada no usuário e o segundo, no humano e em sua rede social. Ou seja, o HCI analisa os aspectos que envolvem a satisfação na realização de tarefas e o Interaction Design vai além, coloca em primeiro lugar as relações humanas e a influência social introduzida pelas TICs. Segundo Donald Norman:

“Os seres humanos são extremamente complexos; a entidade mais complexa já estudada. Cada uma de nossas ações é o resultado de múltiplas interações, de experiências e conhecimentos adquiridos ao longo da vida e de relacionamentos sociais sutis. As ferramentas de medição da ciência tentam remover as complexidades, estudando uma única variável de cada vez. Mas muito do que é valioso para a vida humana resulta da interação entre as partes: quando variáveis simples e únicas são medidas separadamente, perdemos o foco."55 (NORMAN, 1993, p.15)

Com essa observação, o autor faz uma leitura sistêmica da vida humana em sociedade. Ele se opõe a uma visão reducionista que se consolidou no século XIX que acreditava que para se entender um conjunto bastava entender cada parte separadamente. Ele reafirma o interesse em considerar as interações entre as partes como num

\footnotetext{
${ }^{54}$ Do original: "If you are going to create good designs, you first have to understand people - what they need, want and enjoy, as well as how they think and behave." (MOGGRIDGE, 2007, p.725).

${ }^{55}$ Do original: "Humans are extremely complex, the most complex entity ever studied. Each of our actions is the result of multiple interactions, of a lifetime of experiences and knowledge, and of subtle social relationships. The measurement tools of science try to strip away the complexities, studying a single variable at a time. But much of what is of value to human life results from the interaction of the parts: when we measure simple, single variables, we miss the point." (NORMAN, 1993, p.15)
} 
sistema complexo, e retoma o princípio enunciado na introdução do capítulo de que da interação entre as partes emergem processos maiores.

O alcance do Interaction Design não envolve apenas os produtos materiais, mas também os serviços. Uma vez que a vida cotidiana é cada dia mais conectada por meio de redes de telecomunicações e preenchida com coisas imateriais, tais como música, filmes, imagens televisivas, entre muitas outras, esses serviços são tão importantes quanto as máquinas com as quais os acessamos. Assim, o design da interação focaliza a criação tanto de produtos quanto de serviços, avaliando novas maneiras de usar as tecnologias existentes, de forma a auxiliar as pessoas a interagir umas com as outras. A partir dessa linha de pensamento, as propostas de interações entre o homem e os objetos se tornaram mais complexas e experimentais e à ação de design vê-se atribuir um papel ainda mais fundamental nessa tarefa. Com tudo isso, o importante é perceber as possibilidades. O design de software e da interação digitalmente mediada pelos objetos aponta estratégias de um processo no qual o foco passa a ser , a sociabilidade, as pessoas e o estilo de vida.

Como parte das aproximações do Interaction Design, é possível identificar iniciativas paralelas nas quais designers propõem maneiras alternativas de abordar a atividade prática do trabalho com as tecnologias digitais, distanciadas dos aspectos mercadológicos e funcionais que normalmente determinam a produção dos objetos cotidianos. São ideários que, a partir de aproximações críticas e criativas, procuram indicar alternativas à realidade existente, juntando informações e propondo novas leituras com o objetivo de instigar designers e demais profissionais a visualizar outras possibilidades de trabalho. São práticas de pesquisa por meio do design que englobam tanto aspectos relacionados ao conteúdo quanto ao processo. Os designers Anthony Dunne e Fiona Raby trazem à discussão questões relacionadas à cultura digital no contexto específico do design, apontando que:

“Quando a tecnologia está se desenvolvendo tão rápido como no momento, a reflexão e o criticismo são particularmente importantes. Precisamos considerar visões alternativas do que 
àquelas apresentadas pela indústria. 0 design, sendo acessível, contemporâneo e parte da cultura popular, está perfeitamente posicionado para desempenhar esse papel. Mas para que isto seja alcançado, algumas mudanças significativas precisam ocorrer. Precisamos desenvolver uma atividade paralela de design que questione e desafie as estratégias industriais."56 (DUNNE; RABY, 2001, p.58)

Dunne e Raby desenvolvem suas idéias em propostas de objetos que fazem parte do que denominam Critical Design. Segundo eles, o "design crítico, ou design que propõe questões habilidosamente criadas e nos faz pensar, é algo tão difícil e tão importante quanto o design que resolve problemas ou encontra respostas."57 (DUNNE; RABY, 2001, p.58) Por propostas conceituais entendem "não o estágio conceitual do projeto de um design, mas um produto intencionado em desafiar as pré-concepções sobre como os produtos eletrônicos dão forma à nossa vida." 58 (DUNNE, 2005, p. 84) Os autores contrapõem essa aproximação crítica ao que eles denominam design afirmativo, ou seja, aquele que responde às demandas da sociedade apenas reafirmando as coisas como elas são.

Segundo os autores, o design crítico e conceitual vai fundamentalmente contra as formulações tradicionais do design voltadas para o mercado e para o consumo. Para que seja realizado, é necessário um trabalho cujo foco resida nos limites entre a realidade vivenciada e a ficção da visualização de um mundo alternativo. Para Anthony Dunne "o desafio é dissolver as fronteiras entre o real e a ficção de forma que o visionário se torne mais real e o real seja visto apenas como uma possibilidade limitada, um produto de uma ideologia mantida por meio do design não-crítico e do excesso de bens de consumo" (DUNNE, 2005, p.84). Assim, cada um com sua importância,

\footnotetext{
${ }^{56}$ Do original: "When technology is developing as rapidly as it is now, reflection and criticism are particularly important. We need to consider alternative visions to those put forward by industry. Design, being accessible, contemporary and part of popular culture, is perfectly positioned to perform this role. But in order to achieve this, some significant shifts need to occur. We need to develop a parallel design activity that questions and challenges industrial agendas." (DUNNE \& RABY, 2001, p.58)

57 Do original: "Critical Design, or design that asks carefully crafted questions and makes us think, is just as difficult and Just as important as design that solves problems or finds answers" (DUNNE \& RABY, 2001, p.58)

${ }^{58}$ Do original: "It is a form of "conceptual design" - meaning not the conceptual stage of a design Project, but a product intended to challenge preconceptions about how electronic products shape our lives." (DUNNE, 2005, p.84)
} 
formular respostas e proposições para o mercado é tão importante e difícil quanto trabalhar com a crítica e especulação por meio do design.
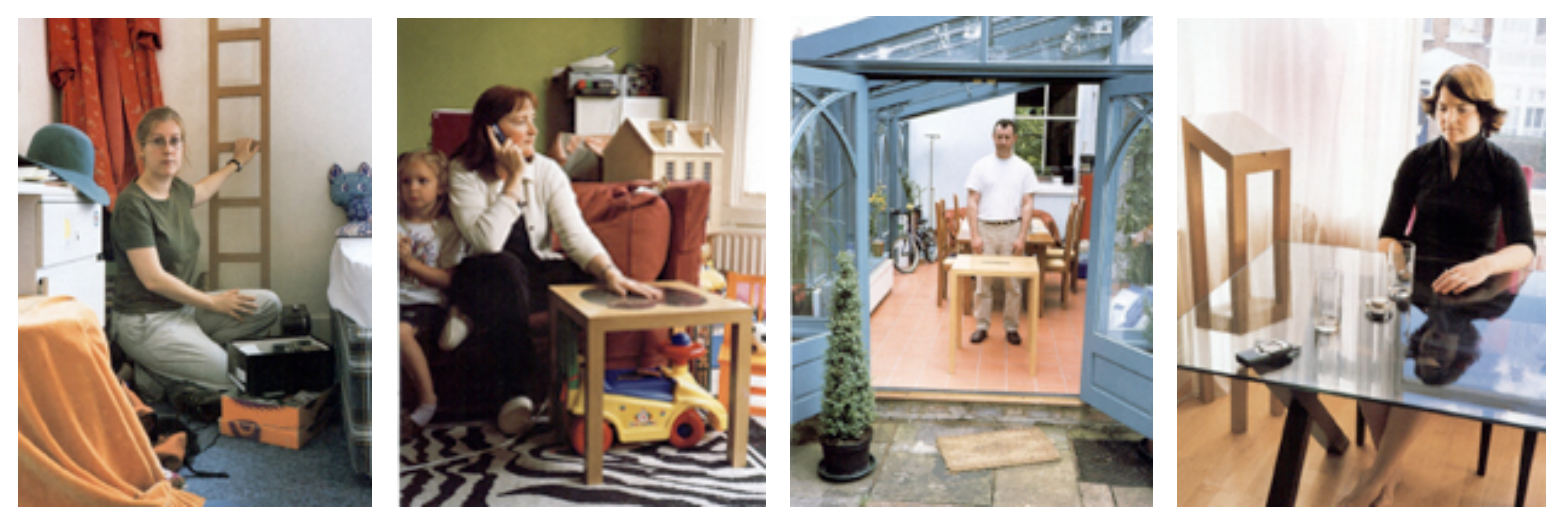

Fig. 6: LOFT - Uma caixa de chumbo no topo de uma escada protege recordações magnéticas de campos eletromagnéticos. Fig. 7: Electricity drain - Ao sentar-se nu nesse banco, a eletricidade é drenada do corpo por um plug especial conectado a um fio-terra. Fig. 8: GPS table - Uma mesa globalmente posicionada mostra sua exata localização no mundo. Para isso necessita de uma constante conexão com os satélites. Fig. 9: Phone table - Um telefone celular no modo silencioso é colocado dentro da mesa que brilha levemente quando ele é chamado.

Fonte: DUNNE, A.; RABY, F. "Design Noir: The Secret Life of Electronis Objects". Basel ; Boston ; Berlin : Birkhauser, 2001. p. 81-89.

'Placebo' é o nome de um dos projetos desenvolvidos pela dupla (Fig. 6-13) e o conceito que o caracteriza. Consiste em um conjunto de objetos destinados ao ambiente doméstico, por meio dos quais se propõe uma reflexão sobre a presença invasiva de campos eletromagnéticos nesses espaços. 0 projeto quer ser uma maneira de tornar perceptíveis aspectos do desenvolvimento tecnológico que normalmente escapam aos sentidos humanos. Esses objetos trariam um certo conforto psicológico na medida em que conscientizam seus usuários de algo em geral despercebido, porém constantemente presente em suas vidas. 

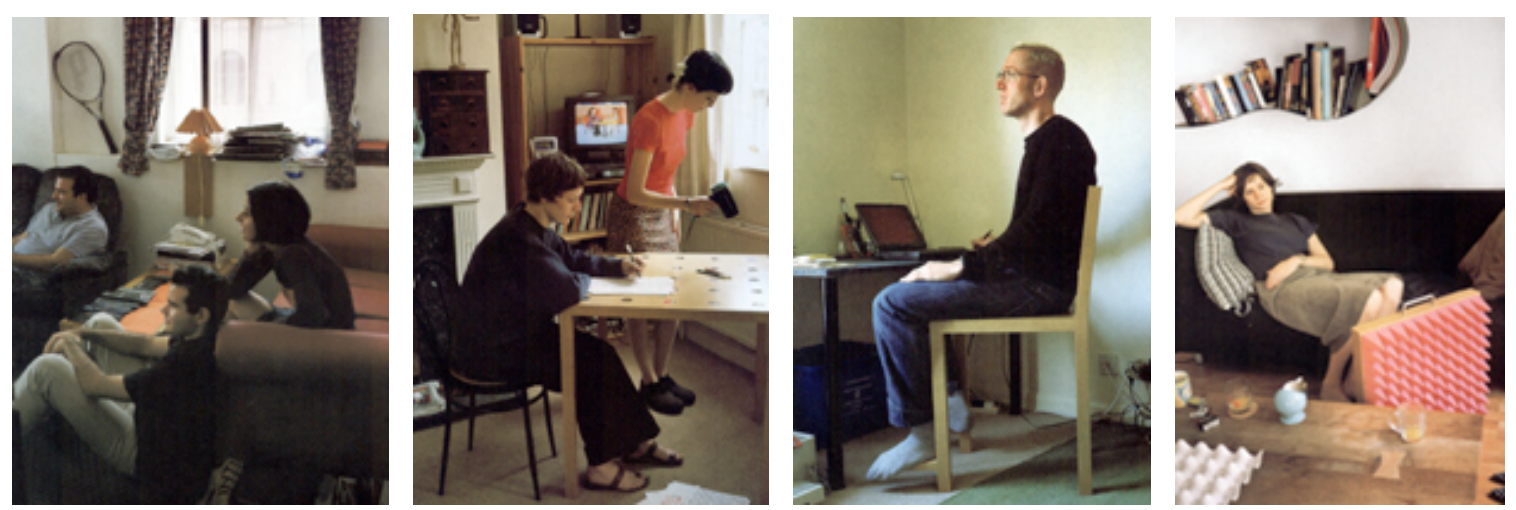

Fig. 10: Parasite Light - Um "objeto necessitado" que só funciona quando está posicionado perto de um aparato eletrônico. Possui um sensor que relaciona a força dos seus 20 leds (alimentados por bateria) à força dos campos eletromagnéticos que estão à sua volta. Fig. 11: Compass table - Uma mesa que faz lembrar a extensão dos objetos eletrônicos para além dos seus limites visíveis. Quando estes aparatos são posicionados na superfície da mesa, fazem com que as agulhas de 25 bússolas reajam ao seu campo eletromagnético. Fig. 12: Nipple chair - nódulos inseridos no encosto da cadeira vibram quando a radiação passa pelo corpo da pessoa que está sentada. Fig. 13: Electro-draught excluder - Possui uma alça para ser carregado e, quando colocado entre a pessoa e o objeto eletrônico, protege-a dos campos eletromagnéticos.

Fonte: DUNNE, A.; RABY, F. "Design Noir: The Secret Life of Electronis Objects". Basel ; Boston ; Berlin : Birkhauser, 2001. p. 81-89.

0 projeto é fruto das preocupações constantemente presentes no trabalho desenvolvido pelos designers, sobre as TICs e as formas alternativas de sua inserção em objetos e no cotidiano das pessoas. "Mesmo nós não podendo mudar a realidade, podemos mudar a percepção das pessoas quanto a ela. Como um placebo médico, os objetos deste projeto não removem ou atacam a causa da preocupação, mas podem fornecer algum conforto psicológico."59 (DUNNE; RABY, 2001, p.75) Para isso, desenvolveram oito peças de mobiliário, produzidas com MDF60 e com a inserção de um ou outro aparato informatizado, dentre eles um GPS61 e sensores que captam

\footnotetext{
${ }^{59}$ Do original: "Although we cannot change reality, we can change people's perception of it. Like a medical placebo, the objects in this project do not actually remove or counteract the cause for concern, but they can provide some psycological comfort." (DUNNE; RABY, 2001, p.75)

60 MDF, do inglês Medium Density Fiberboard (Fibra de Média Densidade), é um painel de fibras de madeira, bastante utilizado na fabricação de móveis, sendo sua composição homogênea em toda a sua superfície como em seu interior.
} 
ondas eletromagnéticas. A simplicidade de suas formas é fruto da intenção de alcançar o meio-termo entre um design fechado, a ponto de não possibilitar a imaginação, e um outro muito aberto, que talvez acarretasse no completo estranhamento e repulsão por parte do usuário. 0 caráter experimental da proposta está claro, já que esses produtos não foram desenvolvidos para serem comercializados. 0 interesse dos designers reside na análise das narrativas produzidas pelos usuários, nas quais aspectos sobre a presença do objeto nas casas são ressaltados. Após seis meses convivendo com as peças em suas casas, os usuários foram entrevistados para avaliar de que maneira aqueles objetos trouxeram questionamentos sobre a convivência dessas pessoas com os aparatos eletrônicos presentes em seu cotidiano. Essa experiência utiliza o design como meio de despertar a imaginação das pessoas e desafiá-las a considerar formas através das quais as tecnologias de informação e comunicação poderiam fazer parte de suas vidas. Gillian Crampton Smith, no prefácio que escreveu para o livro de Dunne (1999), compara essa visão especulativa do design, proposta pelos projetos da dupla Anthonny Dunne e Fiona Raby, com a arquitetura. Segundo a designer, "a arquitetura possui uma longa tradição na 'competição de idéias' cujas propostas não costumam ter a intenção de ser construídas, mas disseminar publicamente idéias radicais sobre como a arquitetura, e possivelmente a vida que ela abriga, pode ser concebida diferentemente." 62 (G. SMITH in DUNNE,1999, p.IX) Ressalta a importância de trazer esse universo experimental também para o processo que envolve objetos interativos a fim de, através dessas propostas, "imaginar futuros possíveis e impossíveis com o computador, ampliar aquilo com que as pessoas devem achar agradável viver e o que os fabricantes poderiam imaginar fazer e vender."63 (G. SMITH in DUNNE, 1999, p.IX)

\footnotetext{
${ }^{61}$ GPS, do inglês Global Positioning System (Sistema de Posicinamento Global) é a abreviatura de NAVSTAR GPS (NAVSTAR GPS- NAVigation System with Time And Ranging Global Positioning System). É um sistema de radionavegação baseado em satélites, desenvolvido e controlado pelo departamento de defesa dos Estados Unidos da América (U.S.DoD), que permite a qualquer usuário saber a sua localização, velocidade e tempo, 24 horas por dia, sob quaisquer condições atmosféricas e em qualquer ponto do globo terrestre.

62 Do original: "Architecture has a long tradition of the 'ideas competition' whose entries are not usually intended to be built but to publicly disseminate radical ideas about how architecture, and possibly the life it accommodates, might be differently conceived". (G. SMITH, in DUNNE, 1999, p.IX).

${ }^{63}$ Do original: "The world of electronic product design needs a similar speculative arena, to imagine possible and impossible futures with computer and to extend what people might find enjoyable to live with and what manufacturers could imagine making and selling". (G. SMITH in DUNNE, 1999, p.IX
} 
\{idéias e explorações\} 
Como forma de ilustrar o universo no qual se inserem as idéias estudadas nessa pesquisa, serão analisados alguns exemplos de aplicação das tecnologias de informação e comunicação (TIC) em aparatos nas diversas escalas. Entende-se que, por mais que possam contemplar aspectos e preocupações específicas, objetos, espaços e edificações interativas fazem parte de um mesmo fenômeno, caracterizado pela chamadas realidades híbridas nas quais espaços e objetos físicos são criados no entrelaçamento com instâncias virtuais informatizadas. Constituem, ainda, proposições que partem do entendimento de algumas questões colocadas pelas TIC no cotidiano, e intervêm em objetos de diversas escalas como meios através dos quais é possível explicitar aspectos peculiares do comportamento das pessoas ao lidar com aparatos interativos. Acredita-se, assim, que o conhecimento de diferentes procedimentos para a aplicação inovadora da tecnologia possa gerar novas questões sobre, para e através do design, capazes de auxiliar a determinação de pontos de partida para o processo de concepção e desenvolvimento deste tipo de objeto.

Paul Dourish aponta duas tendências que levam a crer que, no século XXI, outros caminhos estão sendo trilhados em relação ao desenvolvimento dos meios digitais. "Estas duas tendências - o acréscimo massivo de poder computacional e a expansão do contexto no qual colocamos esse poder em uso - sugerem que precisamos de novas formas de interação com os computadores; formas que sejam melhor conectadas com nossas necessidades e habilidades"64 (DOURISH, 2004:02). Para isso, dentre os diversos temas emergentes na área da computação, os

64 Do original: "These two trends - the massive increase in computational power and the expanding context in which we put that power to use -both suggest that we need new ways of interacting with computers, ways that are better tuned to our need and abilities". (DOURISH, 2004:02) 
conceitos de computação ubíqua, realidade aumentada e interfaces tangíveis interessam especificamente a essa pesquisa uma vez que exploram possibilidades de emprego da computação para além do computador pessoal. Objetos na escala do corpo, do mobiliário, do edifício e da cidade sugerem diferentes aproximações do tema. Devem ser entendidos como exemplos das possibilidades colocadas pelo panorama técnico que se desenvolve a partir da diminuição do tamanho e do preço dos microcontroladores e outros componentes eletrônicos, permitindo assim sua integração ao cotidiano das pessoas.

\section{1 | Computação ubíqua e interfaces tangíveis}

Um dos pesquisadores interessados em divulgar a idéia de que o futuro da computação estaria na sua dispersão pelos lugares e objetos foi Mark Weiser, citado por diversos autores (MOGGRIDGE, 2007; SHARP, 2007; McCULLOUGH, 2004; GREENFIELD, 2006) como o criador da expressão Computação Ubíqua. No início dos anos 1990, no texto "The computer for the 21st century", ele menciona sua busca, juntamente com os demais pesquisadores da Xerox PARC65, em "conceber uma nova forma de pensar sobre os computadores no mundo, que leve em conta o ambiente natural humano e permita que os próprios computadores desapareçam no pano de fundo"66 (WEISER, 1991:sp).

"Uma importante idéia era que o aparecimento da computação ubíqua (ou UbiComp, como é normalmente conhecida) mudaria radicalmente a forma como as pessoas pensam e interagem com computadores. Em particular, os computadores seriam projetados para serem parte do meio ambiente, incorporados em uma grande variedade de objetos, dispositivos e monitores. A idéia por trás da visão de Weiser era de que um aparato de computação ubíqua entraria no centro de

65 Xerox PARC - Palo Alto Research Center.

66 Do original: "to conceive a new way of thinking about computers in the world, one that takes into account the natural human environment andallows the computers themselves to vanish into the background."(WEISER, 1991:sp) 
atenção de uma pessoa quando necessário e se moveria para a periferia de sua atenção quando não necessário, possibilitando que a pessoa alterne atividades calmamente e sem esforço sem ter que descobrir como usar um computador ao cumprir suas tarefas. Em essência, a tecnologia não seria notável e desapareceria no pano de fundo. As pessoas seriam capazes de tocar suas vidas cotidianas, interagindo com a informação, comunicando e colaborando com outras pessoas sem serem distraídas ou frustradas pela tecnologia."67 (SHARP, 2007:218-219)

Em seu artigo, Weiser conduz esse raciocínio por meio da exposição de alguns princípios, da descrição de aspectos da infra-estrutura necessária e da narração de um cenário hipotético. A idéia de uma computação ubíqua, segundo o autor, baseia-se no seu entrelaçamento com a vida cotidiana de forma que uma se torne indistinguível da outra, assim como acontece com a escrita. A escrita, primeira tecnologia comunicativa, está presente no pano de fundo do cotidiano nos livros, sinalização, placas, etc. Weiser nota que esses elementos são trazidos para o plano da atenção das pessoas apenas quando necessários, e acredita que o mesmo deveria acontecer com a computação. Esse tipo de abordagem busca evitar que a atenção das pessoas seja dividida entre a tecnologia e a atividade principal. Para que a computação seja ubíqua, da maneira como Weiser propõe, não basta que as pessoas possuam notebooks e os levem a toda parte. Conforme aponta Paul Dourish:

"A interação com a tela e o teclado, por exemplo, tende a demandar nossa atenção direta; temos que olhar para a tela para ver o que estamos fazendo, o que implica olhar para além de qualquer outro elemento que esteja em nosso meio ambiente, inclusive outras pessoas. A interação com o

\footnotetext{
${ }^{67}$ Do original: "A main idea was that the advent of ubiquitous computing (or UbiComp as it is commonly known) would radically change the way people think about and interact with computers. In particular, computers would be designed to be part of the environment, embedded in a variety of everyday objects, devices and displays. The idea behind Wiser's vision was that a ubiquitous computing device would enter a person's center of attention when needed and move to the periphery of their attention when not, enabling the person to switch calmly and effortlessly between activities without having to figure out how to use a computer in performing their tasks. In essence, the technology would be unobtrusive and largely disappear into the background. People would be able to get on with their everyday and working lives, interacting with information and communicating and collaborating with others without being distracted or becoming frustrated with technology." (SHARP, 2007:218-219)
} 
teclado requer nossas mãos. 0 computador fica na mesa e também nos amarra à mesa"68 (DOURISH, 2004:27)

O ideal seria trazer a capacidade de computação de dados para o mundo real ao invés de mantê-la fechada nas caixas que são, em última instância, os computadores pessoais. Em termos de infra-estrutura necessária, Weiser refere-se a centenas de pequenos computadores por cômodo, sendo que o poder da ubiqüidade emergiria não de objetos específicos e, sim, da interação e troca entre eles. Exemplifica esses objetos a partir de idéias desenvolvidas com seus colegas que compreendem um conjunto de superfícies display em diferentes escalas: na escala da polegada (inchscale), na escala do pé (footscale) e na escala da jarda (yardscale) ${ }^{69}$. Para ilustrar a idéia de computação ubíqua ele cria, no artigo, um cenário cotidiano e relata um dia na vida de uma mulher fictícia chamada 'Sal'. Entre outros objetos, descreve o despertador que, ao tocar, verifica se a mulher quer café, caso ela assinale que quer, o despertador se conecta com a cafeteira na cozinha que providencia seu preparo; o autor apresenta também canetas com a capacidade de capturar imagens, com ela pedaços de notícias de jornais ou trechos de livros e revistas podem ser salvos em arquivos para serem posteriormente compartilhados. Vários outros exemplos são descritos, sendo que todos os objetos são baseados no emprego de tecnologias relativamente baratas, sempre conectados em rede, dotados de software específicos para essas aplicações ubíquas.

Nesse sentido, Adam Greenfield, em seu livro "Everyware: the dawning age of ubiquitous computing”, chama a atenção para o fato de que essa tendência de dispersão está, desde há muito, presente em diversas iniciativas. Termos tais como intelligent ambience, reactive environment, wearable computing, augmented realities, entre outros, são constantemente utilizados para designar diferentes focos e aplicações da tecnologia. 0 que Greenfield

68 Do original: "Interaction with screen and keyboard, for instance, tends to demand our direct attention; we have to look at the screen to see what we're doing, which involves looking away from whatever other elements are in our environment, including other people. Interaction with the keyboard requires both o four hands. The computer stand by the desk and tiés us by the desk, too." (DOURISH, 2004:27)

${ }^{69} \mathrm{Inch}$, foot e yard são as unidades do sistema americano de medidas e correspondem, respectivamente, a 2,54 cm, $30.48 \mathrm{~cm}$ e $91,44 \mathrm{~cm}$ 
aponta é que estas áreas consistem nas inúmeras configurações que a computação ubíqua vem sendo tratada, sendo que, segundo o autor, todas estas abordagens são indistinguíveis a partir da perspectiva do usuário e utiliza o termo everyware para designar o paradigma único que este conjunto de iniciativas representa. Sem dar um nome a esse fenômeno, Bill Moggridge (2007, p.639) o descreve ao dizer que

"“'Tudo isto se combina para indicar uma maneira futura que conecte o físico e o digital, e que nos ofereça a chance de projetar interações cheias de riquezas de forma e movimento, libertando-nos do sentimento de estarmos limitados por nossos dispositivos computacionais"70.

Em 1997, Iroshi Ishii, professor do Tangible Media Group ${ }^{71}$, do MIT, escreveu um artigo juntamente com Brigg Ulmer descrevendo alguns projetos desenvolvidos pelo grupo e associando-os ao que denominam Tangible User Interfaces, TUI, ou interfaces tangíveis. As interfaces tangíveis representam outra abordagem das formas de exploração da computação que vai além das interfaces gráficas (Graphic User Interfaces, GUI). Partem da constatação de que "as interações entre as pessoas e o ciberespaço estão amplamente confinadas a tradicionais caixas baseadas em interfaces gráficas - instaladas em computadores de mesa ou laptops. As interações com estas GUI estão separadas do ambiente físico no qual vivemos e interagimos"72 (ISHII; ULLMER, 1997:1). Por mais que o mouse e o teclado sejam objetos que possibilitam o controle das informações através da manipulação dos elementos das interfaces gráficas de forma maleável e flexível, suas características genéricas os impediram de estabelecer uma relação significativa com as representações gráficas dos bits na tela. Segundo Ishii, a idéia básica das interfaces tangíveis é dar uma forma física, uma representação tangível à informação e computação

70 Do original: "This all combines to indicate a way forward that connects the physical and digital, and offers us the chance to design interactions that are full of the richness of form and movement, freeing us from the feeling of being constrained by our computing devices." (MOGGRIDGE, 2007:639)

${ }^{71}$ Informações sobre todos os projetos do Tangible Media Group, tal como vídeos e artigos podem ser acessados no web-site do grupo: $<$ http://tangible.media.mit.edu/>. (Acesso em 16/10/2008)

72 Do original: "The interactions between people and cyberspace are now largely confined to traditional GUI (Graphical User

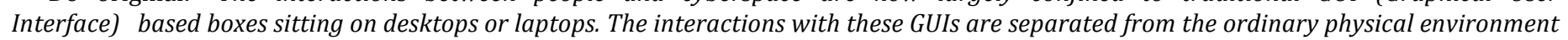
within we live and interact." (ISHII, 1997: 1) 
"tirando vantagem dos múltiplos sentidos e da multimodalidade das interações humanas com o mundo real. Nós acreditamos que a utilização de objetos empunháveis e mídia ambiente nos levará a uma experiência multisensorial da informação digital"73 (ISHII; ULLMER, 1997:8).

Essa abordagem, segundo Ishii, foi inicialmente influenciada pela riqueza encontrada nos instrumentos e objetos históricos de medição, tais como bússolas e ábacos, cujos mecanismos de funcionamento são, hoje, geralmente substituídos pelo processamento digital da informação. Ishii argumenta que o fato de esses antigos objetos poderem ser tocados e manipulados estimulava uma linguagem rica, que valorizava a interação tátil com os objetos e com a informação. A abordagem do Tangible Media Group passou então a olhar para o futuro das tecnologias da informação e comunicação a partir do que teria sido negligenciado pelo advento do computador pessoal, como, por exemplo, a habilidade de manipulação e de percepção periférica das pessoas. As interfaces tangíveis tratam da interseção entre o mundo concreto e o mundo digital de maneira mais suave, "desenvolvendo meios de tornar os bits acessíveis através do ambiente físico"74 (ISHII; ULLMER,1997:2). Segundo o autor, essa perspectiva é baseada nos escritos de Weiser mas diferencia-se da abordagem de computação ubíqua proposta por ele na medida em que:

"Enquanto esta abordagem [a da computação ubíqua] claramente tem seu espaço, nosso interesse reside em olhar para a abundância de dispositivos físicos ricamente produzidos nos últimos poucos milênios e inventar maneiras de reaplicar estes elementos de 'mídias tangíveis' ampliadas pela tecnologia digital. Portanto, nossa visão não é sobre tornar os 'computadores' ubíquos per se, mas ao contrário, despertar para a mediação computacional de objetos físicos, instrumentos,

\footnotetext{
73 Do original: "Taking advantage of multiple senses and the multimodality of human interactions with the real world. We believe the use of graspable objects and ambient media will lead us to a much richer multi-sensory experience of digital information." (ISHII, 1997:8)
}

74 Do original: "developing ways to make bits accessible through the physical environment." (ISHII, 1997, p.2) 
superfícies e espaços ricamente produzidos, talvez tomando mais emprestado das formas físicas da era pré-computador do que das formas do presente."75 (ISHII; ULLMER, 1997: 3)

Em um artigo mais recente, Ishii introduz os conceitos básicos das interfaces tangíveis acompanhados por uma variedade de tipos de aplicações nas quais podem ser empregadas e desenvolvidas. Mesmo onze anos depois do seu primeiro artigo, o autor considera que "as TUI ainda estão na sua infância [seu estágio inicial de desenvolvimento], é necessária pesquisa extensiva para identificar aplicações prodigiosas, conjuntos flexíveis de ferramentas TUI, e um conjunto de princípios fortes"76 (ISHII, 2008, p. xxiii). Um olhar direcionado a compreender, analisar e propor aplicações para as interfaces tangíveis precisa ter claro que elas "servem como uma interface de finalidades especiais para aplicações específicas que utilizam formas físicas evidentes, enquanto as GUI funcionam como uma interface de finalidades genéricas, implementando várias ferramentas por meio da utilização de pixels em uma tela"77 (ISHII, 2008, p. xvi).

No artigo são apresentados sete gêneros de aplicação das interfaces tangíveis, exemplificados tanto com projetos do próprio grupo quanto por propostas externas que sugerem as mesmas questões. Uma passagem rápida sobre cada um deles faz-se importante pois ajudam a organizar os diversos caminhos passíveis de serem explorados pela perspectiva das interfaces tangíveis (ISHII, 2008, p.xviii-xx):

75 Do original: "While this approach clearly has a place, our interest lies in looking towards the bounty of richly-afforded physical devices of the last few millenia and inventing ways to reapply these elements of "tangible media" augmented by digital technology. Thus, our vision is not about making 'computers' ubiquitous per se, but rather about awakening richly-afforded physical objects, instruments, surfaces, and spaces to computational mediation, borrowing perhaps more from the physical forms of pre-computer age than the present." (ISHII; ULLMER, 1997: 3)

76 Do original: "TUI is still in its infancy, and extensive research is required to identify the killer application, scalable TUI toolkits, and a set of strong principles." (ISHII, 2008, p.xxiii)

77 Do original: "Tangible User Interface serves as a special purpose interface for a specific application using explicit physical forms, while GUI serves as a general purpose interface by emulating various tools using pixels on a screen." (ISHII, 2008, p. xvi) 
[1] A Telepresença Tangível (Tangible Telepresence) refere-se às explorações da comunicação interpessoal a partir de interações táteis, transformando inputs táteis em representações táteis remotas.

[2] Os Tangíveis com Memória Cinética (Tanglibles with Kinetic Memory) consistem em objetos com a capacidade de gravar e repetir estímulos físicos. Podem ser utilizados para o ensino de conceitos relevantes de programação e matemática por meio da análise da transformação de movimentos simples em comportamentos complexos.

[3] 0 gênero da Montagem Construtiva (Constructive Assembly) trabalha com a interconexão de elementos físicos modulares. Este campo das interfaces tangíveis preocupa-se com a ligação física de peças que podem dar forma a variedades de composições e movimento.

[4] 0 gênero Símbolos e Limitações (Tokens and Constraints) refere-se à utilização de pequenos objetos espacialmente reconfiguráveis que representam informações ou operações digitais (Tokens), combinados com locais específicos, estruturas físicas (Constraints), nos quais são colocados.

[5] As Superfícies Interativas (Interactive Surfaces ou Tabletop TUI) são um gênero promissor que reúne superfícies de exibição e objetos. Na medida em que os objetos são manipulados, seus movimentos são captados e o feedback visual é fornecido pela própria superfície na qual o objeto se apóia. Atualmente, pesquisas estão sendo desenvolvidas para fazer com que elas também sejam capazes de movimentar os objetos.

[6] As pesquisas em TUI Plásticas (Continuous Plastic TUI) utilizam materiais maleáveis, tais como massa de modelar e areia como interfaces tangíveis.

[7] 0 trabalho com Objetos Cotidianos Aumentados (Augmented Everyday Objects) consiste na utilização de objetos tradicionais e na manipulação das suas características por meio da adição da informação digital.

É importante perceber que essa classificação não tem como objetivo definir categorias estanques para as diferentes proposições. Elas apenas assinalam diferentes possibilidades e caminhos possíveis a partir da perspectiva das interfaces tangíveis. Entre os diferentes gêneros, Ishii aponta o trabalho com objetos cotidianos aumentados como o mais promissor para os designers e artistas, pois aborda diretamente o envolvimento de artefatos físicos cotidianos com a tecnologia digital (ISHII, 2008, p.xx). 

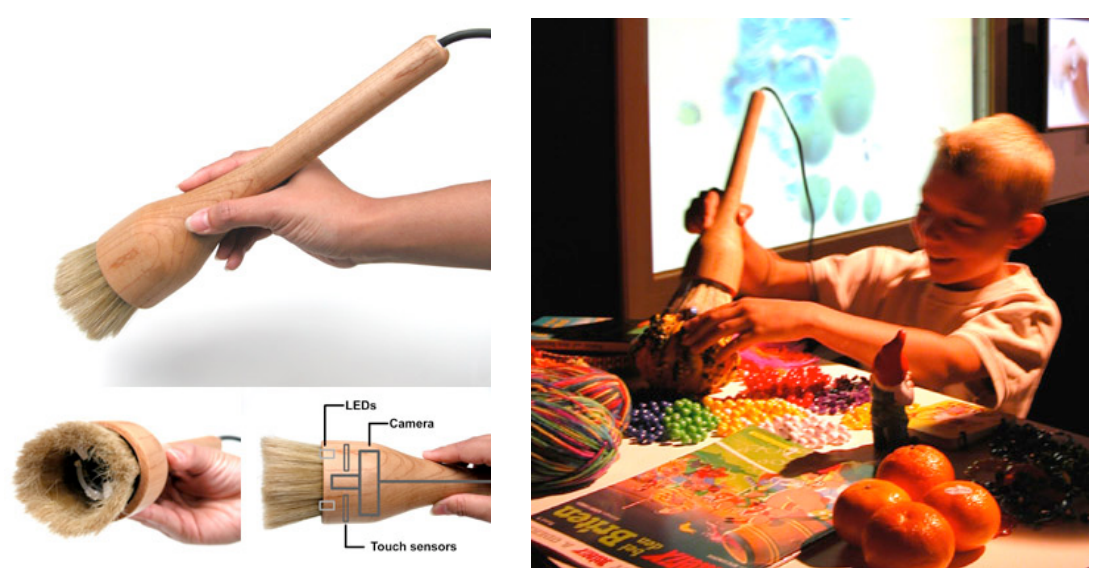

Fig. 14-17: I/O Brush (Tangible Media Group, 2003-2006) Fonte: $<$ http://web.media.mit.edu/\%7Ekimiko/iobrush/>

O projeto I/O Brush (Fig. 14-17), desenvolvido pelos pesquisadores Kimiko Ryokai, Stefan Marti e Hiroshi Ishii, ilustra bem essa perspectiva. Segundo descrição disponível no website da proposta78 o I/0 Brush é uma nova ferramenta de desenho que explora as cores, texturas e movimentos encontrados em materiais e objetos cotidianos. Para isso o pincel é dotado de uma pequena câmera de vídeo com luzes e pequenos sensores acoplados no seu interior que captam características do ambiente que se tornam a "tinta" com a qual é possível desenhar em uma superfície específica. Com isso os usuários conseguem controlar e compreender conceitos abstratos através da construção de significados, pela exploração de objetos familiares. Segundo os pesquisadores relatam:

"Ao usar o I/O Brush, as crianças não apenas produziram desenhos complexos como também exploraram objetos e materiais ao seu redor. Durante o processo conversaram explicitamente

\footnotetext{
78 Uma descrição detalhada do projeto $\mathrm{I} / \mathrm{O}$ Brush, assim como vídeos e artigos, podem ser encontrados no web-site:
} <http://web.media.mit.edu/\%7Ekimiko/iobrush/>. (Acesso em 07/01/2008) 
sobre os elementos e princípios do design, tais como cor, textura e movimento. Apesar do resultado de seus trabalhos de arte ter sido sintético e digital, o processo envolveu a busca e a interação com vários objetos físicos, os quais estão disponíveis e são significativos em suas vidas."79 (RYOKAI; MARTY; ISHII, 2004, p.7)

Apesar de sedutoras, um cuidado precisa ser tomado com essas abordagens. Em um artigo dedicado especificamente à abordagem de Weiser sobre a computação ubíqua, Augustin Araya acrescenta algumas preocupações que julga ser tão importantes quanto a projeção de possibilidades tecnológicas em cenários futuros. Araya faz algumas críticas e defende que as propostas de Weiser não se justificam pelas necessidades e atividades dos usuários e sim pela própria tecnologia.

"Levando em consideração a prioridade dada à tecnologia acima das necessidades, a sugerida penetração massiva na vida cotidiana por um tipo particular de tecnologia, a tentativa de imergir tecnologia no pano de fundo como forma de ultrapassar a resistência a ela, e o fato de que esses desenvolvimentos não são questionados e sim vistos como absolutos, caracterizamos o pensamento que permeia a computação ubíqua como uma forma emergente de absolutismo tecnológico." 80 (ARAYA, 1995, p.236)

Para Araya, o que falta é uma preocupação sobre os efeitos que essa tecnologia teria no cotidiano. Aspectos relacionados com as transformações da vida na qual a computação ubíqua é inserida e como essas

79 Do original: "Using I/O Brush, children not only produced complex drawings, but they also explored objects and materials that surround them, and during the process, explicitly talked about the elements and principle of design such as color, texture, and movement. Although the outcome of their artwork was synthetic and digital, the process of their work involved searching for and interacting with many physical objects that are available and meaningful to them in their life." (RYOKAl; MARTY; ISHII, 2004, p.7)

80 Do original: "Taking into account the primacy given to technology over needs, the proposed massive penetration of everyday life by a particular kind of technology, the attempt to immerse technology into the background partially as a way to bypass resistance to technology, and the fact that these developments are not questioned but regarded as absolute, we characterize the thinking underlying Ubiquitous Computing as an emerging form of technological absolutism."(ARAYA, 1995, p. 236) 
transformações afetam a forma como o mundo se mostra para as pessoas, as pessoas para o mundo, e como dialogam entre si, devem ser cuidadosamente tratados. Desse modo, os fatores que conduzem uma proposta tecnológica, ou seja, como o pensamento por trás dela a justifica, devem ter a mesma importância das soluções e possibilidades alcançadas. Diante desse quadro, mais importante que analisar profundamente as capacidades técnicas em profundidade é perceber o universo de possibilidades que se abre em termos de meios de expressão e projeto. Para o contexto deste trabalho, a principal contribuição do artigo escrito por Weiser e pela abordagem do Tangible Media Group reside na ilustração de possibilidades e caminhos que podem ser seguidos para se pensar em usos da tecnologia para além do computador. Segundo Weiser, "nenhuma revolução na inteligência artificial é necessária - apenas a acomodação apropriada dos computadores no mundo cotidiano"81 (WEISER, 1990, sp). Essa perspectiva alternativa é o ponto central do artigo e parece ter feito, dele, referência para inúmeras pesquisas que lidam com as tecnologias digitais diluídas no cotidiano.

Apesar de parecer recente para muitos, a idéia de se inserir experimentalmente computação na concepção de objetos e espaços físicos coexiste, há muito com o desenvolvimento da máquina. Já nos anos 1970, Myron Krueger, precursor da denominada vídeo-arte, realizou diversos experimentos buscando de entender e expressar a essência do computador em termos humanísticos. A partir da interação dos espectadores de suas obras com vídeos projetados em grandes superfícies, construía ambientes responsivos ${ }^{82}$ à presença, posição e movimento das pessoas. Utilizava técnicas híbridas para a conexão de ambientes remotos e, assim, pessoas situadas em locais distintos eram capazes de interagir ao mesmo tempo em que suas imagens eram captadas e projetadas. Com essas obras, Krueger buscava explorar mais possibilidades desse meio, que ultrapassassem as funcionais. Sobre seus experimentos, ele escreveu:

81 Do original: "no revolution in artificial intelligence is needed - just the proper imbedding of computers into the everyday world" (WEISER, 1990, $\mathrm{sp})$.

82 O termo 'responsivo' é utilizado como tradução da palavra inglesa responsive, bastante utilizada por diversos autores para se referir aos ambientes e objetos dotados da capacidade interpretar digitalmente as ações das pessoas e responder a elas. A responsividade (responsiveness) difere da reatividade, como se verá mais em detalhe, no próximo capítulo. 

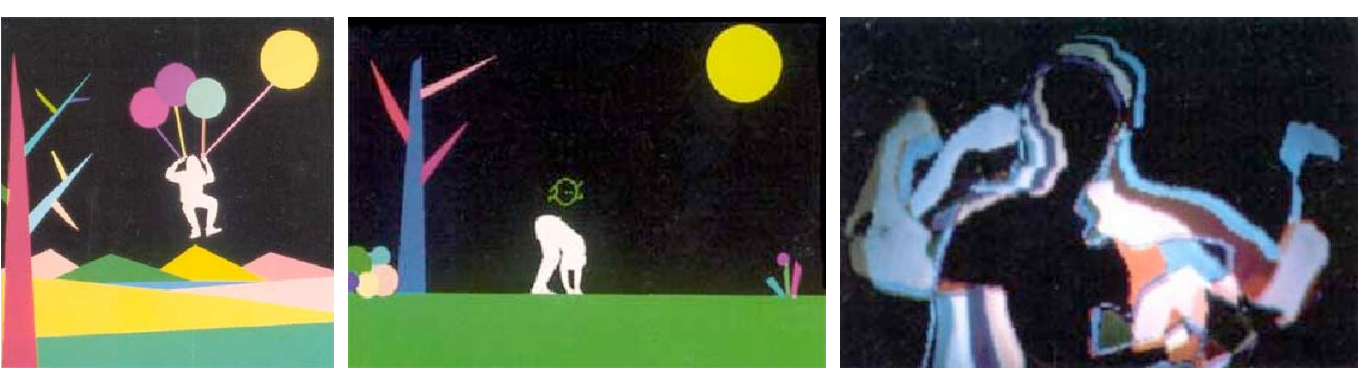

Fig. 18-20: Videoplace (Myron Krueger, 1970s).

Fonte: <http://www.virtualart.at/common/viewWork.do?selected=0\&id=619>

“Estamos incrivelmente acostumados com a idéia de que o único propósito de nossa tecnologia é resolver problemas. Ela também cria conceitos e filosofia. Devemos explorar mais plenamente estes aspectos de nossas invenções, pois a próxima geração de tecnologia irá se comunicar conosco e perceberá nossos comportamentos. A tecnologia irá entrar em cada residência e escritório e intercederá entre nós e a maioria da informação e experiência que recebemos. 0 design de tal tecnologia tão íntima é uma questão estética tanto quanto de engenharia. Devemos reconhecer isto se desejarmos entender e escolher em quem nos transformaremos como resultado do que teremos feito." ${ }^{83}$ (KRUEGER, 1977, p.389)

De certa maneira, as experiências de Krueger foram, limitadas por aspectos técnicos, mas pode-se dizer que sua visão foi além do seu tempo ao atentar para o momento em que essas dificuldades seriam superadas e para as possibilidades que ainda estavam por vir. Sua contribuição se deu em especial no campo da arte computacional

83 Do original: "We are incredibly attuned to the idea that the sole purpose of our technology is to solve problems. It also creates concepts and philosophy. We must more fully explore these aspects of our inventions, because the next generation of technology will speak to us, and perceive our behavior. It will enter every home and office and intercede between us and much of the information and experience we receive. The design of such intimate technology is an aesthetic issue as much as an engineering one. We must recognize this if we are to understand and choose what we become as a result of we have made." (KRUEGER, 1977, p.389) 
interativa, no qual introduziu a idéia de um artista criador de espaços inteligentes e responsivos. Na obra Videoplace, de 1970 (Fig. 18-20), elaborou um ambiente no qual o computador replicava aos gestos da sua audiência, interpretando e mesmo antecipando suas ações. Os diferentes usuários tinham a sensação de poder tocar o corpo projetado um do outro, assim como podiam manipular objetos gráficos estranhos e organismos animados que apareciam na tela. Restritas às salas de exposição, essas obras utilizavam diversos sensores mas a resposta aos estímulos limitava-se, na sua maioria, aos sentidos visual e auditivo.

A situação atual é outra. Percebe-se, no início do século XXI, um crescente interesse de designers, arquitetos e profissionais das mais diversas áreas em explorar o uso das TIC. Assim como Krueger fez no seu tempo, o trabalho desses contemporâneos procura integrar as possibilidades oferecidas aos aspectos cotidianos e criar uma diversidade de possibilidades, definições e pensamentos, resultantes da experimentação alternativa do meio digital. Segundo Greenfield:

“O que estamos contemplando aqui é a extensão das capacidades de sentir, processar e conectar em rede informações para classes inteiras de coisas, nunca antes imaginadas como 'tecnologia'. Pelo menos, não temos pensado nelas desta forma durante muito, muito tempo: falo de artefatos tais como roupas, mobiliário, paredes e corredores."84 (GREENFIELD, 2006, p.18-19)

Como parte do conjunto de profissionais responsáveis por determinar nossa relação com as novas tecnologias digitais, Anthony Dunne e William Gaver descrevem o que chamam de artistas-designers. Diferentemente dos designers tradicionais, Dunne e Gaver não criam objetos para se tornarem sucessos de vendas, sendo que, muitas vezes, a implausibilidade dos projetos não se deve a questões técnicas ou econômicas e sim aos valores culturais

\footnotetext{
84 Do original: "What we're contemplating here is the extension of information-sensing, -processing, and -networking capabilities to entire classes of things we've never before thought of as 'technology'. At least, we haven't thought of them that way in a long, long time: I'm talking about artifacts as clothing, furniture, walls and doorways." (GREENFIELD, 2006, p.18-19)
} 
(DUNNE \& GAVER, 1997). O resultado é a prática de um design detentor de aspectos críticos, o qual, Segundo Malcolm McCullough :

“... desafia os valores dominantes através de trabalhos baseados em algum outro conjunto de valores. Esta é uma forma de conscientização. Em um mundo no qual a técnica tem constantemente se tornado um fim em si mesma, uma atitude culturalmente crítica se tornou essencial para o design significativo. Buscar e identificar um problema são tarefas tão importantes quanto a resolução do mesmo."85 (McCULLOUGH, 2005, p.165)

A partir dessa perspectiva crítica, situada na fronteira entre design, arte e tecnologias computacionais, são abordados os projetos que são analisados ao longo deste trabalho. Essa compreensão de atividade, que transita em diferentes campos do conhecimento, engloba o que se entende aqui como espacialidades híbridas, ou seja, aquelas possibilitadas por artefatos que possuem comportamento baseado na computação e processamento de informações, somado à sua materialidade. Para um melhor entendimento do objeto de estudo deste trabalho, propoe-se a compreensão e análise dessa realidade híbrida a partir de quatro diferentes escalas. Tal escolha baseia-se na definição proposta por Marcelo Tramontano (2006, p.50), que classifica as espacialidades híbridas em cinco escalas para seu estudo, concepção e produção: 1. dos ambientes unicamente digitais; 2 . do corpo; 3. dos objetos e mobiliário; 4. das edificações e 5. da cidade e ambientes urbanos. Apenas a primeira escala proposta por Tramontano não é tratada por este trabalho. As demais são abordadas de forma a auxiliar o entendimento dos procedimentos que podem embasar a aplicação das TIC no ambiente construído, além de buscar ampliar o leque de possibilidades de objetos de estudo para outras pesquisas que abordem o desenvolvimento tecnológico e suas influências na sociedade.

85 Do original: ".. challenges prevailing values through works based in some other set of values. This is a form of conscientiousness. In a world where technique has too often become an end in itself, a culturally critical attitude has become essential to meaningful design. How to seek and identify a problem is as important as how to solve a problem." (McCULLOUGH, 2005: 165) 


\section{2 | Interatividade na escala do corpo}

As questões relacionadas à aplicação da tecnologia na escala do corpo partem de duas abordagens propostas por Adam Greenfield. Uma, trata o corpo como fonte de informação, e a outra, discute possibilidades de seu emprego como plataforma (GREENFIELD, 2006, p. 48-53). Apesar de distintas, ambas derivam de uma reconsideração do corpo, entendido agora como parte de um sistema maior composto por aparatos conectados digitalmente. Por si próprio, o corpo é uma rica fonte de informações e manipulá-las significa envolver-se com as complexidades ocultas do seu funcionamento interno. Essas informações são extraídas das atividades desempenhadas pelos diversos sistemas e partes que compõem o corpo humano. Proposições com o viés crítico nessa instância aproveitam-se da ampla pesquisa empregada no desenvolvimento de aparatos tecnológicos para o sensoriamento de atividades do corpo humano. A diminuição do tamanho dos componentes eletrônicos e a ampliação do leque de suas aplicações, em especial por suas possíveis ligações diretas com a saúde e o bem estar das pessoas, apresentam-se como um rico universo do qual informações podem ser extraídas e manejadas de forma significativa.

Como proposta que utiliza informações do corpo captadas por aparatos eletrônicos, o Brainballo6 (Fig. 21-22)é um exemplo interessante que se aproveita do sensoriamento de atividades elétricas do cérebro para criar o que os autores denominam de 'anti-jogo'. Sua ambigüidade reside na justaposição do relaxamento com a competição, duas atividades que no dia-a-dia são entendidas como opostas. Cada participante veste uma tira com eletrodos na cabeça, conectadas a um sistema biosensor, cuja função é captar os valores das atividades cerebrais dos jogadores. Estes dados são então processados e utilizados para manipular uma pequena bola disposta sobre a 
mesa na qual o jogo acontece. Quanto menor o valor das ondas cerebrais de um participante, mais a bola se afasta dele rumo à outra extremidade da mesa na qual o outro jogador se encontra. Quem conseguir, por meio de baixas ondas cerebrais, fazer a bola chegar até o lado oposto da mesa, é o vencedor.

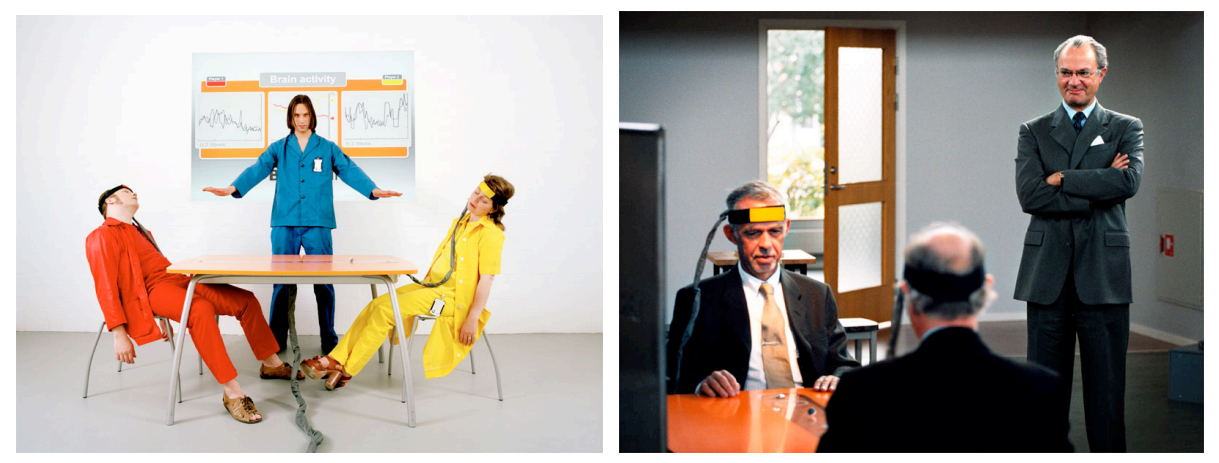

Fig. 21: Brainball (Interactive Institute, 1999-2000)

Fonte: <http://www.tii.se/touchingtheinvisible/brainball/brainball_pose-800.jpg>.

Fig. 22: Brainball (Interactive Institute, 1999-2000).

Fonte: <http://www.tii.se/touchingtheinvisible/brainball/brainball_king-800.jpg>

A abordagem do corpo como plataforma aproveita-se do fato de ele ser o "veículo por meio do qual vivenciamos o mundo."87 (GREENFIELD, 2006, p.48) Nesta abordagem se insere o conceito de wearable computing (computação vestível), que parte deste entendimento no qual são acoplados no corpo pequenos objetos dotados de microcontroladores e outras tecnologias que possam ser vestidas ou carregadas pelo indivíduo. Os primeiros experimentos neste sentido, segundo Adam Greenfield (GREENFIELD, 2006, p.50), tiveram como foco sua utilização na realização de tarefas laborais, sem a preocupação de inserção desses aparatos na vida cotidiana. Eram espécies de uniformes inteligentes, utilizados durante o turno de trabalho e retirados assim que acabava o expediente. Durante os anos 1980 a idéia de aparatos vestíveis para serem utilizados pelas pessoas no seu dia-a-

87 Do original: "As both a rich source of information in itself and the vehicle by which we experience the world, it was probably inevitable that sooner or later somebody would think to reconsider it [the body] as just another kind of networked resource." (GREENFIELD, 2006:48) 
dia já era consistente, porém a tecnologia disponível naquele momento ainda era de difícil portabilidade, devido ao tamanho dos componentes para essa aplicação.

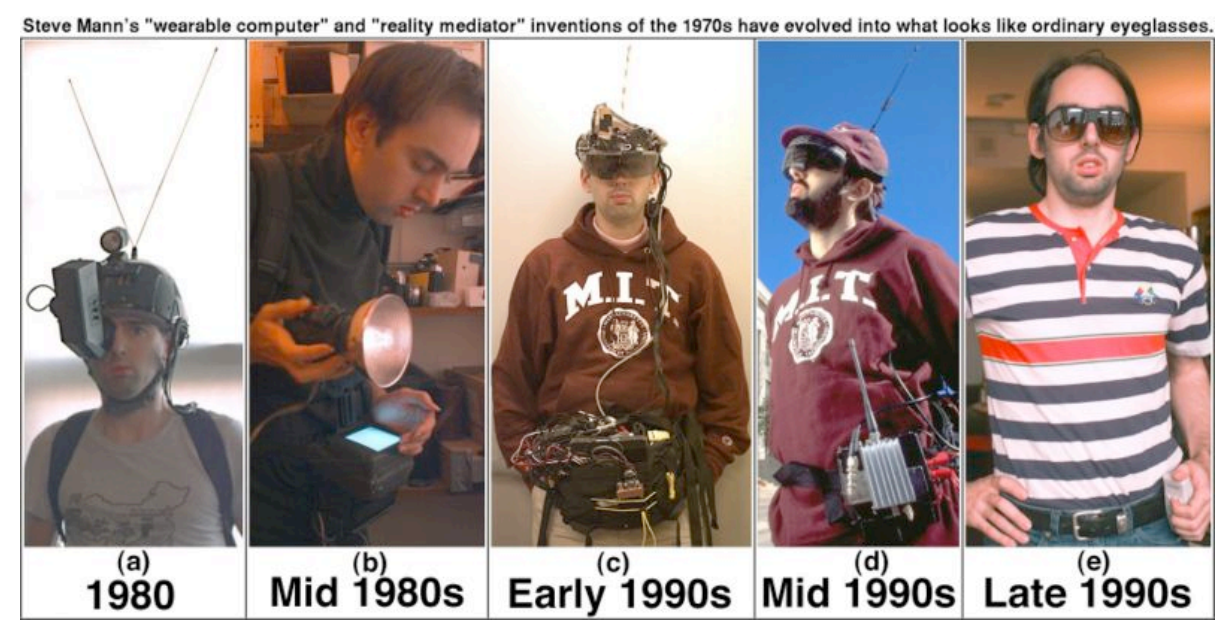

Fig. 29: Steve Mann e a evolução das suas web-câmeras sem fio vestíveis. Ele é um dos fundadores do grupo de pesquisa em Wearable Computing do MIT e referência constante para o campo. Apontado como um dos pioneiros a trabalhar com o computador, objeto genérico de suporte de atividades, como um aparato vestível.

Um exemplo de experimento que começou nessa época é o trabalho de Steve Mann e sua proposta de criação de um exoesqueleto digital para ser usado pelas pessoas durante todo o tempo (Fig. 23). 0 próprio criador relata que, no início, o grande porte dos elementos que carregava inibia-o de utilizá-lo cotidianamente. Apesar de dizer que as pessoas não estavam preparadas para isso, pode-se cogitar que, se naquela época a tecnologia fosse discreta como hoje, a impressão causada seria outra. Com a miniaturização, leveza e barateamento dos componentes, essa computação vestida pôde ser pensada como, além de aparatos a serem carregados, componentes dispersos pela roupa. 

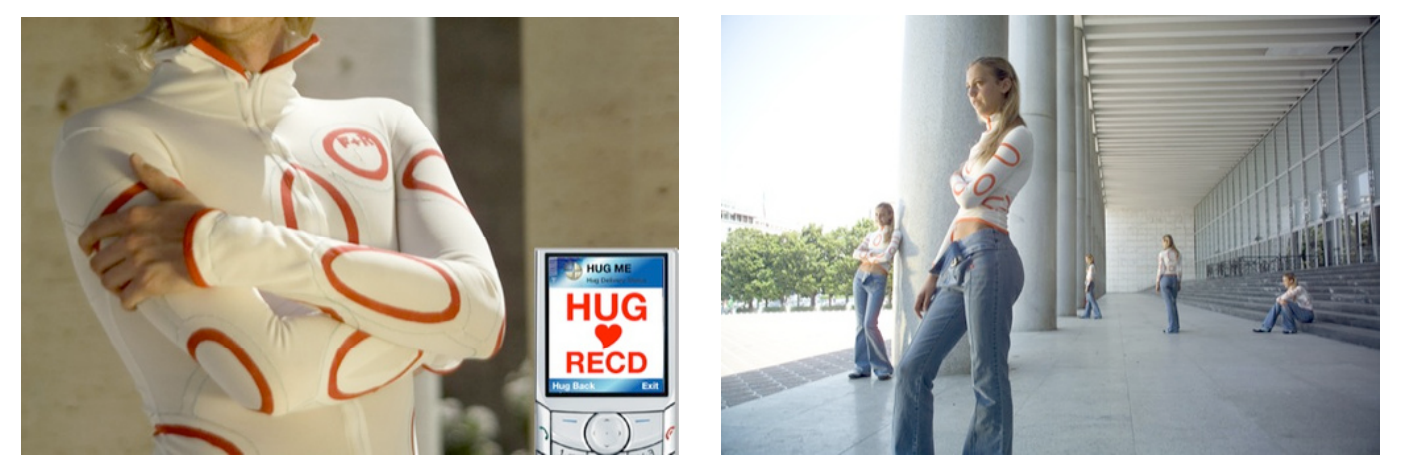

Fig. 24: The Hug Shirt (Cute Circuit, 2006)

Fonte: <http://cutecircuit.com/pictures/album/the-hug-shirt-fr-hugs/page/1/photo/sun-five>.

Fig. 25:The Hug Shirt (Cute Circuit, 2006)

Fonte: <http://cutecircuit.com/pictures/album/the-hug-shirt-fr-hugs/page/1/photo/8hug>.
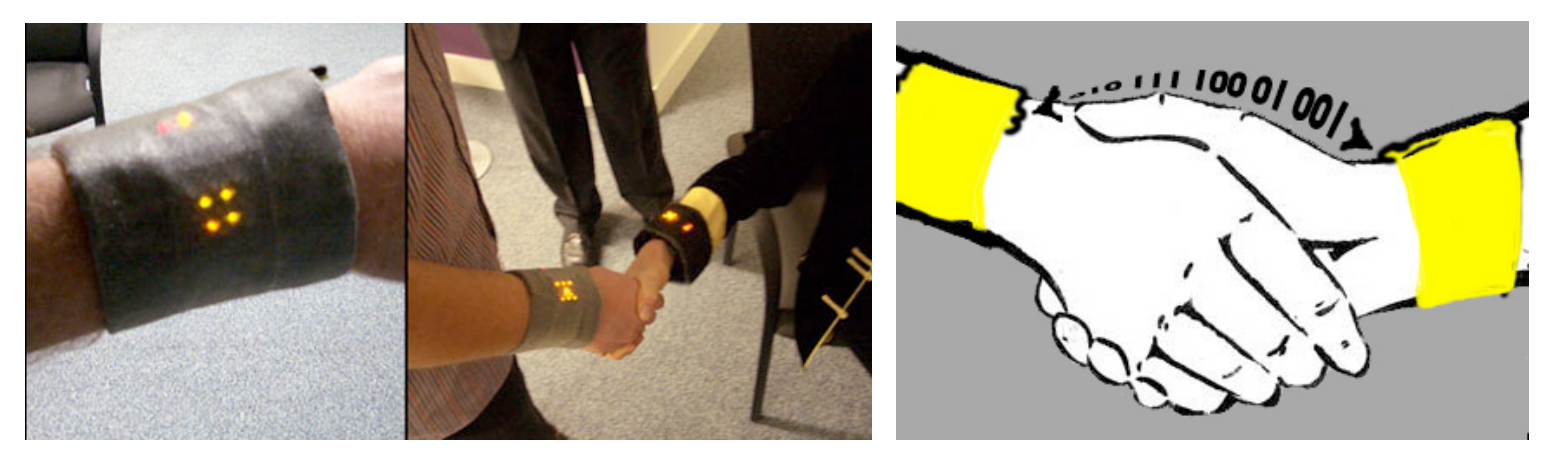

Fig. 26-28: iBand (Human Connectedenes Group: Media Lab Europe, 2004).

Fonte: $<$ http://web.media.mit.edu/ stefan/hc/projects/iband/>.

Um exemplo é a camiseta The Hug Shirt ${ }^{88}$ (Fig. 24-25), dotada de sensores que captam o toque da pessoa que veste e o transmite a outro usuário que também possui uma. 0 toque é captado por sensores de pressão, transmitido via celular e sentido por meio de estímulos físicos de atuadores dispersos na camiseta. Questões 
sobre relações e ações interpessoais também são tratadas no projeto iBand89 (Fig 26-28). São braceletes que utilizam o aperto de mão, momento que marca a criação de novas relações ou o reencontro com antigas, para trocar informações. A troca acontece apenas durante a ação, a informação é adquirida e processada e os resultados estimulam padrões de imagens no bracelete por meio da introdução de displays. A percepção do aperto se dá com a utilização de acelerômetros juntamente com antenas transmissoras e receptoras infravermelhas que identificam a presença de outro bracelete e ativam a troca de informação entre os objetos Além da questão da utilização da roupagem como display, o objetivo é aumentar o significado do gesto, acrescentando a ele instâncias informatizadas que exploram outros significados da ação.

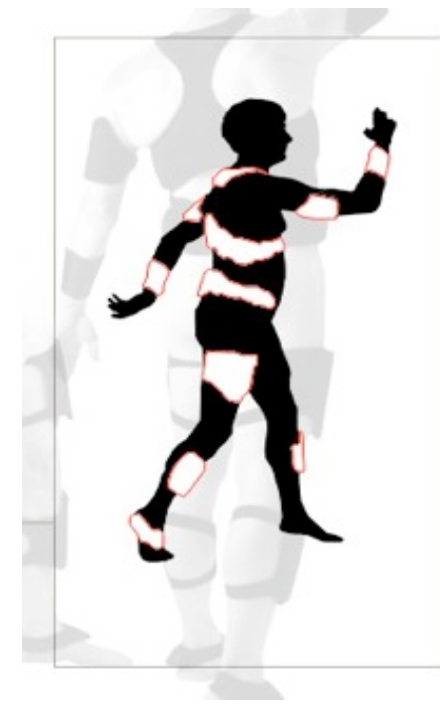

Fig. 29: Locais do corpo apropriados para colocar equipamentos rígidos, segundo estudos desenvolvidos pelo Interaction Design Studio da Universidade Carneige Mellon . Fonte: <http://www.ices.cmu.edu/design/wearability/ front.html>.

${ }^{89}$ Informações sobre o projeto disponíveis em : <http://web.media.mit.edu/ stefan/hc/iband/> . (Acesso em 06/09/2008) 
Esta preocupação com a inserção de elementos eletrônicos nos elementos vestíveis estimulou o Interaction Design Studio da Universidade Carneige Mellon ${ }^{90}$ a pesquisar sobre a disposição de elementos no corpo (Fig. 29). Os estudos foram conduzidos no sentido de localizar, entender e definir locais nos quais formas sólidas e flexíveis podem ser situadas sem interferir nos movimentos fluídos das pessoas. Isso é importante não apenas para questões relacionadas ao conforto como também para a utilização de sensoriamento em atividades que exigem muita movimentação e deslocamento. Uma grande contribuição, nesse sentido, seria na inserção de componentes em figurinos de dança e teatro para performances com algum tipo de interatividade em seu contexto.

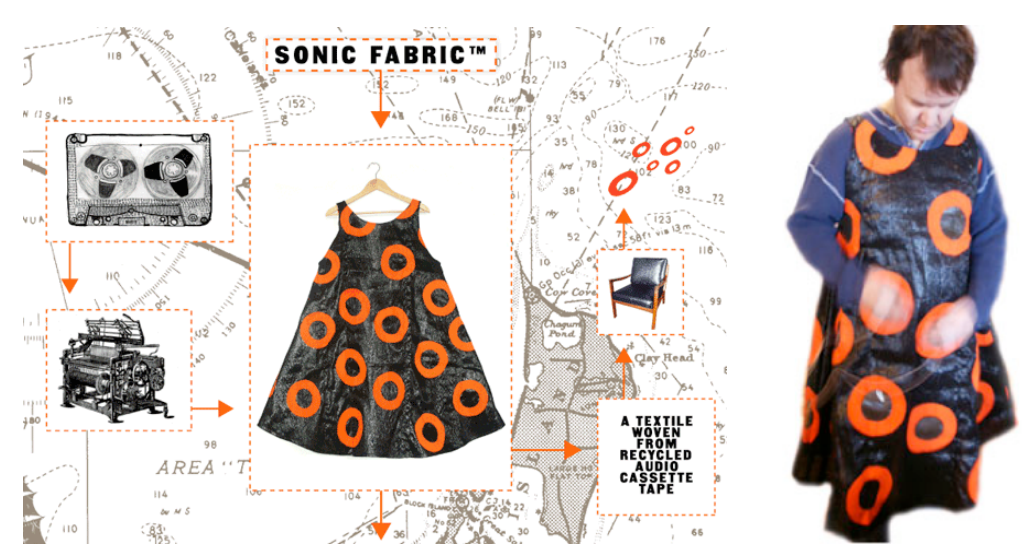

Fig. 30: Imagem da página inicial do web-site SonicFabric [Alyce Santoro, 2005].

Fonte: <http://www sonicfabric.com/fabric.html>.

Fig. 31: SonicFabric [Alyce Santoro, 2005]

Fonte: <http://www.sonicfabric.com/index.html>

Com a atual tendência de miniaturização e barateamento dos componentes eletrônicos, a computação vestível se torna cada dia mais viável e as soluções mais ricas e variadas. Suas possibilidades são também ampliadas com o

90 Informações detalhadas estão disponíveis em <http://www.ices.cmu.edu/design/wearability.html> .(Acesso em 21/01/2008) 
desenvolvimento dos chamados tecidos inteligentes (Smart Textiles), caracterizados por sua capacidade de responder a estímulos externos a partir de mudanças específicas em algumas de suas variáveis como cor, luz, temperatura, condutividade, entre outras. Esses novos tecidos não são apenas resultado de pesquisas de alta tecnologia, também fazem parte de experimentos que exploram a recombinação de materiais já existentes.

Nesse contexto insere-se o tecido SonicFabric, desenvolvido por Alyce Santoro (Fig. 30-31), resultado da elaboração de uma trama que utiliza fitas magnéticas de cassetes. Do ponto de vista das preocupações com o meio ambiente, seu feito já merece atenção, uma vez que utiliza um material que hoje é constantemente descartado pela sociedade urbana. No entanto, o mais interessante de seu experimento é a possibilidade de ouvir os sons contidos nas fitas ao esfregar, na superfície do tecido, o cabeçote do tocador. Segundo descrição encontrada no website do projeto, "quando você esfrega o cabeçote do tocador no tecido, você está lendo quatro ou cinco fios de fita de uma só vez (...) em outras palavras, 16 ou 20 faixas de músicas todas misturadas. 0 som parece o de um disco, arranhando-o de trás para frente ou com interferências no rádio."91 Essa solução ilustra que a inovação resulta não apenas do emprego de alta tecnologia, mas também do agenciamento criativo de recursos disponíveis.

\section{3 | Interatividade na escala do objeto / mobiliário}

As tecnologias comunicativas digitais fizeram-se presentes inicialmente nos objetos que permeiam o ambiente de trabalho, como suporte às atividades ali desempenhadas. Posteriormente penetraram em outros aspectos da vida cotidiana, inclusive nas casas. Apesar de se tratar de contextos diferentes, observa-se que a abordagem

91 Descrição disponível em <http://www.sonicfabric.com> (acesso em 21/01/2007). Do original: "When you run the tape head over the fabric you
are reading 4 or 5 strands of tape at once ... in other words, 16 or 20 tracks all mixed together. It sounds kind of like scratching a record backwards or radio static." 
funcionalista de um foi transferida para o outro sem maiores preocupações em relação aos aspectos específicos da casa. Propostas baseadas no controle e monitoramento, como as Smart Houses, cujo objetivo reside primordialmente em facilitar as atividades do dia-a-dia, ilustram essa aproximação. Sobre estas casas Victor Margolin , já no final da década de 1980, previa que:

"Sistemas utilitários mais avançados irão combinar sistemas elétricos e de comunicação, por exemplo, e irão monitorar e controlar fluxos de energia pela casa com mais eficácia do que a média dos proprietários pode fazer hoje. Sensores em outros objetos irão torná-los mais eficientes e acessíveis."92 (MARGOLIN, 1988, p.279)

Essa vontade de conexão e controle à distância dos equipamentos sempre esteve presente, seja com o desenvolvimento dos controles para aparelhos eletrônicos, seguidos por sua versão universal capaz de unificar as funções em apenas um dispositivo, ou mesmo para comandar portões, luzes, condicionadores de ar e demais objetos cotidianos. A possibilidade de conexão em rede desses aparelhos, tanto elétricos quanto eletrônicos, expandiu as possibilidades dessas casas inteligentes e seus equipamentos passaram a ser parte de um sistema único conectado por intranets e também pela Internet. Esta última permite, inclusive, o acionamento e monitoramento da casa a partir de outras localidades físicas, seja do local de trabalho ou mesmo durante uma viagem. Isso forneceu insumos para o desenvolvimento de complexos sistemas de segurança, assim como inovações nos demais objetos cotidianos. Grande parte desses projetos podem ser incluídos no que se entende hoje por automação residencial, ou seja, a automatização e controle eletrônico das atividades cotidianas. Na maioria das vezes em que a expressão casa inteligente é utilizada, refere-se às casas que possuem algum desses sistemas instalados.

92 Do original: "more advanced utility systems will combine electrical and communication systems, for example, and will monitor and control energy flows throughout the house more effectively than the average owner can do now. Sensors in other objects will make them more efficient and accessible." (MARGOLIN, 1988:279) 
Com o intuito de ampliar as possibilidades e o entendimento do que seriam as casas inteligentes, pesquisadores do Instituto de Tecnologia da Geórgia, em Atlanta, EUA (Georgia Institute of Technology) desenvolveram a iniciativa "A Casa Consciente: um Laboratório Vivo para a Pesquisa em Computação Ubíqua."93 (Fig. 32) 0 projeto consiste em uma casa que, construída a partir de idéias convencionais de arquitetura, capta informações relacionadas às atividades de seus ocupantes e fornece, a partir do desenvolvimento de tecnologias, suporte para as atividades cotidianas, ampliando as funções diárias e promovendo a conectividade dentro e fora da casa. 0 diferencial entre essa iniciativa e as demais casas inteligentes é a convergência dos fatores humanos e tecnológicos nas suas propostas. Destaca-se aqui o papel simbólico desempenhado pela casa e a ampla gama de possibilidades de exploração presentes neste local que, "não é apenas um abrigo material mas também um abrigo para o que faz a vida significativa."94 (CSICKSZENTMIHALY, 1981, p.138)

A escala do objeto tratada neste trabalho diz respeito ao mobiliário destinado ao ambiente doméstico, a partir da exploração de possibilidades de inserção de narrativas e ambigüidades nesse contexto. Isto se faz com o intuito de exemplificar aproximações especulativas na escala do objeto, utilizando-se da riqueza desse local onde as pessoas se sentem mais à vontade de expressar sua individualidade e onde as relações afetivas estão presentes com maior intensidade. Segundo Csickszentmihaly:

“A importância do lar deriva do fato de que o mesmo gera um espaço para ação e interação no qual as pessoas podem desenvolver, manter e mudar sua própria identidade. Em sua privacidade, as pessoas podem cultivar seus próprios objetivos sem medo do isolamento e do ridículo. O lar é um abrigo para estas pessoas e para os objetos que definem seu ser: dessa maneira se torna um

93 "The Aware Home: A Living Laboratory for Ubiquitous Computing Research". Mais informações disponíveis em $<$ http://awarehome.imtc.gatech.edu/>. (Acesso em 15/01/2008)

94 Do original: "The home is not only a material shelter but also a shelter for those things that make life meaningful." (CSICKSZENTMIHALY 1981:138) 
ambiente simbólico indispensável, para a maioria das pessoas."95 (CSICKSZENTMIHALY, 1981, p.122)
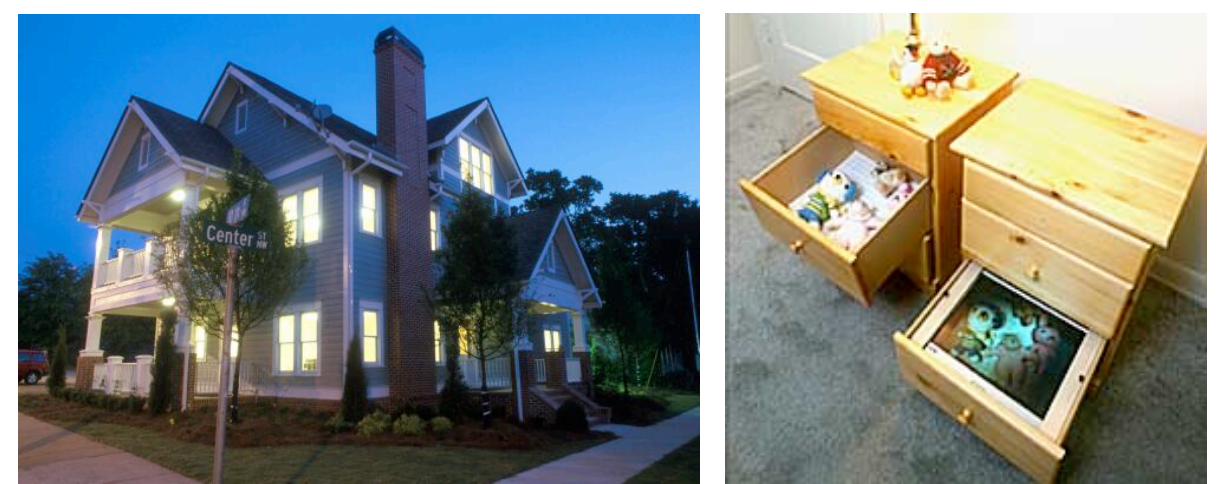

Fig. 32: The aware home (Georgia Institute of Technology, 2000-2008)

Fonte: <http://www.cc.gatech.edu/fce/house/house.html>.

Fig. 33: Peek-A-Drawer(Georgia Institute of Technology, 2002).

Fonte: <http://gtresearchnews.gatech.edu/reshor/rh-ss02/age-side.html>.

Um dos projetos da Casa Consciente, o PeekaDrawer (Fig. 33), consiste na expansão da funcionalidade de dois criados mudos que compartilham o conteúdo guardado nas suas gavetas. A imagem dos objetos colocados na gaveta de um são mostrados em um display localizado no outro. 0 intuito é promover uma interação social entre membros da família, no caso os avós e netos, distantes geograficamente. Neste caso, o mobiliário atua como suporte para comunicações discretas entre as pessoas. Mais simples de usar do que email ou câmeras digitais, possui uma única função e não requer uma ação deliberada para ativar a comunicação; basta colocar um objeto na gaveta e fechá-la.

95 Do original: "The importance of the home derives from the fact that it provides a space for action and interaction in which one can develop, maintain and change one's identity. In its privacy, one can cultivate one's goals without fear of ostracism or ridicule. The home is a shelter for those persons and objects that define the self: thus it becomes, for most people, an indispensable symbolic environment." (CSICKSZENTMIHALY, 1981:122) 
Esta intenção de utilizar objetos para expandir o espaço físico além das fronteiras do cômodo no qual se encontram é também explorada no projeto Remote home ${ }^{96}$ (Fig. 34-38), produzido por Tobi Schneidler no Smart Studio / Interactive Institute. Para evocar sentimentos e idéias de como as casas do futuro poderiam vir a ser, propôs um apartamento dividido em dois espaços remotos, no qual a dicotomia do perto e do longe é dissolvida pela simulação da presença por meio de objetos inseridos nos espaços. Configura-se como um protótipo que especula o conceito do que seriam os espaços conscientes das casas e dos ambientes dotados de tecnologias comunicativas digitais.
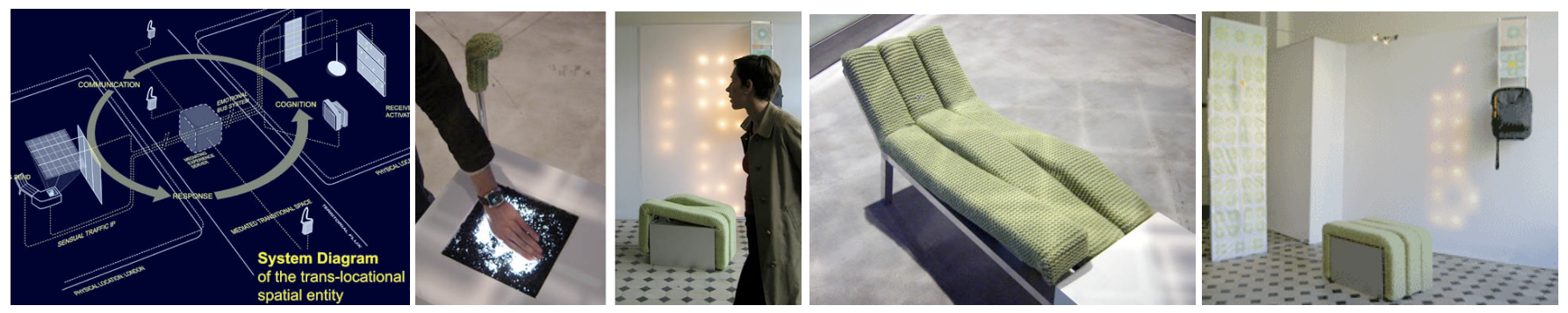

Fig. 34: Remote Home (Tobi Schneidler, 2001). Diagrama do sistema que conecta os dois espaços.

Fig. 35-38: Remote Home (Tobi Schneidler, 2001). Objetos mediadores da interação entre os moradores.

Fonte: $<$ http://www.tobi.net/page.php?id=19>.

Na proposta, uma pessoa fornece sinais discretos da sua presença física para outra, apesar da distância geográfica. Quando um morador entra em sua casa e utiliza seus objetos, movimentos e luzes são estimulados na outra localidade, como tentativa de simular a presença remota e aproximar as pessoas. Uma informação disponível como pano de fundo de um cenário cotidiano alimenta, no morador, uma consciência periférica do que acontece do outro lado. Um dos interesses dessa investigação é propor princípios de designs capazes de levantar questões que vão além da introdução de mecanismos responsivos e trazer à tona aspectos da privacidade e das relações interpessoais dos moradores.

96 Descrição do projeto disponível em: <http://www.remotehome.org>. (Acesso em 09/09/2008) 
Na maioria dos casos nos quais a influência das mídias digitais no cotidiano doméstico é abordada, explora-se a automatização das atividades e o controle à distância de equipamentos, aquecimento e iluminação. Contra essa corrente, algumas proposições do Philips Home Lab partem de propostas de cenários alternativos nos quais a presença de objetos tecnológicos altera a experiência das pessoas. No projeto Nébula (Fig. 39-40), os atos de ir para cama, deitar-se e dormir tornam-se ações interativas nas quais fluxos comunicativos são abstraídos e representados por projeções no teto do ambiente.

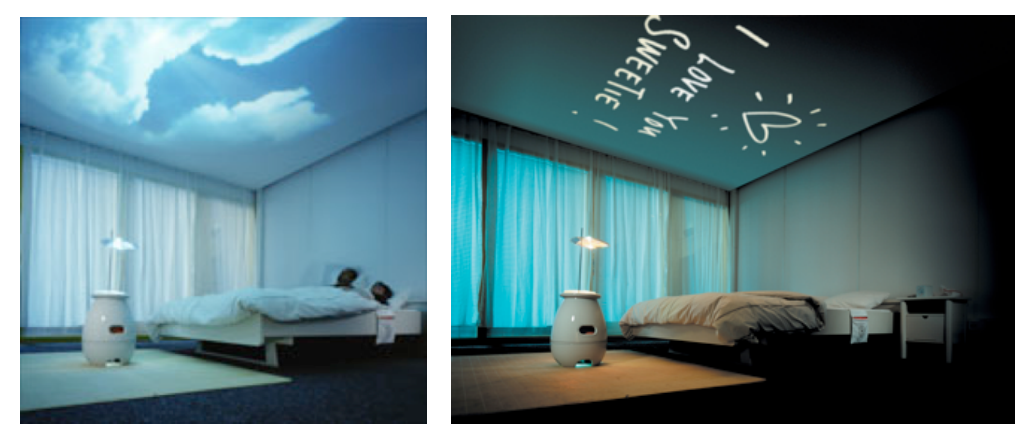

Fig. 39-40: Nebula (Philips Design). Fonte: <http://www.design.philips.com>.

Seguindo o raciocínio da realidade aumentada, na qual projeções são sobrepostas ao cenário físico, neste pode-se falar também de uma experiência aumentada na qual os fatores que envolvem a ação tratada são ampliados através de um sistema sensitivo, adaptativo e responsivo. Segundo descrições da intenção do projeto, "como as dinâmicas entre indivíduos são aleatórias e imprevisíveis, o fluxo do conteúdo criado pelo casal será único e específico a eles. Em geral, a projeção no teto se torna mais viva na medida em que os participantes se tornam mais ativos." 970 recebimento da informação, no caso captada por sensores espalhados pelo lençol da cama, é

97 Descrição do projeto disponível em: <http://www.design.philips.com/about/design/designnewscenter/inthemedia/article-14315.page> (acesso em 09/09/2008) 
seguido pelo reconhecimento de padrões de comportamento e uma classificação do sinal é feita com o intuito de avaliar a vivacidade da ação e fazer com que a projeção responda a essa.

Essa habilidade de implementar trocas mais significativas entre usuário e sistema, baseada em aspectos afetivos, faz parte do campo de pesquisa denominado affective computing que estuda as possibilidades da computação no auxílio do reconhecimento e expressão de emoções. Não se trata de reconstruir o inconsciente humano eletronicamente e, sim, de expandir as possibilidades de relação entre homem e máquina, inserindo nesta, capacidades que vão além da sua funcionalidade (PICARD, 1998). Nesse sentido, grande parte dos trabalhos nesse campo focalizam as maneiras pelas quais os computadores podem se tornar conscientes de diferentes humores e as maneiras de expressar seu entendimento das emoções humanas.

Os sensores são os dispositivos responsáveis por perceber ou medir as propriedades físicas do ambiente e dar a eles a capacidade de "sentir". Um discurso baseado em aspectos técnicos discutiria aqui as possibilidades de captação de informações a partir desses dispositivos, porém o caminho proposto procura mostrar diferentes soluções baseadas em especulações subjetivas sobre a aplicação tecnológica no cotidiano. Nesse sentido, três objetos desenvolvidos pela equipe do Royal College of Art, dentro do projeto Equator ${ }^{98}$, exploram mobiliários interativos a partir da percepção do peso como meio para que ocorra a interação. Tablecloth (Fig. 41-42), Key table (Fig. 43) e Drift table (Fig. 44-47)partem da manipulação de um mesmo dado e ilustram como a interpretação permite múltiplas soluções que induzem a uma reflexão sobre diferentes aspectos da relação entre usuário, mobiliário e mídias digitais. Segundo descrição encontrada na documentação do workshop que deu origem às idéias, as propostas consideram maneiras pelas quais o mobiliário pode ser responsivo às ações das pessoas, sendo que cada objeto trabalha a questão do peso para enfatizar diferentes aspectos da vida cotidiana.

98 Equator consiste em uma pesquisa colaborativa entre oito instituições acadêmicas do Reino Unido, que aconteceu de 2000 a 2006, financiada pelo Engineering and Physical Sciences Research Coucil (EPSRC), e envolveu mais de 60 pesquisadores entre cientistas da computação, psicologia, sociologia, design e artes. 

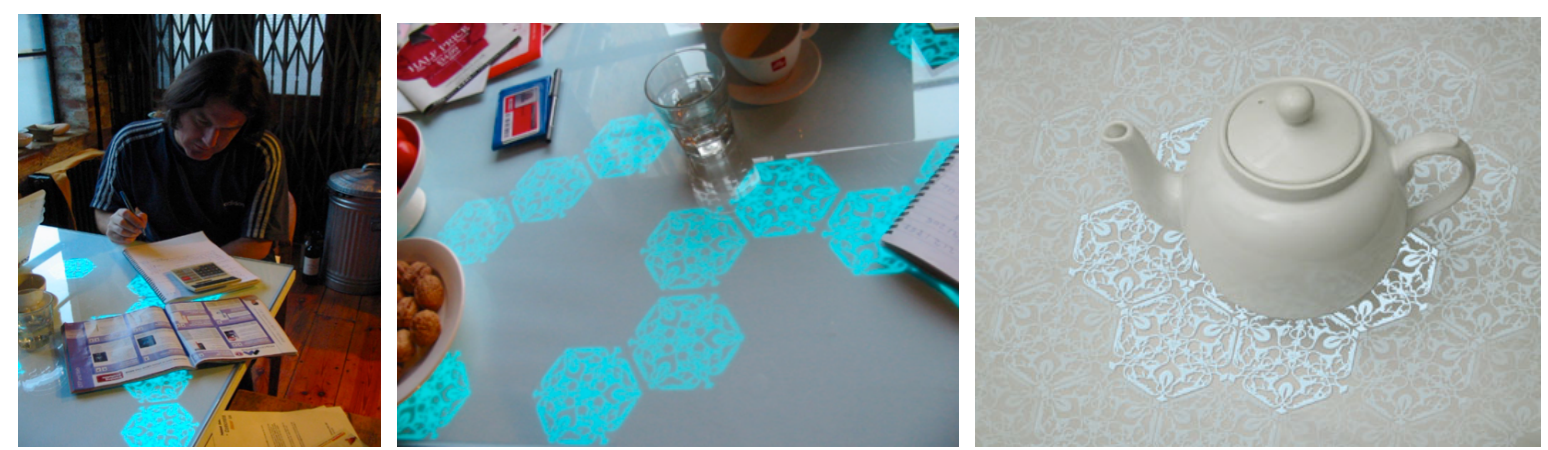

Fig. 41-42: Tablecloth. Teste de protótipo em casa de família. (RCA, Equator, 2005).

Fonte: Gaver, W., Bowers, J., Boucher, A., Law, A. Pennington, S. and Villars, N. (submitted). The History Tablecloth:

Illuminating Domestic Values. Submitted to DIS 2006. systems. Cambridge, MA: MIT Press, pp. 17-50.
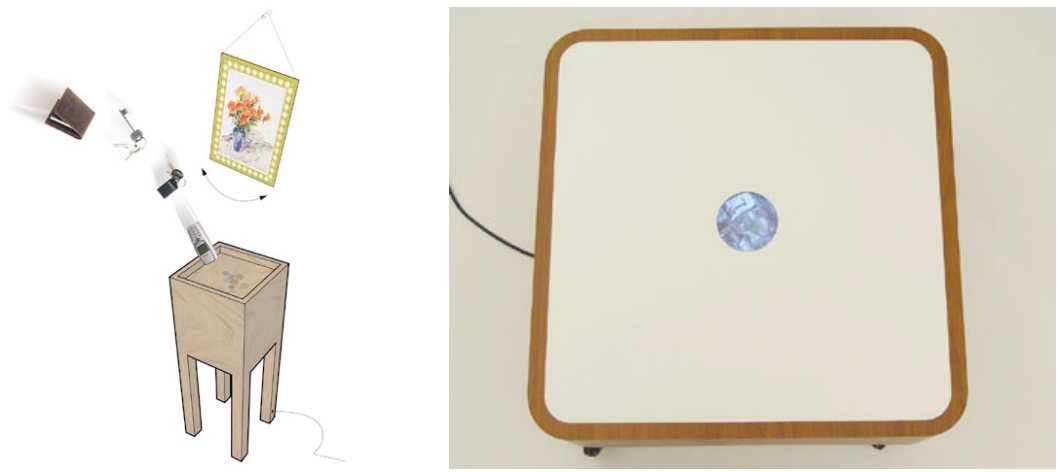

Fig. 43: Key table (RCA, Equator, 2005).

Fig. 44: Drift table(RCA, Equator, 2005).

Fonte: <http://archive.interaction.rca.ac.uk/equator/weight_furniture.html>.

As três soluções foram fruto de minuciosas pesquisas feitas nas residências de famílias cujo objetivo era mapear a forma como o mobiliário e os aparatos comunicativos eram utilizados. Essas investigações enfatizaram a importância das superfícies como locais estratégicos para a coordenação das atividades diárias. Dentro dessa perspectiva, Tablecloth é uma toalha de mesa que exibe padrões luminosos, a partir da colocação de objetos na 
sua superfície, que aumentam de acordo com o tempo que permanecem no mesmo lugar. Dessa maneira, faz com que aspectos sutis da história dos objetos sejam revelados, induzindo seus usuários a levantar assuntos sobre sua permanência e movimentação dentro da casa.

Já a Key table foi desenvolvida com o intuito de interpretar o humor das pessoas a partir da força com a qual ela coloca os objetos na sua superfície. Essa informação é então reenviada para os outros habitantes da casa através de um quadro, pendurado na parede, que se desloca de acordo com a força captada, como se um terremoto tivesse sacudido aquele espaço. 0 comportamento do objeto baseou-se no reconhecimento de um padrão de ação no qual a pessoa, quando está mais nervosa, chega em casa, bate a porta e joga seus pertences com força em cima da mesa. Esta exploração baseia-se na idéia de que a alteração da força de impacto pode ser uma rica fonte sobre a dinâmica de comportamento das pessoas dentro de casa.

Na Drift table, o intuito é investigar a inserção de aspectos lúdicos na relação entre as pessoas e a tecnologia. Nesse caso, o lúdico é entendido como atividades motivadas pela curiosidade, exploração e reflexão, no lugar de tarefas pré-determinadas, trabalhadas como mecanismos para o desenvolvimento de novos valores e metas, para o aprendizado e alcance de novos entendimentos (GRAVER, 2004, p.01-02). Drift é a palavra em inglês para flutuar, vaguear, e traduz a idéia básica da interação proposta que consiste em uma mesa de centro com um pequeno círculo no meio, através do qual é possível passear por uma vista aérea da Inglaterra, que se move vagarosamente, como se a pessoa estivesse em um balão. A partir do momento em que diferentes objetos são colocados nas extremidades da mesa, a altura, direção e velocidade do passeio são alteradas. 0 design da mesa visou torná-la completamente não-funcional, buscando criar uma situação exploratória para seus usuários. 

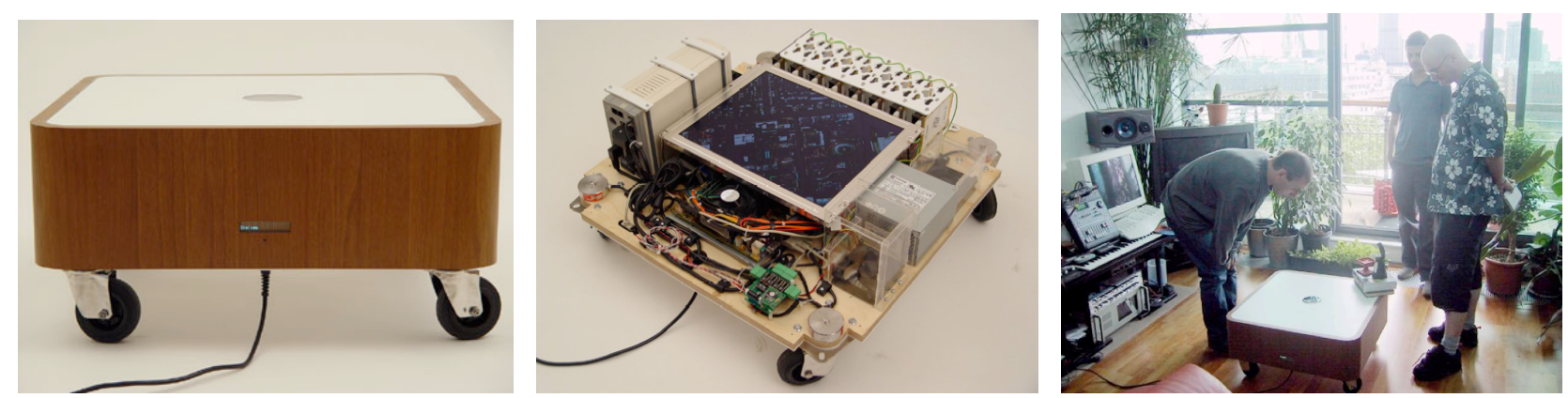

Fig. 45-47: Drift Table. (RCA, Equator,2004)

Fonte: Gaver, W., Bowers, J., Boucher, A., Gellerson, H., Pennington, S., Schmidt, A., Steed, A., Villars, N., \& Walker, B.

(2004). The Drift Table: Designing for ludic engagement. Proc. CHI'04 Design Expo. New York: ACM Press, 885-900.

Além de tratar de superfícies que reagem ao peso, o que os três objetos também possuem em comum é não induzirem o tipo de atitude que as pessoas devem ter frente a eles. 0 que fazem é provocar situações nas quais os usuários são levados a refletir, através de diferentes interpretações, sobre o que ocorre entre suas ações e as reações provocadas. Para testar esse aspecto do experimento, protótipos das três peças foram construídos e deixados por um longo período na casa de possíveis usuários. Nos três casos, o fato de não ter sido esclarecido o que as pessoas deveriam fazer com eles, criou uma situação na qual elas puderam explorar o que lhes pareceu ser possibilidades de uso. Apesar de seu caráter experimental, percebeu-se que a construção do objeto e a validação da idéia com possíveis usuários se mostrou uma trajetória importante capaz de extrair da espontaneidade das atitudes e comportamentos novas aplicações e possibilidades.

\subsection{Interatividade na escala do edifício}

Assim como a pele, que delimita e protege os órgãos do corpo humano, o edifício configura a camada mais externa de uma estrutura, desempenhando o papel de elemento separador de uma série de atividades que acontecem dentro e fora de seus limites, além de permitir e gerenciar a troca entre estes. Na instância física da 
arquitetura, essa troca se realiza por meio da abertura e fechamento de janelas e outros meios de ligação entre exterior e interior. Nesse sentido, a introdução das TIC permite que seus pisos, paredes e tetos ampliem sua função de proteção e limite, e passem a ser capazes de realizar sua tarefa de pele com mais dinâmica e interatividade.

Resultado de uma tendência à valorização dos aspectos funcionais e otimizadores da tecnologia, a primeira relação estabelecida entre as possibilidades técnicas e sua aplicação nos edifícios refere-se a sistemas de controle e gerenciamento de recursos. Esta abordagem está ligada diretamente ao tipo de automação já tratada no item anterior, no qual o sistema é pré-programado por profissionais e as pessoas se tornam usuárias de configuracoes-padrão, muitas vezes sem ter a opção de alterá-las de acordo com necessidades não-previstas.

Mais do que criticar aproximações funcionalistas, vale lembrar que o objetivo deste trabalho como um todo é mostrar alternativas de exploração das tecnologias digitais nos diversos objetos que permeiam o cotidiano. É nesse contexto experimental que a Reconfigurable House (Fig. 48-50), projeto dos arquitetos Usman Haque e Adam Somlai-Fischer, foi concebida. Ainda que a proposta não se configure completamente como um edifício, a idéia baseia-se na possibilidade de constante alteração da maneira como os sistemas informatizados são conectados. Traz consigo a idéia de um sistema aberto e personalizado, que pode ser alterado pelo usuário, de acordo com sua vontade. Segundo o website do projeto, a casa consiste em superfícies e objetos que respondem ao som, luz, toque, passos, telefonemas, tocadores de MP3 e, até mesmo, à espaços conectados remotamente, sendo que seus componentes foram construídos a partir da alteração e apropriação de tecnologias de brinquedos e objetos eletrônicos lowtech.

"Vários sensores e atuadores da Casa/Lar Reconfigurável podem ser infinitamente reconectados na medida em que as pessoas mudam de idéia, de forma que a Casa pode absorver completamente novos comportamentos. Algumas pessoas devem entrar na Casa e achar que está 
muito barulhenta, muito reativa, ou talvez não-reativa o suficiente. Talvez algumas pessoas prefiram sons, outras podem preferir luzes. Ainda outros indivíduos podem preferir a delicada sensação de umidade. Cada visitante poderá utilizar uma simples interface para configurar as reações e interações da Casa de maneiras completamente diferentes." 99
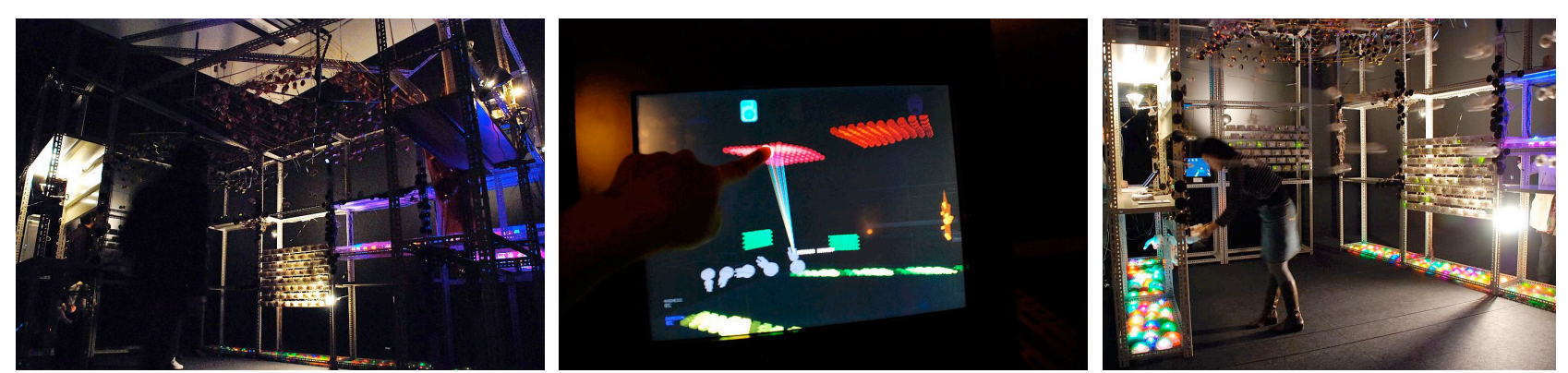

Fig. 48-50: Reconfigurable House (Usman Haque, 2007-2008). Fonte: <http://house.propositions.org.uk/>.

A partir do caráter espontâneo e lúdico do projeto, um aspecto a ser ressaltado é a forma como inclui o usuário no processo de monitoramento e tomada de decisões. Ele possibilita que as pessoas entrem em contato e compreendam frações dos sistemas interativos digitais que permeiam a vida cotidiana. A tecnologia hoje disponível permite que diferentes informações, relacionadas ao edifício e às atividades que ocorrem no seu interior, sejam visualizadas de variadas maneiras, fazendo com que este se torne mais do que um simples invólucro e passe a exercer uma relação de troca constante com o meio no qual se insere. No caso do museu Kunsthaus, na cidade austríaca de Graz ${ }^{100}$, projetado pelos arquitetos Peter Cook e Colin Fournier, a vontade de

99 Descrição do projeto disponível em: <http://house.propositions.org.uk/> (acesso em 19/01/2008). Do original: "The many sensors and actuators of Reconfigurable House can be reconnected endlessly as people change their minds so that the House can take on completely new behaviors. Some people may walk into the House and find that things are too noisy, too reactive, or maybe not reactive enough. Perhaps some people may prefer sound outputs, others may prefer lights. Still others may prefer the delicate feeling of mist. Each visitor will be able to use a simple interface to configure the reactions and interactions of the house in a completely different way."

100 Mais informações disponíveis em <http://www.kunsthausgraz.steiermark.at> (acesso em 18/01/2008) 
conscientizar os passantes das atividades que ocorrem dentro do museu e fazer com que obras expostas se estendam ao domínio público, culminou na integração da fachada BIX ${ }^{101}$ ao edifício (Fig. 51-52) .

A abordagem dos arquitetos reflete uma das possibilidades que a arquitetura encontrou de adaptar-se a uma sociedade caracterizada pela abundância e fluidez da informação, ou seja, por meio da integração do espaço físico com o informacional. Mais do que um painel conectado à Internet, o projeto integra o display à estrutura como um todo, sendo que esta se torna indissociável do edifício. A primeira idéia era que o museu fosse completamente transparente, o que prejudicaria sua principal funcionalidade, que é a de abrigar obras de arte interativas. Optou-se, então, pelo completo isolamento do seu interior, acrescido da possibilidade de mudança constante de sua pele exterior.
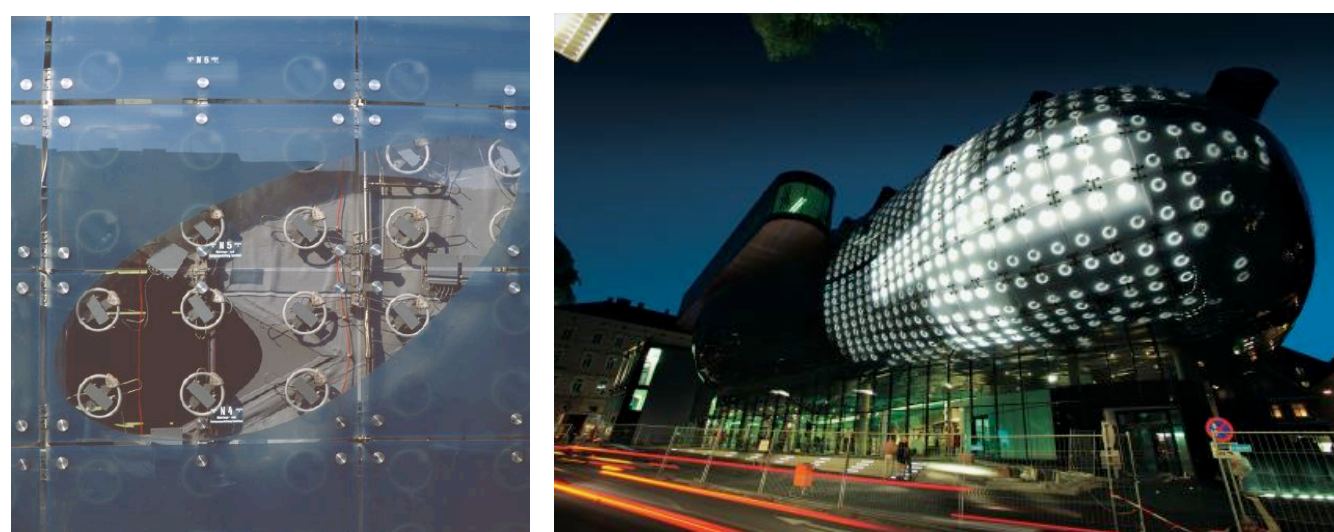

Fig. 51-52: Bix (realites:united, 2003) e Kunsthaus (Cook, Fournier, 2003). Fonte: <http://www.bix.at/>.

A fachada BIX foi desenvolvida pelos arquitetos do escritório berlinense realites:united e possibilitou que sinais luminosos de baixa resolução, como imagens, filmes e animações, pudessem ser veiculados ao longo de uma de

101 Mais informações disponíveis em: <http://www.bix.at>. (acesso em 18/01/2008) 
suas fachadas, sendo visível de vários pontos da cidade. De acordo com descrição retirada do website do projeto, na medida em que “dividem a mesma escala, juntos a arquitetura e a 'mídia-instalação' geram um novo resultado estético. Não se trata de uma parede de vídeo montada separadamente, mas o próprio edifício da Kunsthaus irradia caracteres e imagens; a ligação entre os aspectos da projeção e do edifício como entidade alcançam um nível elevado de integração."102 Dessa forma, o edifício como display estende o intuito primeiro do museu, multiplicando e potencializando seu poder comunicativo pela cidade.
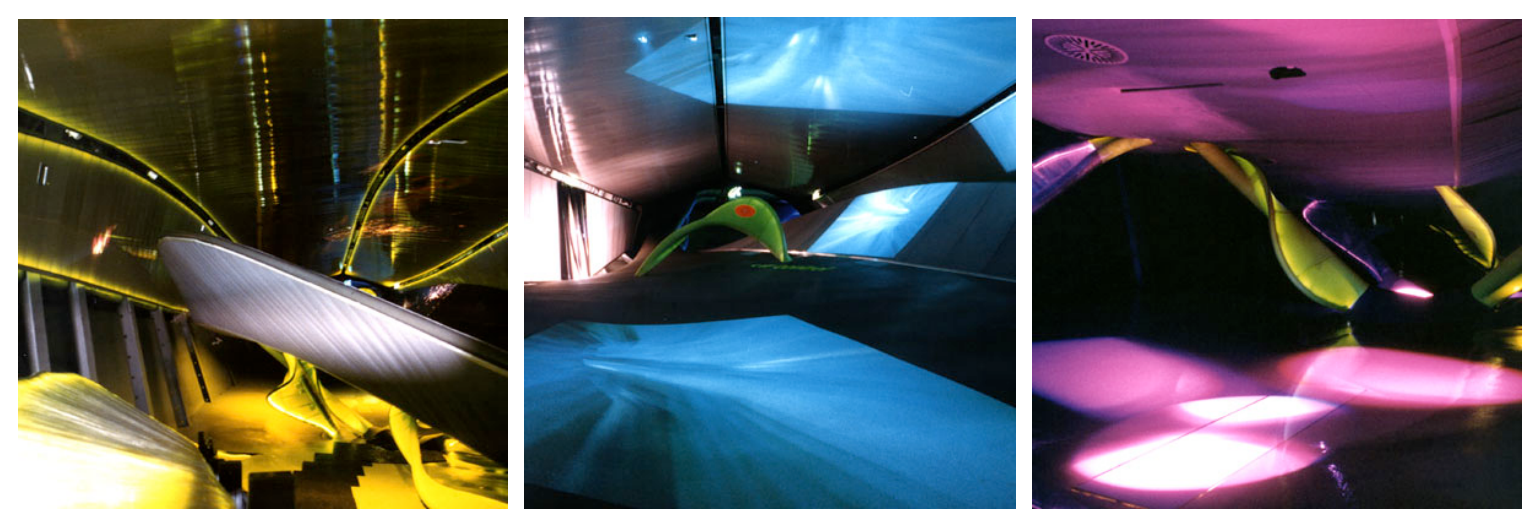

Fig. 53-55: H2O Pavillion (NOX, Edwin van der Heide, 2006). Fonte: <http://www.evdh.net/>

As tecnologias digitais podem também ser exploradas de forma a fazer o movimento inverso e trazer para o interior informações externas ao edifício. No caso do H2O Pavillion (Pavilhão da Água, Fig. 53-55), obra dos arquitetos do escritório holandês NOX ${ }^{103}$ juntamente com o artista Edwin van der Heide ${ }^{104}$, a idéia foi criar um ambiente na forma de organismo vivo que se expressa pela arquitetura, luz, imagens, água e som. Seu

102 Descrição retirada do web-site do projeto: <http://www.bix.at> (acesso em 18/01/2008). Do original: "Sharing the same scale, the architecture and the media installation together generate new aesthetic results. Not a separately mounted vídeo wall but the Kunsthaus itself radiates characters and images; the link between the aspect of projection and the building as an entity achieves an extremely high level of integration".

103 Mais informações sobre os trabalhos do NOX disponíveis em <http://www.noxarch.com>. (Acesso em 18/01/2008)

104 Mais informações sobre os trabalhos do artista Henri van der Heide disponíveis em <http://www.evdh.net>. (Acesso em 18/01/2008) 
comportamento é baseado em processos e metáforas sobre a água e influenciado pela movimentação das pessoas no seu interior e por parâmetros ambientais, tais como informações sobre o tempo e sobre o nível da água do mar. A interação se dá na forma de sons, produzidos eletronicamente, compostos no momento em que são tocados. Essa interação com parâmetros nao-previsíveis (pessoas, clima, mar) faz com que um caráter de unicidade seja trazido para o edifício, uma vez que faz a música tocada ser sempre única.

Segundo Sachin Anshuman e Bimal Kumar, em um artigo que escreveram sobre o design de espaços responsivos, o projeto ilustra a busca de arquitetos e designers em integrar dinamismo e responsividade ao espaço construído. Os autores apontam a distância ainda existente entre as formas dinâmicas geradas por campos de força aplicados a modelos digitais e o que é finalmente construído.

"Ferramentas de modelagem 3D, software de análise estrutural integrado, modelagem NURBS [Non Uniform Rational B-Splimes] e cinemática inversa fizeram não apenas a concepção, design e modelagem de geometrias previamente não-imagináveis mas também possibilitaram a animação destas formas. Isto fez surgir processos que permitem que os objetos sejam conectados a fluxos dinâmicos de informação e sejam alterados; ou em outras palavras, permitiram aos processos que respondessem às forças dinâminas definidas pelo designer, através de alterações estruturais contínuas na forma, textura, volume ou outras características físicas. No entanto, tal reação e fluidez permanece limitada aos estágios de design (...). Embora tais métodos sinalizem uma inovação na arquitetura na qual o espaço deixa de ser um container estático e passa a ser um entidade dinâmica capaz de se moldar e se adaptar em situações diferentes, o que é construído, ainda permanece bastante inerte e estático."105 (ANSHUMAN; KUMAR, 2004, p.274)

105 Do original: "3D modeling tools, integrated structural analysis software, NURBS [Non Uniform Rational B-Splimes] modeling, and inverse kinematics have not only made conception, design and modeling of previously unimaginable geometries possible but also made it possible do animate these forms. This gave birth to processes that allowed the objects to be linked to dynamic information flows, and be altered; or in other words, it allowed them to respond to dynamic forces that the designer wanted them to respond to through undergoing structural alterations in shape, texture, volume or other physical characteristics. However, such responsiveness and fluidity remains limited to the design stages (...). 
No caso do H20 Pavillion, com a integração de sensoriamento, imagens e som por meio do processamento das informações, a busca reside na alteração de aspectos experienciais do espaço. Neste caso, as tendências apresentadas por outros campos de atuação relacionados à computação e processamento de dados são incorporadas ao edifício na busca de efetivar a inclusão de aspectos responsivos e dinâmicos na forma e percepção do espaço.
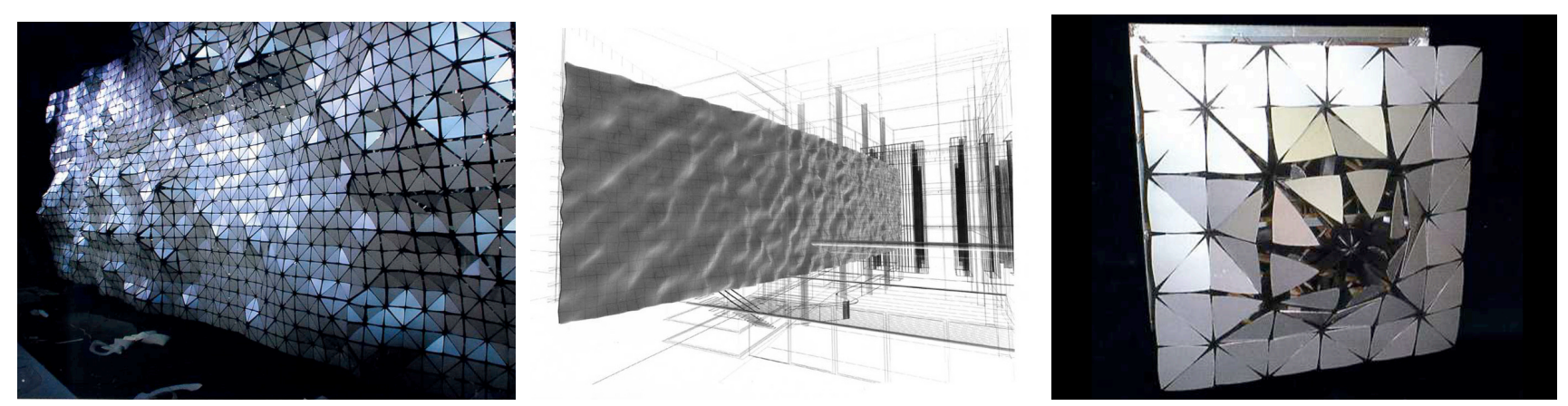

Fig. 56: Aegis Hyposurface: superfície em funcionamento. Fonte: PRAXIS: Journal of Writing + Building, Issue 06, 2004.

Fig. 57: Aegis Hyposurface: ilustração da idéia inicial. Fonte: AD Hypersurface Architecture II, Vol. 69 9-10, 1999.

Fig. 58: Aegis Hyposurface: detalhe das placas com os pistões pneumáticos. Fonte: PRAXIS: Journal of Writing +

Building, Issue 06, 2004

Um outro tipo de experimento que busca alcançar formas e espacialidades dinâmicas consiste no que os autores chamam de responsividade cinética, caracterizada por transformações na forma, topologia, posição e propriedades físicas dos elementos que compõem o edifício (ANSHUMAN; KUMAR, 2004). É o caso da Aegis Hyposurface 106 (Fig. 56-58): objeto situado entre uma proposição artística e a exploração de elementos arquitetônicos, consiste em uma superfície metálica que possui a capacidade de se deformar fisicamente como

Although such methods signal a new departure in architecture where space would no longer be a static container, but a dynamic entity that could morph and adapt to changing situations, what is built, still remains pretty much inert and static." (ANSHUMAN; KUMAR, 2004, p.274)

106 Mais informações no web-site do projeto:

<http://www.sial.rmit.edu.au/Projects/Aegis Hyposurface.php>. (Acesso em 09/09/2008) 
resposta a estímulos do ambiente (movimentos, som, luz etc.). Comandada por pistões pneumáticos, a superfície ilustra a exploração de um material resultante da articulação e da dissolução dos limites entre arquitetura, engenharia e computação.

Os exemplos abordados acima apenas indicam algumas possibilidades que se abrem quando o desenvolvimento de sistemas computacionais é abordado de forma a ampliar as possibilidades do design de edifícios. A questão colocada concerne especificamente à manipulação expressiva das mídias digitais de forma a empregá-las de maneira significativa no contexto cotidiano. Assim, elas podem vir a atuar para estabelecer relações mais responsivas entre as pessoas, suas necessidades e os espaços criados para abrigar suas relações.

\subsection{Interatividade na escala da cidade}

Traçar um mapa da cidade, destacando os usos e ocupação de seu território, tornou-se uma atividade complexa, em uma sociedade marcada pela fluidez comunicativa possibilitada pelas tecnologias digitais. Segundo William Mitchell compara, traçar um mapa significava diferenciar os espaços públicos (ruas, praças e igrejas) dos espaços privados ${ }^{107}$. No início do século XXI, essa distinção categórica é marcada por uma constante contradição na qual as fronteiras tradicionais entre os espaços públicos e privados da cidade são dissolvidos de forma que um penetra e redefine o outro, em um movimento de trocas constantes.

"No passado, a condição natural das cidades era a opacidade; arquitetos criaram transparências limitadas por meio de aberturas em portas e janelas, cômodos abertos e espaços públicos. Hoje, a

107 William Mitchell utiliza como comparação o mapa de Roma feito pelo arquiteto Giambattista Nolli (1701-1756) no ano de 1748. Nolli devotou sua vida para documentar as referências arquitetônicas e urbanas da cidade. Uma versão interativa do mapa pode ser acessada no web-site: <http://nolli.uoregon.edu/default.asp>. (Acesso em 09/09/2008) 
condição estabelecida é a transparência eletrônica e é preciso trabalhar muito para produzir zonas de privacidade limitadas."108 (W. MITCHELL, 2003, p. 29)

A diferenciação e marcação dos espaços por meio das obras de arquitetura e geometria da cidade são então substituídas pelo controle e mapeamento possibilitados pelas tecnologias digitais. Os fluxos de informação tornam-se assim desconectados da geografia da cidade. A utilização de câmeras filmadoras em sistemas de segurança e de telefones celulares são exemplos de tecnologias responsáveis por esta hibridização do espaço. A percepção que se tem de determinado lugar altera-se completamente, por exemplo, no momento em que se atende a uma ligação no ônibus ou na fila de um banco. Falar ao telefone tornou-se uma atividade onipresente nas ruas da cidade, agora palco de conversas privadas antes restritas ao espaço doméstico privado. Sobre a utilização de câmeras e como estas alteram os limites espaciais, Mitchell comenta que

“Câmeras de segurança fornecem aos espaços privados interiores uma visão de via única dos exteriores públicos (...). Videoconferências de via dupla podem conectar público com público, conectar privado ao privado, ou misturar eletronicamente público e privado. Novos estilos de exibicionismo e voyeurismo eletrônico, tais como web-cams em dormitórios e reality shows de TV, colocam o espaço privado em telas públicas." ${ }^{109}$ (W. MITCHELL, 2003, p.28)

Aos espaços da cidade agora também se sobrepõe uma outra paisagem, presente em toda superfície terrestre e invisível aos olhos das pessoas, aquela formada pelas ondas eletromagnéticas. 0 espaço hertziano (herzian space) é o produto de inúmeras transmissões eletromagnéticas e dos reflexos e obstruções dessas transmissões.

108 Do original: "Once, the natural conditions of the cities was opacity; architects created limited transparency by means of door and window openings, enfilades, open rooms, and public spaces. Today, the default condition is electronic transparency, and you have to work hard to produce limited zones of privacy." (W. MITCHELL, 2003, p.29)

109 Do original: "Security cameras provide interior private spaces with one-way views of public exteriors (...). Two-way videoconferences can link public to public, connect private to private, or electronically mix public and private. New genres of electronic exhibitionism and voyeurism, such as dorm room web-cams and reality television shows, put private spaces on public displays." (W. MITCHELL, 2003, p.28) 
Fruto da exploração desse espaço considerado vazio pelas pessoas, a instalação Sky Ear110 (Fig. 59-60), coordenada pelo arquiteto Usman Haque, rememora que diversos aspectos da vivência da cidade estão sujeitos à ampliação e conexão a partir da introdução dos aspectos comunicativos e informacionais das tecnologias digitais. Em um momento no qual vigora a velocidade associada à eficácia individual, essas mídias podem também ser catalisadoras de experiências coletivas, fazendo com que as pessoas se desloquem da inércia cotidiana e participem ativamente de encontros com o lugar e mundo que habitam. Proposições experimentais neste sentido podem auxiliar as pessoas na compreensão e questionamento das possibilidades trazidas por esse meio.
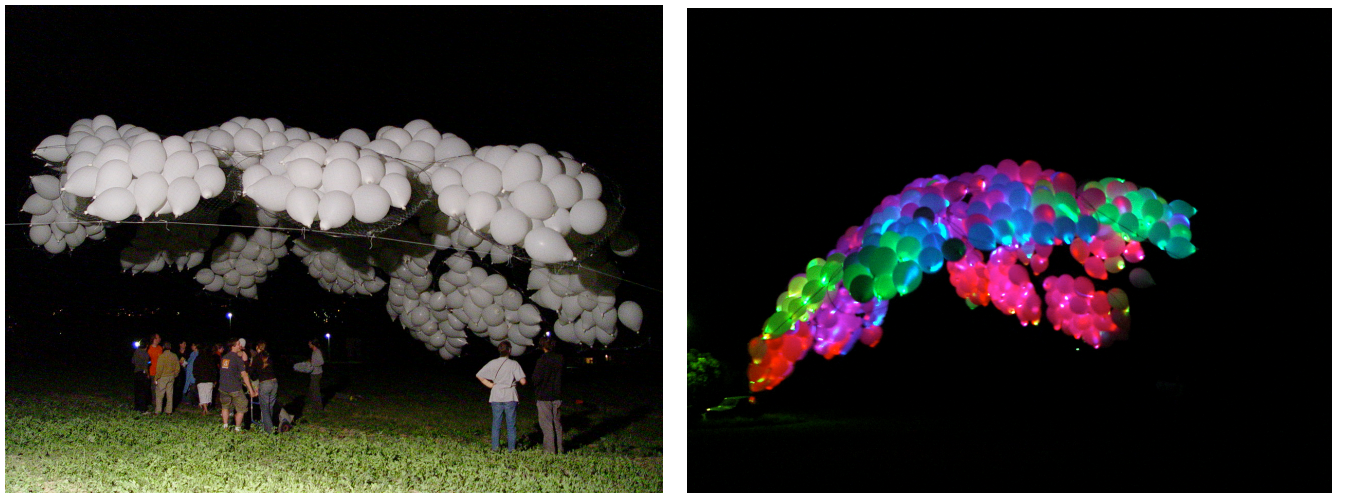

Fig. 59: Nuvem de balões, Sky ear (Usman Haque, 2003-2006).

Fonte: <http://www.haque.co.uk/skyear/hires/DSC01767.JPG>

Fig. 60: Sky ear - nuvem interagindo com as ondas eletromagnéticas (Usman Haque, 2003-2006).

Fonte: <http://www.haque.co.uk/skyear/hires/DSC01704.JPG >.

O Sky Ear consistiu em uma instalação na qual, em uma noite, mil balões extragrandes inflados por gás hélio e com aparelhos celulares em seu interior, foram fixados em uma rede de fibra de carbono e lançados ao ar, de forma que as pessoas pudessem telefonar para essa espécie de nuvem artificial e ouvir os diferentes sons

110 Descrição do projeto disponível em <http://www.haque.co.uk/skyear/information.html> . (Acesso em 09/09/2008) 
propagados pelo ar. Dentro de cada balão foram colocados seis LEDs ${ }^{111}$ ultra-brilhantes, cujas cores respondiam aos impulsos eletromagnéticos. A experiência possibilitou a visualização de fenômenos invisíveis criados por tempestades distantes, telefones celulares, rádio, televisão e outros incontáveis sinais que transitam diante e ao redor dos nossos corpos todos os dias.

A instalação possibilitou que as pessoas visualizassem e interagissem com um espectro importante para o dia-adia, composto pelas ondas eletromagnéticas. Grande parcela da população nunca parou para refletir e imaginar como é possível falar ao telefone celular, receber imagens ao vivo, do espaço, ou até mesmo trocar o canal da TV por meio de um controle remoto. A rapidez da evolução tecnológica faz com que esses feitos da técnica sejam absorvidos de maneira pouco crítica. Anthony Dunne e Fiona Raby também tratam do que eles chamam de "vida secreta dos objetos", em seu projeto Placebo, e ressaltam que "apesar de não sentirmos a radiação eletromagnética, ela é atual e muito verdadeira, e interage com o mundo físico para produzir uma nova 'paisagem entre' de sombras e picos, denominada eletrogeografia"112 (DUNNE; RABY, 2002, p.18).

Esta sobreposição de camadas ressalta o caráter da cidade como um complexo emaranhado de relações. 0 artista Rafael Lozano-Hemmer explora essas múltiplas facetas na sua instalação Under Scan (Fig. 61-62). Nela, o foco volta-se para a conexão dos corpos presentes, tão próximos e tão distantes uns dos outros na correria do dia-adia. Vídeo-retratos dos habitantes da cidade são projetados e cobertos por uma forte luz. Na medida em que passantes caminham pela praça, estes retratos são descobertos e interagem com a pessoa. Esta proposta retrata uma busca de reconectar a esfera pública a partir da participação ativa dos habitantes na configuração e percepção de determinado espaço, possibilitada pelas TIC.

111 LED, do inglês Light Emissor Diode (diodos emissor de luz), é um diodo semicondutor que, quando energizado, emite luz visível. É bastante utilizado por gastar pouca energia, pela facilidade de manuseio, por sua dimensão reduzida e também pela qualidade da luz emitida.

112 Do original: "Although we cannot sense electromagnetic radiation, it is actual and very real, and interacts with the physical world to produce a new in-between landscape of shadows and hotspots we call an electrogeography." (DUNNE ; RABY, 2002, p.18) 
A proposta cria uma espécie de experiência coletiva ampliada com o emprego da tecnologia digital. 0 artista diz que "usando projeções, robótica, som, conexão em rede e sensores locais, o input e o feedback dos participantes se tornam parte integral do trabalho e o resultado é ditado por suas ações"113 (LOZANO-HEMMER, 2002, p.146). A obra faz parte do que ele denomina de "arquitetura relacional", conceito que reflete sua busca em criar situações sociais, utilizando a tecnologia para alterar a forma como as pessoas se relacionam com a arquitetura e o espaço urbano. 0 que ele faz é estabelecer algumas condições iniciais, uma plataforma ou veículo a partir do qual propicia que as pessoas explorem livremente as limitações e possibilidades da própria peça.

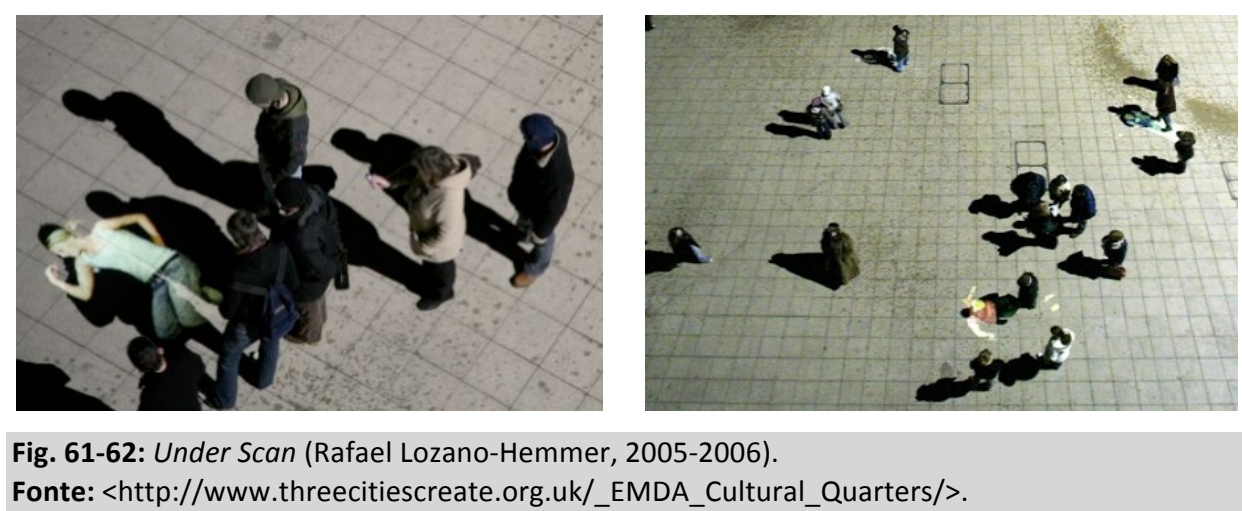

Na sua Arquitetura Relacional 4, Vectorial Elevation (Elevação Vetorial, Fig. 63-65), participantes com acesso à Internet puderam intervir na configuração da obra, por meio de seu elemento virtual. Em sua primeira versão, mostrada na Cidade do México durante um mês em 1999-2000, 18 potentes canhões de luz, instalados no topo dos edifícios que conformam a praça Zócalo, foram configurados através do web-site do projeto por qualquer pessoa que tivesse acesso à Internet. A cada seis segundos os canhões se moviam para a posição programada e

113 Do original: "Using projections, robotics, sound, net connections and local sensors, the input and feedback from participants become as integral part of the work and the outcome is dictated by their actions." (LOZANO-HEMMER, 2002, p.146) 
uma mensagem do autor daquela nova configuração era projetada na praça. Aquele espaço passava então a ser ocupado e percebido a partir de uma escala que ia além do espaço físico da cidade. Consistia na visualização da idéia de um habitar globalizado, no qual o alcance das intervenções pessoais vão além do espaço físico em que se encontram. 0 responsável pela configuração dos holofotes se vinculava com aquela praça específica e as pessoas podiam contemplar intervenções vindas de várias partes do mundo.
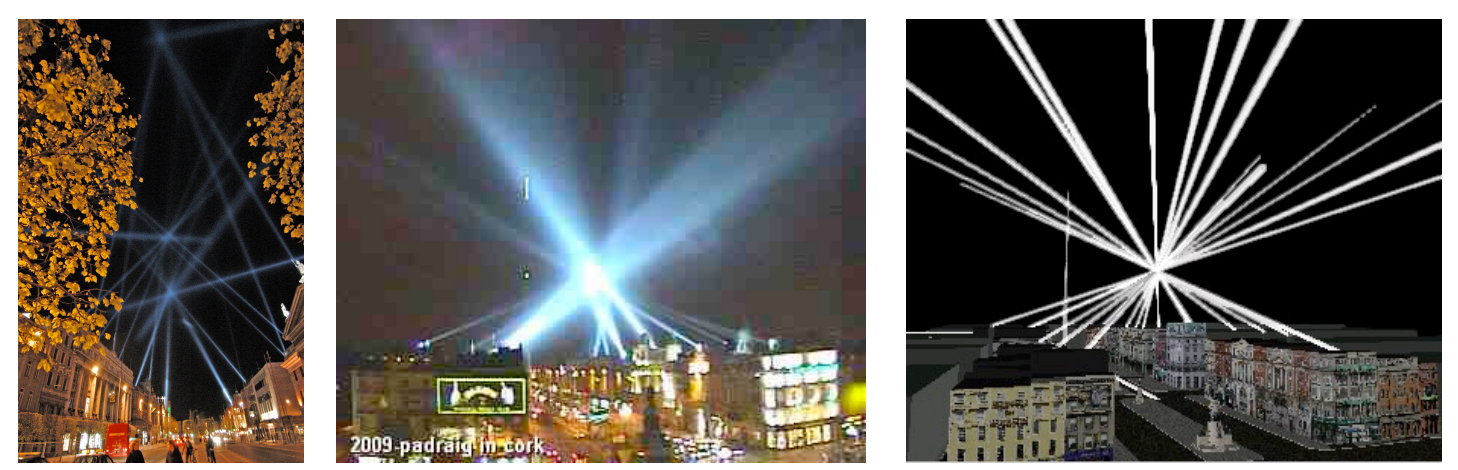

Fig. 63: Vectorial Elevation. Praça Zócalo, Mexico City. (Rafael Lozano-Hemmer, 1999-2004).

Fonte: <http://www4.alzado.net/pages/eD2008.html>

Fig. 64-65: VIsualização de um layout pelo web-site e sua respectiva conformação na praça Zócalo, Mexico City.

Vectorial Elevation (Rafael Lozano-Hemmer, 1999-2004).

Fonte: <http://www4.alzado.net/edinformacion.html>.

Os exemplos mencionados neste item indicam possibilidades de trabalho com as TIC que estimulam a participação ativa de pessoas além de encorajar o encontro, muito mais do que o controle e o individualismo. É importante ressaltar que as quatro escalas abordadas nesse trabalho - do corpo, do objeto, do edifício e da cidade - são interdependentes, uma vez que se misturam constantemente. 0 objetivo maior ao analisar alguns projetos é o de trabalhar suas especificidades sabendo, porém, que fazem parte de um mesmo conjunto. Os exemplos utilizados expõem a aproximação proposta pela pesquisa que busca ilustrar possibilidades que ultrapassam o que normalmente se espera ao tratar das tecnologias de informação e comunicação. Buscam introduzir a abordagem do tema a partir do foco na poética, criatividade e outras experiências alternativas. 

Dois projetos interativos foram desenvolvidos durante esta pesquisa, frutos das explorações colocadas ao longo do trabalho. Affective Twins e PIX exploram instâncias do habitar interativo e das espacialidades híbridas, por meio da prática de introdução da computação digital no ambiente construído. Seja a partir da apropriação do mobiliário ou da fachada de um edifício, algumas questões que perpassaram essas criações são partilhadas, uma vez que ambas buscam a justaposição entre elementos concretos e informação digital. Outras diferem, na medida em que a dinâmica da criação e seus objetivos são distintos.

A análise dos projetos faz-se com o intuito de relacionar e estabelecer trocas entre a teoria e prática. A partir dessa abordagem, busca-se não apenas embasar conceitualmente os projetos, mas também apontar de que maneira sua execução auxilia no entendimento de questões mais amplas, respondendo perguntas mas também colocando novas. Para isso, além dos tópicos já discutidos, outros elementos são gradualmente inseridos de forma a ampliar o alcance do trabalho.

As análises foram feitas através de três categorias: das características do objeto, de seus processos de criação e das interações mediadas por eles. Essa divisão foi feita apenas com o intuito de esclarecer as partes, mas a riqueza do objeto reside nas interlocuções e nas trocas que ocorrem entre elas. Mais do que esgotar as possibilidades de análises, o objetivo aqui é o de explicitar caminhos para que elas ocorram, de forma que conceitos sejam esclarecidos e possibilitem outras interpretações. 
Servindo-se de um olhar baseado em aproximações da complexidade, dos sistemas, e da cibernética, a abordagem aqui colocada busca elucidar a relação entre processos de criação e os objetos produzidos, através da investigação do emprego dos meios digitais neste campo. As discussões colocadas são auxiliadas tanto por questões relacionadas com o input, output e processamento, como partes do sistema interativo, quanto pelas idéias de circularidade e feedback, que configuram maneiras de lidar com este sistema. A atividade prática insere desafios no sentido de exigir um conhecimento técnico básico, suficiente para que o diálogo entre distintos campos do conhecimento seja viabilizado. Isso aumenta o entendimento do processo como um todo e contribui para o enraizamento das questões que são colocadas. Assim, a partir de uma perspectiva da ação, do entendimento, e da fruição, é feito então um entrelaçamento mais estreito da atividade prática com os outros exemplos e projetos discutidos ao longo deste trabalho.

\subsection{Affective Twins e PIX}

Os projetos Affective Twins e PIX foram desenvolvidos durante esta pesquisa e refletem, a partir das suas especificidades, a busca por um entendimento aprofundado sobre particularidades dos objetos interativos. Eles exploram instâncias híbridas por meio da adição da capacidade de processamento de informações em objetos cotidianos, a partir de perspectivas distintas, em diferentes escalas.

Para possibilitar um maior entendimento dos projetos analisados neste capítulo, é necessária uma explanação sobre as partes básicas que compõem o sistema que compreende um objeto interativo, entendido aqui como um conjunto de partes interconectadas. O reconhecimento dessas partes auxilia na apreensão das diferenças existentes entre os projetos, a partir da descrição técnica dos fatores envolvidos. Dan O’Sullivan e Tom Igoe (2004, p. xx), em um livro dedicado a explicar técnicas para a construção do que denominam "computação física" (Physical Computing), dividem o sistema em input, processamento e output. 0 esquema da Fig. 66 ilustra 
sucintamente estas três partes, cujas funções podem ser descritas a partir de uma analogia com as ações humanas de ouvir (input) , pensar (processamento) e falar (output).

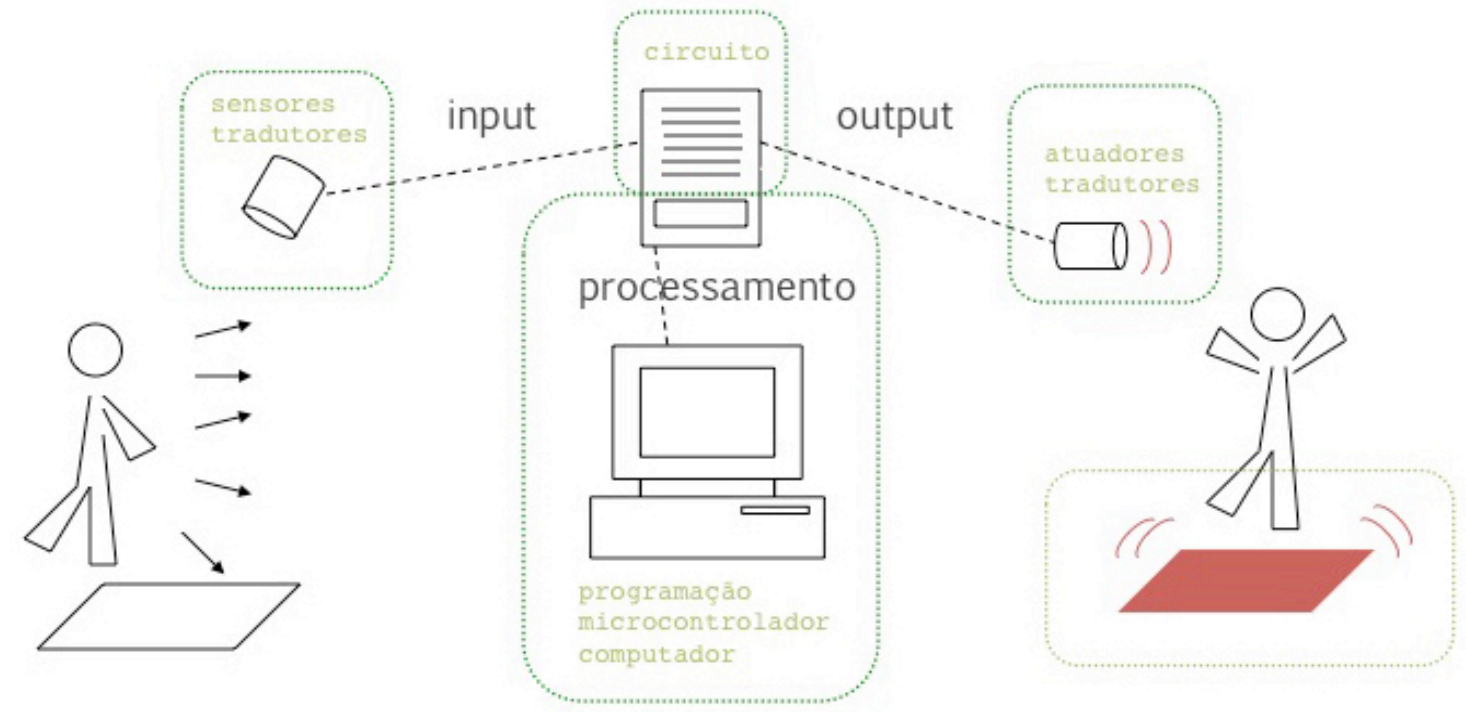

Fig. 66: esquema ilustrativo das três partes que compõem um objeto interativo: input, processamento e output. Fonte: Nomads.usp, 2008

No item 2.2 deste trabalho - A interação com o meio digital - foram apresentadas as lógicas que regem a computação digital. Foi dito que esse meio opera a partir da manipulação de informações discretas, ou seja, de pequenos pulsos de energia interpretados como 0 ou 1 e submetidos a operações matemáticas. Sendo assim, de uma forma simplificada, pode-se dizer que os inputs denominam os dados que alimentam as operações e os outputs são os resultados obtidos.

Os inputs são normalmente adquiridos com a utilização de sensores, elementos responsáveis por converter as ações físicas em dados computáveis. Um exemplo básico são os botões que, a partir do toque (ação física), 
permitem ou impedem a passagem de energia. Da mesma forma que o botão reage ao toque, existem outros tipos de interruptores e controladores de corrente elétrica que reagem à presença, à ausência e mesmo à variação de luz, som, radiação etc. Não cabe aqui listar todos os tipos de sensores existentes, o importante é esclarecer sua função de tradutor ao converter diferentes tipos de energia em dados digitais.

“Um sensor responde a uma mudança de estado. 0 meio no qual o estado existe pode ser mecânico, elétrico, magnético, hidrostático, fluído, químico, luminoso ou lógico. A mudança pode ser um evento discreto, o alcance gradual de alguma fronteira ou o estabelecimento de um padrão. Efetivamente, mesmo o mais simples sensor mecânico serve essencialmente como um dispositivo lógico, o qual apenas reporta a ocorrência de uma mudança." 114 (McCULLOUGH, 2004,

Oposto aos sensores, os atuadores fazem o movimento inverso, convertem os outputs em ações físicas. Trata-se de "um componente que altera o estado de um sistema quando é ativado por condições apropriadas"115 (McCUllOUGH, 2004, p. 83). Nesse caso, elementos que emitem luz, som, movimento e mesmo os displays são exemplos comuns de atuadores. Normalmente são mais complexos de serem trabalhados pois podem demandar conhecimentos elétricos e mecânicos mais aprofundados.

Os sensores, fornecedores dos inputs, e os atuadores, manipuladores dos outputs, são elementos físicos que fazem as conversões necessárias, tanto para que a informação possa ser trabalhada quanto para que os resultados possam ser visualizados. 0 processamento encontra-se entre essas duas partes. Se for feita uma

${ }^{114}$ Do original: "A sensor responds to a change in state. The medium in which the state exists might be mechanical, electrical, magnetic, hydrostatic, flowing, chemical, luminous or logical. The change might be a discrete event, the gradual attainment of some threshold, or the establishment of a pattern. In effect even the simplest mechanical sensor intrinsically serves as a logic device, which simply reports whether a change has occurred." (McCULLOUGH, 2004, p. 75)

${ }^{115}$ Do original: "An actuator is a device that alters a system's state when it is triggered by appropriate conditions." (McCULLOUGH, 2004, p. 83) 
analogia com a matemática, o processamento seria representado pelas equações, os inputs seriam as variáveis da equação e os outputs seriam os resultados. 0 processamento dos dados decorre das rotinas descritas no ato da programação do sistema, sendo que escrevê-las é como delinear as equações para serem utilizadas, posteriormente, conforme os valores das variáveis são introduzidos.

A descrição apresentada mostra um sistema inteiramente linear: o dado entra, é processado e sai. Uma vez que a computação digital possui, como característica básica, o processamento em série dos dados, não há como fugir dessa linearidade, porém, na implementação de comportamentos de objetos interativos, outras características podem ser aproveitadas.

“Diferente dos humanos, os computadores podem fazer apenas uma coisa por vez. Entretanto, eles podem fazer as coisas muito mais rápido do que nós, então é possível para um computador completar diversas tarefas - por exemplo, ler um sensor, interpretar o resultado, usá-lo para ajustar a imagem na tela ou a posição de um motor, e preparar para lê-lo novamente - tudo antes que o humano que está interagindo com ele perceba que terminou de falar."116 (O'SULLIVAN; IGOE, 2004, p. Xx)

Os elementos descritos elucidam um pouco mais as dinâmicas que permeiam os objetos dotados de instâncias interativas virtuais. As descrições são fixas, porém é importante perceber que os lugares ocupados pelos elementos que conformam o sistema podem variar. Um microfone, por exemplo, possui a capacidade de captar e de emitir som, sua categorização como input ou output vai depender da forma como é inserido no objeto. Esta variação da função de um elemento no sistema é descrita no relato do workshop sobre sensores e atuadores low-

\footnotetext{
${ }^{116}$ Do original: "Unlike humans, computers can do only thing at a time. However, they can do things much faster than us, so it's possible for a computer to have completed several tasks - for example, reading a sensor, interpreting the result, using it to ajust the image on screen os the position of a motor, and preparing to read it again - all before the human that's interacting with it is aware that she's finished speaking." (O'SULLIVAN; IGOE, 2004, p. xx)
} 
tech organizado pelos arquitetos Usman Haque e Adam Somlai-Fisher. Segundo eles, a intenção original era desenvolver quatro protótipos a partir da apropriação da tecnologia presente em brinquedos: um sensor, um atuador, uma fonte de energia e um comunicador wireless. E sobre a experiência eles colocam:

“Conforme procedemos com o desenvolvimento do design, ficou claro que "sensores" também poderiam ser considerados "atuadores" dependendo da circunstância; "atuadores' poderiam em alguns casos serem considerados "fontes de energia"; uma "fonte de energia" com um interruptor seria na verdade um tipo de "sensor". Em adição, vários dispositivos são considerados wireless mesmo que seu aspecto wireless possa ser o menos interessante" 117 (HAQUE; SOMLAI-FISHER, 2005, p.3)

A questão que permeia essa preocupação não é a de ditar funções específicas para os diferentes elementos. Trata-se de defini-los de acordo com o movimento de entrada e saída em um determinado sistema. É importante que essa divisão seja entendida para que a descrição dos projetos interativos seja melhor interpretada e forneça insumos para o entendimento de outras propostas.

No caso dos projetos a serem descritos neste trabalho, o Affective Twins (Fig. 67-68) compreende dois objetos móveis utilizados como suporte a múltiplas tarefas do cotidiano, capazes de trocar informação entre si e com seus usuários. Sua posição, o ato de tocá-los ou permanecer perto estimulam uma série de respostas-padrões que podem ser visuais, auditivas ou sensitivas.

\footnotetext{
${ }^{117}$ Do original:"As we proceeded with the design development, however, it soon became clear that, depending on circumstance, 'sensors' might also be considered 'actuators'; 'actuators' could in some cases be considered 'power sources"; a 'power source' with a switch was actually a type of 'sensor'; and that many devices are considered wireless even though their wireless aspect might be the least interesting." (HAQUE; SOMLAIFISHER, 2005, p.3)
} 


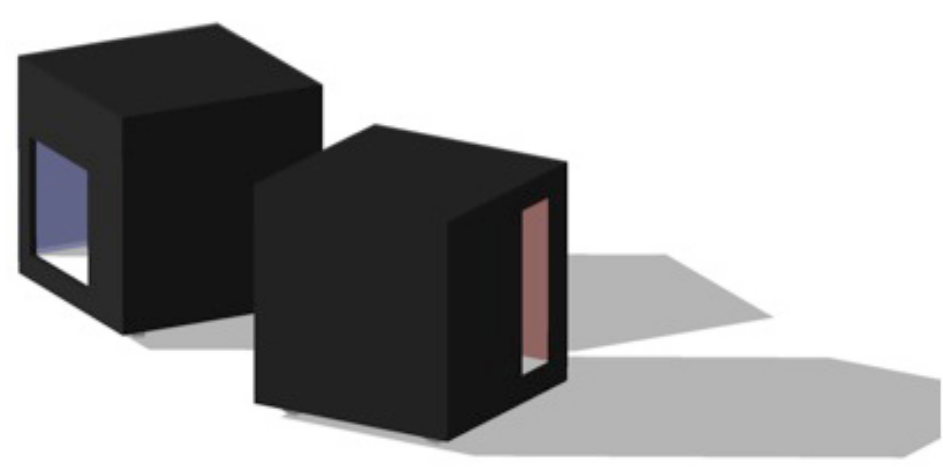

Fig. 67: Modelo virtual do projeto Affective Twins. Fonte: Gabriela Carneiro, 2007.
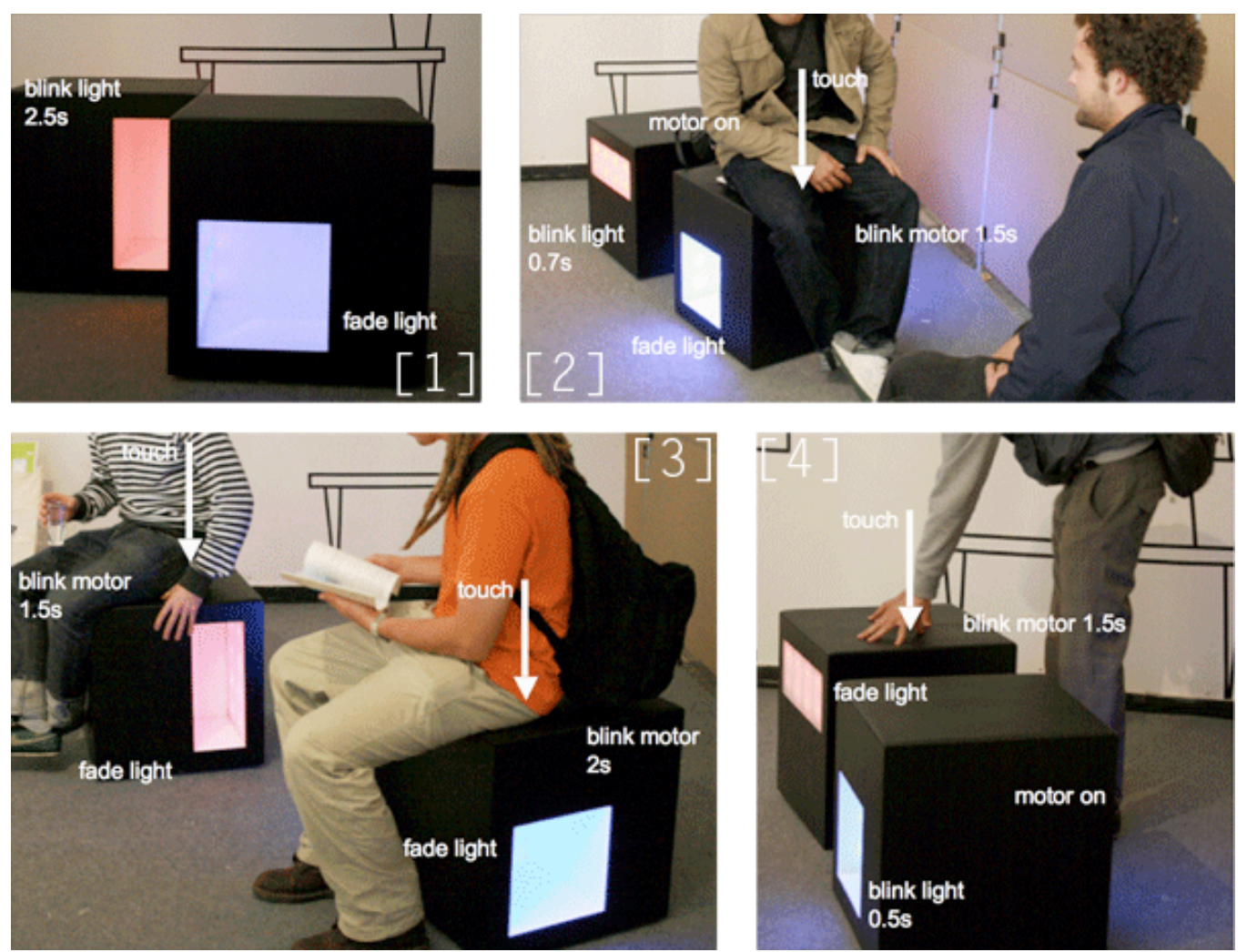

Fig. 68: Detalhamento do comportamento da peça de acordo com o uso. Fonte: Gabriela Carneiro, 2007. 
A narrativa explorada no projeto, direcionadora de todas as decisões tomadas ao longo de seu processo de criação, parte do princípio de que as duas peças são gêmeas e o usuário pode fazer parte e interferir nessa relação. Para isso foram desenvolvidas duas formas básicas - cubos de 50 X 50 X $50 \mathrm{~cm}$. - que assim como os gêmeos humanos, são praticamente idênticas quando vistas pelo ponto de vista exterior, porém buscam sua individualidade através de seu conteúdo interior. A semelhança entre eles é então interrompida por diferentes cores de luz e pela presença de duas aberturas com formatos distintos.

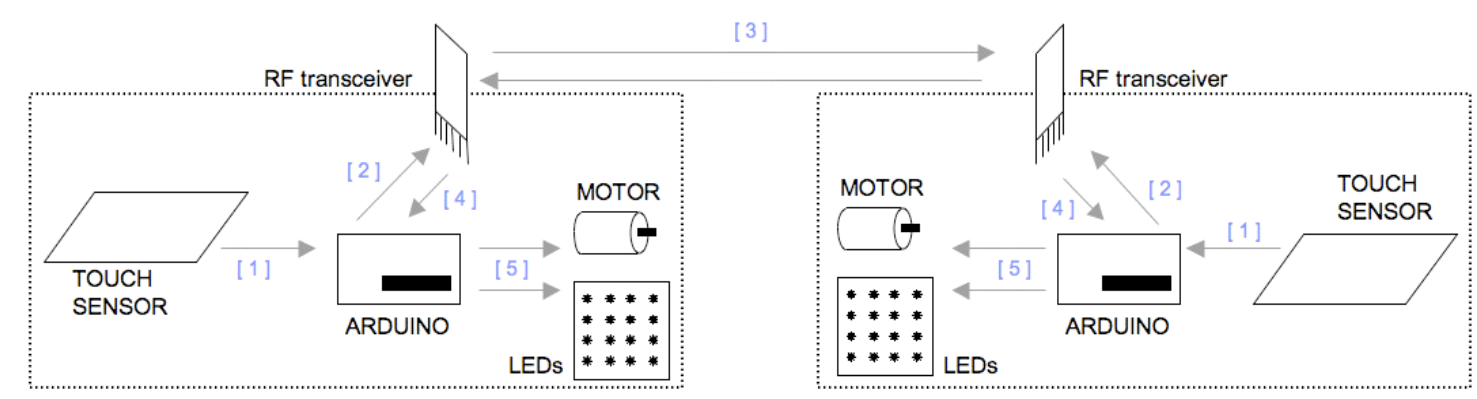

Fig. 69: Esquema do sistema responsável por controlar o comportamento da peça: [1] informação sobre o toque ou não-toque é transmitida para o microcontrolador; [2] este a guarda, ao mesmo tempo em que a repassa para o RF transciever [3] responsável pela troca de informação entre as peças; [4] a informação recebida do outro é adicionada àquela já guardada; [5] a união de ambas determinam padrões de funcionamento para o motor e para os LEDs. Fonte: Gabriela Carneiro, 2007.

O comportamento proposto foi implementado por meio de um sistema de sensores e atuadores, controlados por um microcontrolador (conforme esquema ilustrado na Fig. 69). A informação é obtida (input) por meio de dois sensores de toque localizados na superfície superior de cada peça. Estes repassam a informação para o microcontrolador que, através de uma placa de transmissão de rádio-freqüência, informa o que se passa ao mesmo tempo em que adquire a mesma informação do outro. A partir daí são definidos quatro comportamentos, ilustrados na imagem abaixo, de acordo com o uso, ou seja, se há o toque em um (fig. 68-2) , no outro (fig. 68-4), 
nos dois (fig. 68-3) ou em nenhum deles (fig.68-1). Estes comportamentos são expressos através de diferentes padrões de iluminação e vibração (output). A iluminação se dá por LEDs presentes nas aberturas de cada um e a vibração é alcançada com a utilização de um motor localizado no interior da peça. Ambos exibem diferentes padrões de funcionamento, de acordo com o comportamento estimulado.

O projeto PIX consiste na criação e montagem de um display de baixa resolução na fachada do edifício 001, sede do grupo de pesquisa Nomads.usp (Fig. 70-71). O prédio, inicialmente concebido como um protótipo de habitação social de três andares, possui uma divisão espacial que reflete preocupações do grupo sobre a necessidade de redesenho do espaço doméstico contemporâneo. Os LEDs foram introduzidos no interior da parte central do edifício, entre a cobertura translúcida de fibra de vidro e as escadas de acesso aos andares.
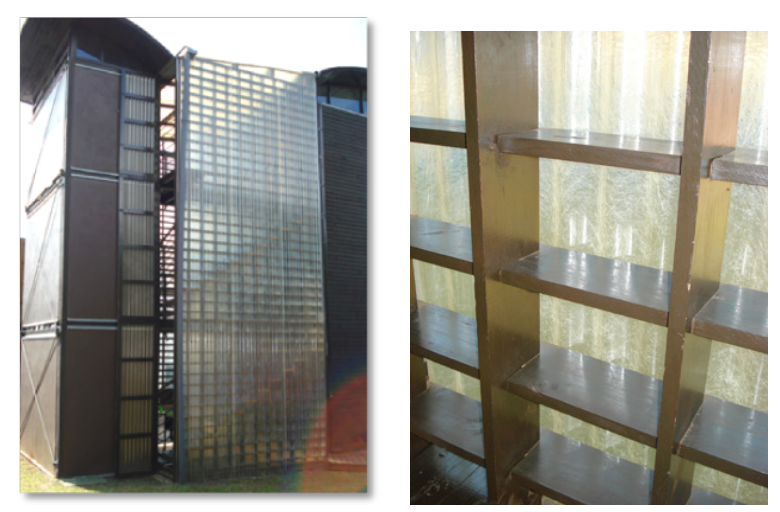

Fig. 70: Foto do edifício 001, sede do grupo Nomads.usp, local onde está sendo montada a instalação PIX.

Fig. 71: Imagem interna do edifício. Grelha na qual os LEDs foram montados. Fonte: Nomads.usp, 2008.

No total são 1200 LEDs agrupados de três em três, nas cores azul, vermelho e verde, controlados individualmente. 0 resultado é uma matriz composta por 10 X 40 conjuntos de LEDs, espalhados nos 2,8m X 10m da fachada, por meio da qual imagens e animações luminosas podem ser visualizadas. Os padrões luminosos 
podem ser gerados a partir de um editor de animações desenvolvido como uma interface gráfica que será disponibilizada através da Internet (Fig. 72-74) . A idéia é trabalhar a integração do espaço físico e do informacional, de modo que, mais do que funcionar como um painel conectado à Internet, o projeto integre o display à estrutura, e assim se torne indissociável do edifício. 0 display funciona como um grande atuador (output), controlado por um microcontrolador que recebe as informações (input) das animações produzidas através da interface gráfica (Fig. 75).
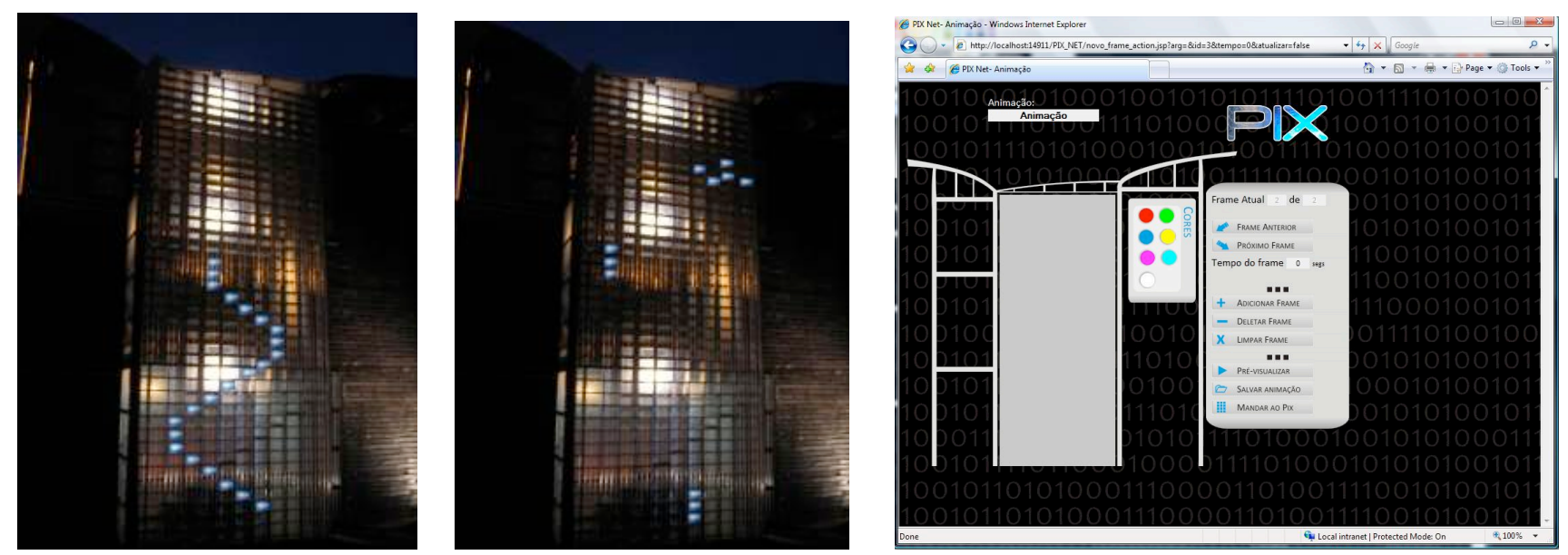

Fig. 72 e 73: imagens de animações produzidas para testes.

Fig. 74: versão preliminar da interface web. Fonte: Nomads.usp, 2008.

A utilização da interface gráfica para gerar o input da fachada compreende apenas a primeira solução implementada. Isso foi feito com o intuito de sanar a necessidade imediata de possibilitar a experimentação de diferentes padrões luminosos pelas pessoas, sem elas terem de programar dispositivos para essa finalidade. Diferentes efeitos da iluminação poderão ser testados e pré-visualizados antes que proposições mais complexas sejam implementadas. 


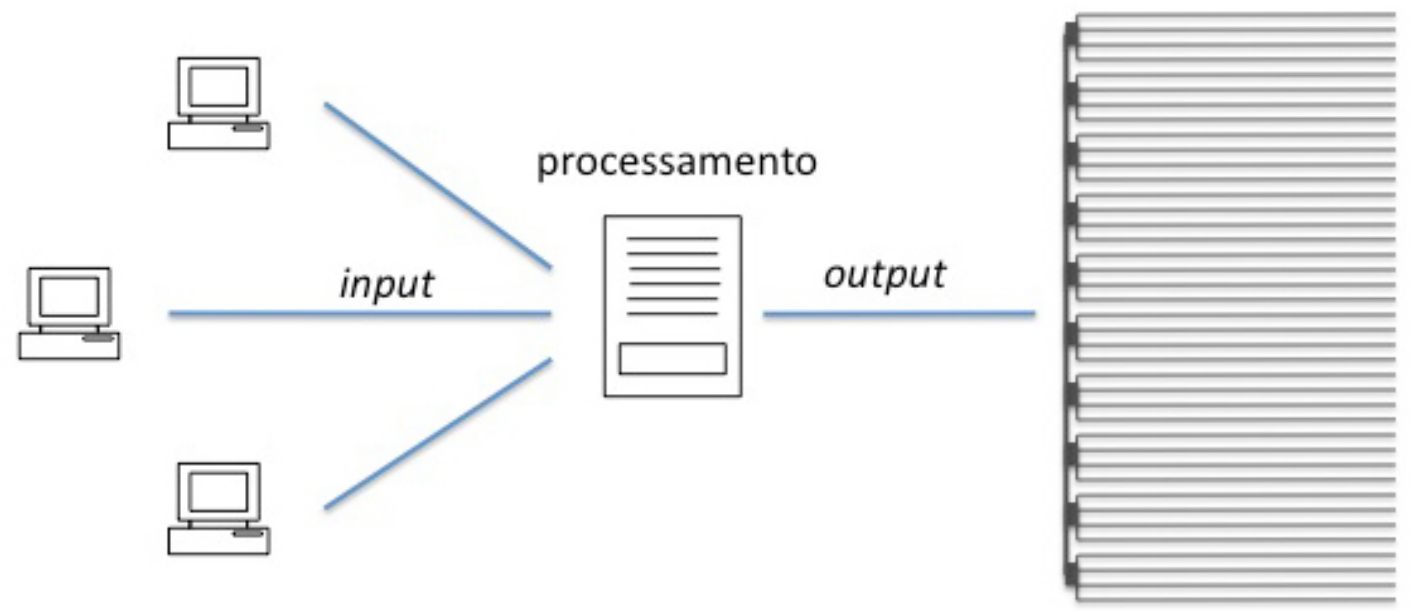

Fig. 75: esquema do projeto com a indicação do input (via web), processamento (utilizando um microcontrolador) e do output (cada linha contém 10 LEDs). Fonte: Nomads.usp, 2008.

Esse fato acentua o caráter múltiplo da proposta. Ela não apenas é um experimento de inserção de mídias digitais no edifício como também se estabelece como uma plataforma para que outras pesquisas se apropriem da estrutura montada e proponham diferentes tipos de interação. Nesse caso, a fachada se tornaria um grande output na espera de diferentes tipos de inputs, além da interface já implementada.

\section{2 | Objeto, processo, interação}

Os projetos Affective Twins e PIX englobam diversos aspectos discutidos ao longo deste trabalho. Uma análise detalhada dessas experimentações permite a retomada de alguns pontos importantes, a introdução de outros e o aprofundamento nas questões que se mostram relevantes para a criação e compreensão deste tipo de proposta. Para isso, serão explicitadas características dos objetos como interfaces tangíveis, dos seus processos de criação e das interações que eles mediam. 
Como já foi dito, os objetos que interessam para esta pesquisa são aqueles dotados da capacidade de processamento da informação digital. Também foi dito que as preocupações que norteiam este trabalho vão além das interfaces desenvolvidas para os computadores pessoais e alcançam a aplicação da computação em outros domínios do cotidiano, ou seja, nas diferentes escalas de intervenção. A ubiqüidade da computação é então trabalhada de forma a indicar caminhos sobre "como a tecnologia da informação deve ser movida do centro do foco de nossa atenção para a periferia; e, ao contrário, como certos contextos se tornam responsivos com a adição da tecnologia."118 (McCULLOUGH, 2004, xiv)

Para dar suporte a esta argumentação, discorreu-se especificamente sobre as interfaces tangíveis (TUI) e sua principal busca, a de dar forma física à informação digital. Isso foi feito pois as interfaces tangíveis se configuram como um campo de pesquisa que vem se consolidando a partir da segunda metade da década de 1990, sendo que em, 2007 os produtos dessa aproximação foram assim descritos na chamada da primeira conferência internacional sobre interação tangível, a International Conference on Tangible and Embedded Interaction ${ }^{119}$ :

“Com o avanço da tecnologia, a computação tem progressivamente se deslocado para além do desktop em novos contextos físicos e sociais. Enquanto os artefatos físicos adquirem novos comportamentos computacionais, eles se tornam reprogramáveis, customizáveis, repropositáveis [no sentido que seu propósito é recolocado], e interoperáveis em ecologias ricas e contextos diversos"120 (TEI'2007)

\footnotetext{
118 Do original: "how information technology must be moved from the Center o four focal attention into the periphery; and conversely, how certain contexts become responsive through the addition of technology." (McCULLOUGH, 2004, xiv)

${ }^{119}$ Mais informações, disponíveis no web-site da conferência: <http://tei-conf.org/>

120 Do original: "With technological advances, computing has progressively moved beyond the desktop into new physical and social contexts. As physical artifacts gain new computational behaviors, they become reprogrammable, customizable, purpose, and interoperable in rich ecologies and diverse contexts." (TEI'2007)
} 
A partir dessa discussão e da compreensão do tema colocado por Iroshi Ishii no seu artigo mais recente “Tangible Bits: Beyond Pixels", analisado no segundo capítulo deste trabalho, foram elaborados dois esquemas, referentes ao projetos analisados neste capítulo, Affective Twins e PIX. Os esquemas foram baseados em dois outros apresentados pelo autor e permitem uma análise mais minuciosa da idéia e dos projetos como interfaces tangíveis.
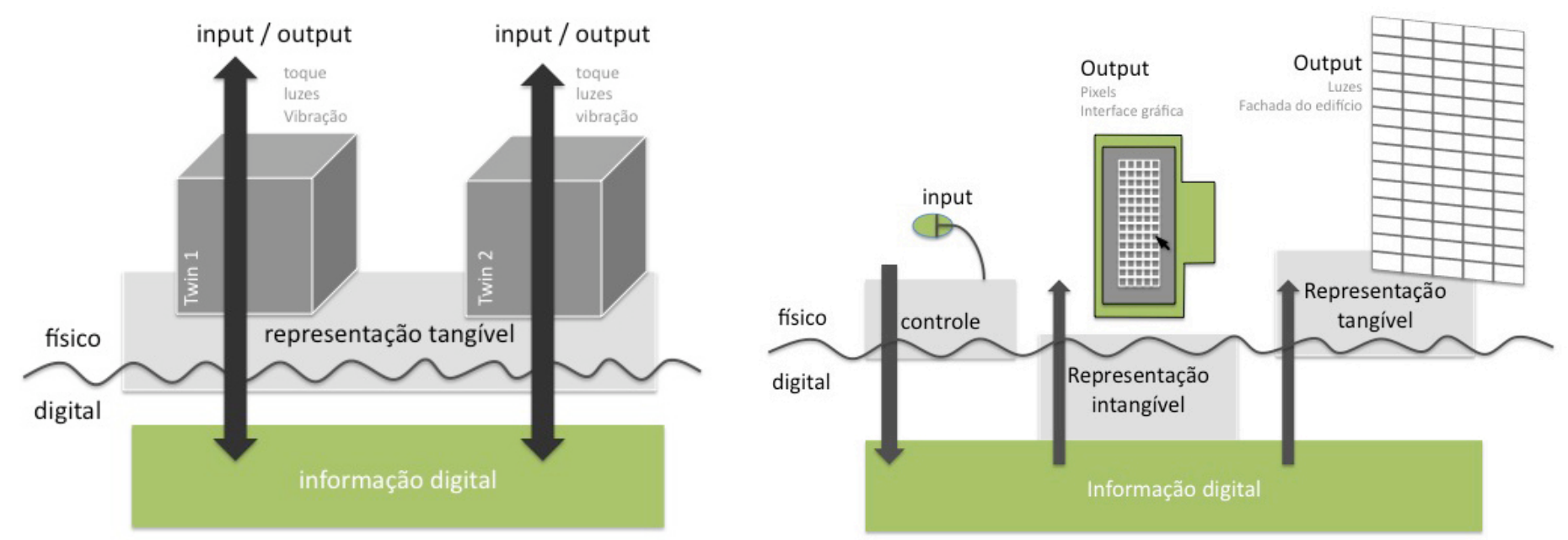

Fig. 76: Esquema analítico da tangibilidade do projeto Affective Twins.

Fig. 77: Esquema analítico da tangibilidade do projeto PIX. Fonte: Nomads.usp, 2008.

No projeto Affective Twins (Fig. 76), a tradução da informação digital é feita unicamente por meio de uma interface tangível, caracterizada pela possibilidade de interação corporal durante sua movimentação e seu uso. 0 input e output se sobrepõem, de modo que "a forma física serve como ambos, representação e controle, para suas contrapartidas digitais"121 (ISHII, 2008, p. xvi). Assim, outras partes do corpo além das mãos, dos olhos e da audição são também engajadas na interação com a informação digital presente no objeto em questão.

${ }^{121}$ Do original: "The physical forms serve as both representations and controls for their digital counterparts" (ISHII, 2007, p. xvi) 
Na primeira implementação do projeto PIX, na qual os padrões luminosos são enviados à fachada a partir de um web-site, representações tangível e intangível se sobrepõem. Se o esquema mostrado (Fig. 77) se resumisse apenas às duas primeiras partes, caracterizadas pelo controle e pela representação intangível, a interação se daria com uma imagem da fachada e nada diferenciaria do uso cotidiano do computador pessoal. Dessa forma, o acesso ao universo digital continuaria “confinado à tela plana e quadrada e aos pixels, ou 'bits pintados'”122 (ISHII, 2008, p. xv). O foco no desenvolvimento de uma representação tangível, configurada pela estrutura instalada na fachada, altera expressivamente o significado do projeto e permite uma maior compreensão do que são, de fato, as interfaces tangíveis.

Ver uma representação gráfica da fachada do edifício na tela do computador e visualizar nessa representação os padrões luminosos, difere completamente da experiência de ter contato com a fachada física funcionando. A representação intangível é necessária para possibilitar o acesso remoto ao projeto e para que experimentações das possibilidades da fachada como output sejam feitas. Porém o interesse maior é no desempenho da porção física do projeto.

Essa análise a partir do esquema apresentado abre caminhos para a visualização do que seria tornar também o input do projeto tangível. Se as animações feitas pelos usuários fossem guardadas em um banco de dados e o acesso a esse banco se desse, por exemplo, através da manipulação física de objetos, por meio da movimentação das pessoas no campus ou mesmo a partir do som emitido pelo andar das pessoas nas redondezas da fachada, nesse caso o input também passaria ter um elemento caracterizado como interface tangível. 0 acesso às informações guardadas seria uma atividade conferida ao corpo como um todo.

\footnotetext{
${ }^{122}$ Do original: "confined to flat, square screens and pixels, or 'painted bits'." (ISHII, 2007, p. xvi)
} 
É evidente que, neste caso, fala-se de uma solução específica, para uma proposta única. Diversas interfaces gráficas poderiam ser desenvolvidas com a utilização de um mesmo computador; por outro lado, cada interface tangível é desenvolvida para aplicações exclusivas. Conforme aponta Iroshi Ishii, as interfaces tangíveis "servem como uma interface para finalidades especiais para aplicações específicas usando formas físicas explícitas, enquanto as GUI [Graphical User Interface] servem como uma interface de finalidade geral ao emular várias ferramentas usando os pixels em uma tela."123(ISHII, 2008, p. xvi) [grifo nosso]

Os caminhos para se chegar à proposição dos projetos em questão também devem ser considerados. Nesse sentido, alguns pontos merecem ser destacados: um diz respeito à necessidade de trânsito entre conhecimentos fundamentalmente distintos e o outro compreende à não-linearidade do processo de criação dos objetos. Cada projeto foi desenvolvido em momentos e contextos específicos, porém, para esta pesquisa, mais interessante do que ressaltar essas condições é descrever e examinar algumas questões nutridas pela prática.

No caso do projeto Affective Twins, o projeto foi desenvolvido por uma única pessoa, arquiteta, com o auxílio de outros na resolução de seus aspectos específicos. A parte mais desafiadora de todo o processo foi o contato com a questão técnica da interação. Para um profissional da área da arquitetura e do design, o raciocínio por trás da programação de sensores, atuadores e microcontroladores mostra-se bastante abstrato, uma vez que difere completamente daquele empregado no desenho de edifícios e produtos. Existe um bloqueio inicial e desafiador no qual se deve passar a raciocinar de outra forma, porém o aprofundamento neste campo traz benefícios inigualáveis para o entendimento das questões que permeiam as tecnologias como um todo. "O design desses sistemas requer um pensamento interdisciplinar. Sua criação deve não apenas englobar software, eletrônica e

\footnotetext{
${ }^{123}$ Do original: "Tangible User Interface serves as a special purpose interface for a specific application using explicit physical form, while GUI serves as a general purpose interface by emulating various tools using pixels on a screen"
} 
mecânica, mas também a forma física e o comportamento do sistema, seu ambiente social e físico, e outros"124 (TEI'2007).

A partir da idéia inicial, o projeto desenvolveu-se através do aconselhamento dos professores e diálogo com colegas. A primeira diretriz obtida sobre o trabalho com a tecnologia diz respeito ao uso desta como meio de expressão, porém com a cautela de não deixar as motivações iniciais se perderem no meio das soluções técnicas. O sentido que rege a proposta deve ser alcançado reduzindo ao máximo a tecnologia empregada.

O desenho da peça e da interação procurou interpretar de forma simples e coerente a relação que se estabelece entre gêmeos e o ambiente que os circunda. Desta forma, introduziu-se uma narrativa a ser contada através da proposta, levando o objeto para além da questão funcional presente em um mobiliário. Este princípio delineou todas as decisões tomadas ao longo do desenvolvimento e produção do projeto. A partir daí, seguiu-se uma série de experimentações paralelas (Fig. 78-101). Narrativa, forma, materialidade e interação foram trabalhadas concomitantemente, sendo que cada decisão tomada em uma dessas instâncias afetou diretamente as outras. A instância digital deixou de ser um anexo, incorporado posteriormente por algum especialista técnico, e passou também a influenciar a criação do objeto como um todo. E assim, a camada digital tornou-se passível de ser manuseada tanto quanto todas as outras. "Na medida em que os artefatos eletrônicos se proliferam, torna-se mais importante para os designers considerar novas formas de interação com essas máquinas. 0 trabalho com a eletrônica é um componente essencial para a comunidade de design interativo emergente."125 (REAS; FRY, 2007, p.633)

\footnotetext{
${ }^{124}$ Do original: "Designing such systems requires interdisciplinary thinking. Their creation must not only encompass software, electronics, and mechanics, but also the system's physical form and behavior, its social and physical milieu, and beyond."(TEI'2007)

125 Do original: "As electronic devices proliferate, it becomes increasingly important for designers to consider new ways to interact with these machines. Working with electronics is an essential component for the emerging interaction design community". (REAS; FRY, 2007, p.633)
} 

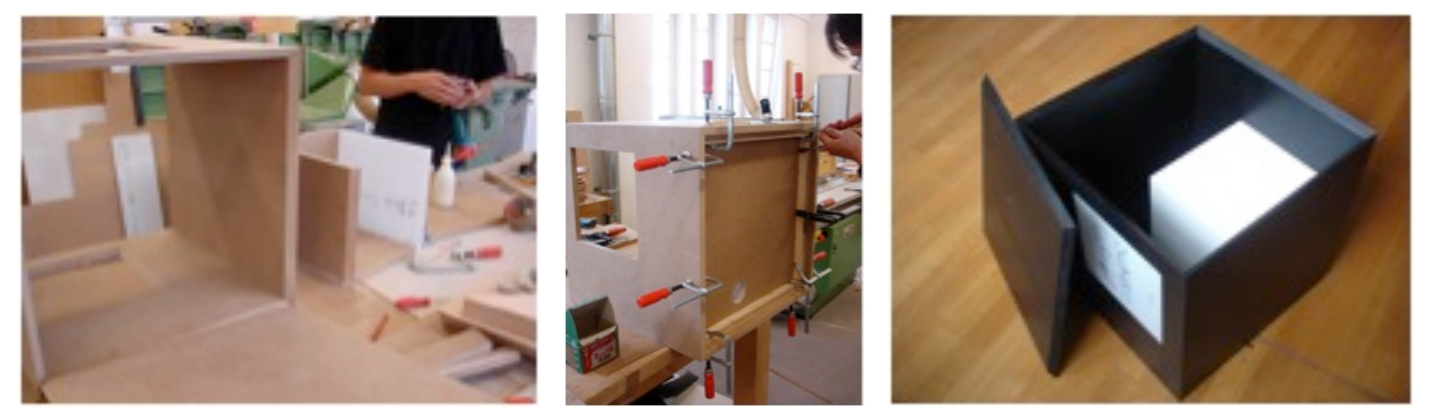

Fig. 78-80: Detalhes da construção dos cubos: a estrutura do projeto foi construída em MDF de $2 \mathrm{~cm}$ de espessura. As partes foram cortadas e coladas com cola própria para madeira, depois foram lixadas e pintadas utilizando tinta preta fosca no cubo e tinta branca brilhante para o volume interno (para que esse refletisse a luz dos LED's). Como se tratava de uma primeira experiência o desenho foi feito com o cuidado de deixar bastante espaço no interior da peça para facilitar a posterior colocação dos componentes. Fonte: Gabriela Carneiro, 2007.

Neste caso, pode-se dizer que existe uma forma híbrida de aproximação na qual o profissional transita por duas linguagens fundamentalmente distintas. Por um lado, lida-se com aspectos familiares relacionados à forma e materialidade de um objeto ou de uma espacialidade. Por outro, o trabalho com a tecnologia envolve conhecimentos de aspectos de programação e eletrônica, baseados em uma lógica e linguagem que não fazem parte da formação e do cotidiano desses profissionais. A união dessas duas capacidades possibilita a apropriação das tecnologias digitais como meio de expressão de forma mais completa e fornece assim possibilidades de desenvolvimento para ambas as áreas do conhecimento. Trata-se de romper as barreiras e preconcepções existentes nas diferentes áreas do conhecimento. 

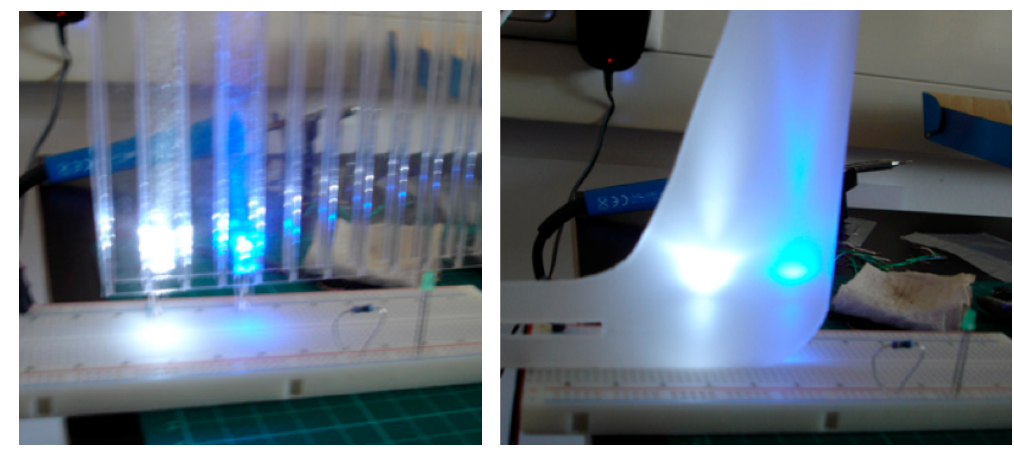

Fig. 81 -82: Testes de reflexão em diferentes materiais, para utilização no fechamento das aberturas: foram feitos estudos em diversos tipos de materiais para depois escolher aquele cujo efeito de dissipação da luz fosse melhor. Foi escolhido então o acrílico fosco com $5 \mathrm{~mm}$ de espessura (Fig. 81). O material foi cortado e instalado com a aplicação de silicone ao longo de seu perímetro. Fonte: Gabriela Carneiro, 2007.
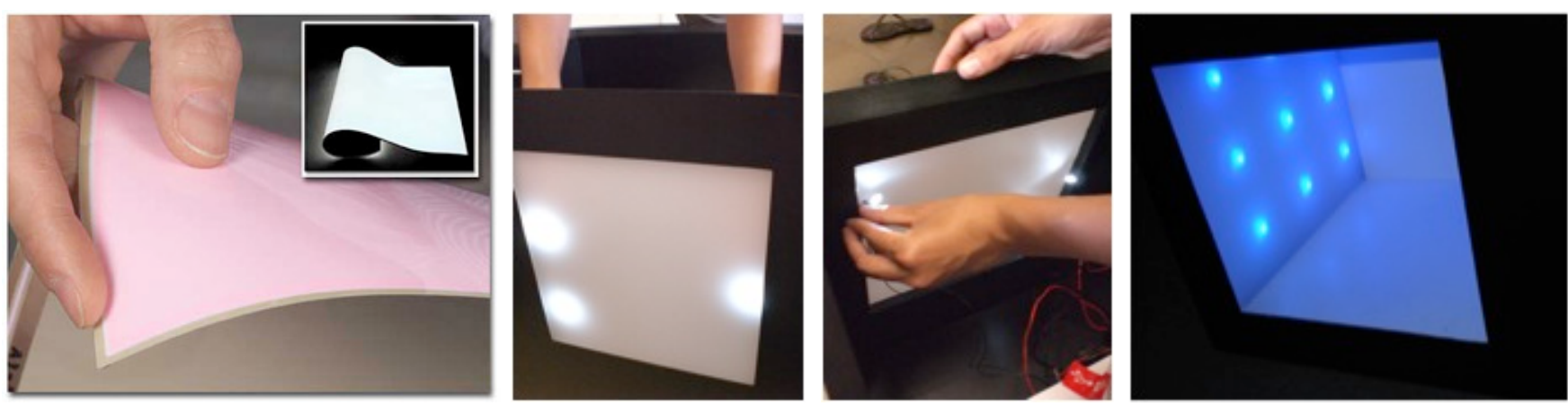

Fig. 83: Folha eletroluminescente: Como primeira opção de iluminação para a peça foram testadas folhas eletroluminescentes, uma opção interessante pelo efeito que proporciona e pelo baixo gasto de energia, porém seu uso foi descartado devido à dificuldade de aquisição e alto custo.

Fig. 84-85: Testes com os LED’s no projeto para verificar sua posição de instalação na peça, mais econômicos e fáceis de serem encontrados

Fig. 86: Resultado final em uma das peças. Fonte: Gabriela Carneiro, 2007. 

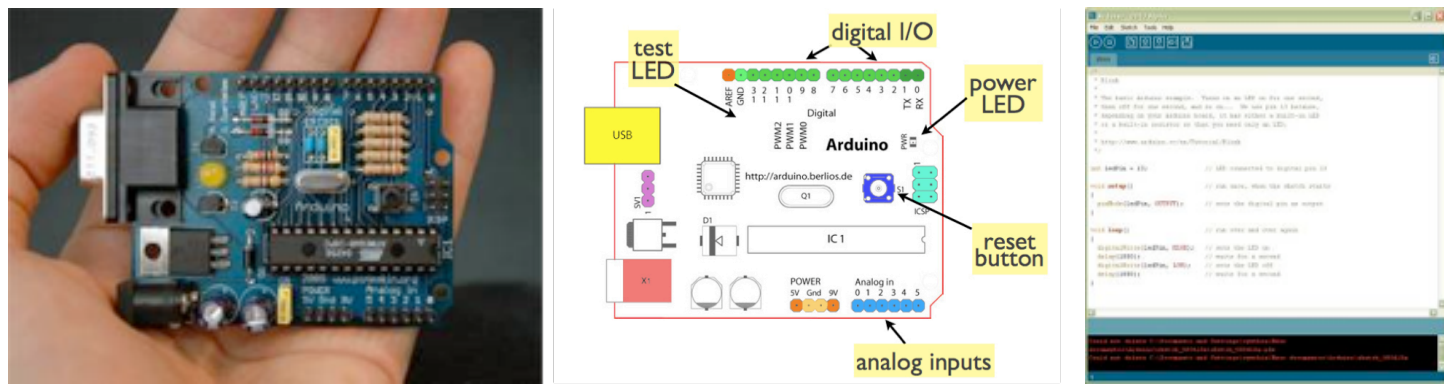

Fig. 87: Para controlar a peça foi utilizado o Arduino, um hardware de prototipagem de eletrônica desenvolvido com código aberto, utilizado por artistas, designers e pessoas interessada em criar objetos e ambientes interativos.

Fig. 88: Esquemática da placa.

Fig. 89: Para sua programação foi utilizado o software Arduino, um ambiente de programação com código aberto para o hardware Arduino, utilizado para escrever e gravar o código na placa I/O. O ambiente é escrito em Java e baseado no Processing, avr-gcc e outros software open-source. A escolha de uso desta placa se deu devido à sua grande popularidade, existem diversos fóruns e muita documentação na Internet sobre projetos, e também ao tipo da linguagem de programação, acessível para as pessoas que não tem experiência com este tipo de prática. Fonte: $\langle$ http://www.arduino.cc >.
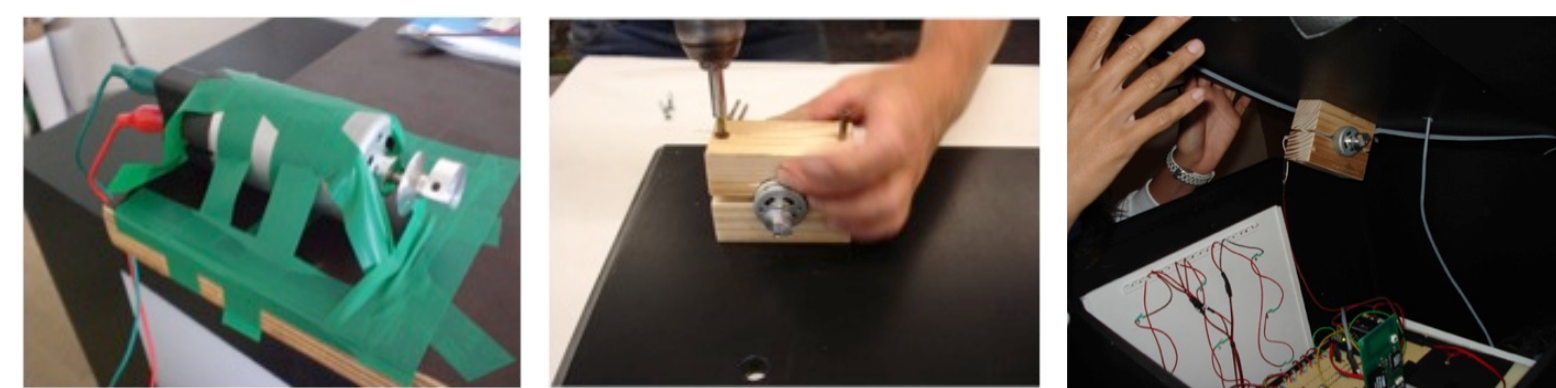

Fig. 90: Para a vibração foi utilizado um motor de alto giro no qual foi adicionado um peso que tira sua centralidade e causa a sensação de vibração. Esta é a mesma prática utilizada em telefones celulares quando colocados no "modo vibra". No caso do projeto o motor foi utilizado tanto para vibração quanto como estímulo sonoro. A imagem mostra o motor fixado na mesa com fitas para teste.

Fig. 91: Instalação do motor: um cuidado especial foi tomado na sua instalação para que o motor não se soltasse durante o uso da peça. Uma pequena estrutura de madeira foi adicionada para garantir sua imobilidade.

Fig. 92: Imagem do interior da peça final com o motor instalado no tampo. Fonte: Gabriela Carneiro, 2007. 

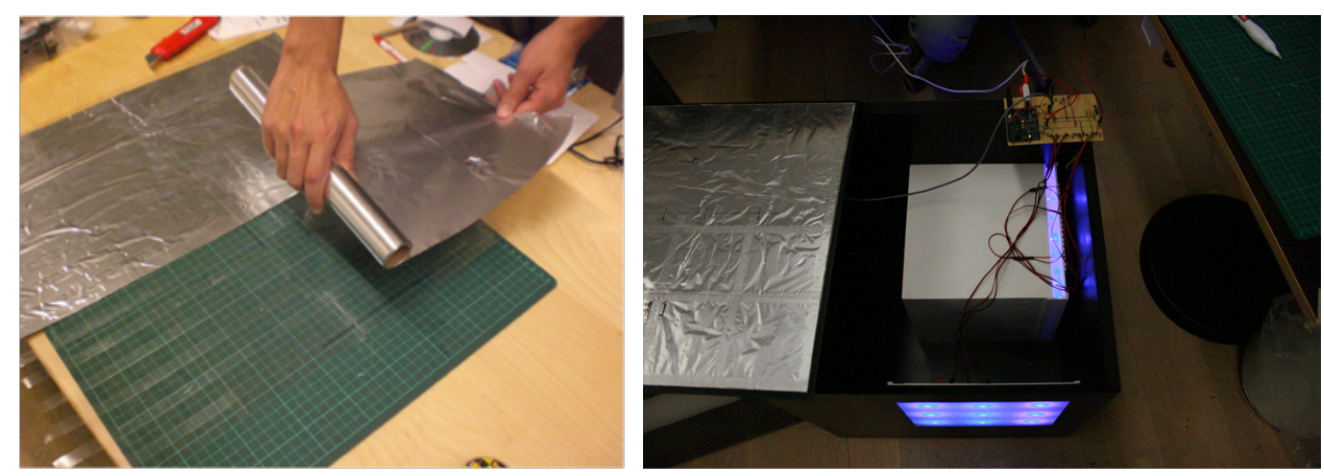

Fig. 93: Sensor de toque: o sensor de toque foi construído manualmente com duas superfícies de plástico nas quais foram fixadas camadas de papel alumínio (uma em cada parte), com espumas separadoras entre elas e disposto no tampo do objeto. Do meio do sensor sai um cabo que é conectado com o circuito central da peça. A imagem mostra a fixação do alumínio em uma das superfícies plásticas com a utilização de fita adesiva dupla face.

Fig. 94: Primeiros testes do sensor já conectado ao circuito central e LED's. Quando há o toque, uma cada de alumínio encosta na outra e permite a passagem de energia. Fonte: Gabriela Carneiro, 2007. Fonte: Gabriela Carneiro, 2007.
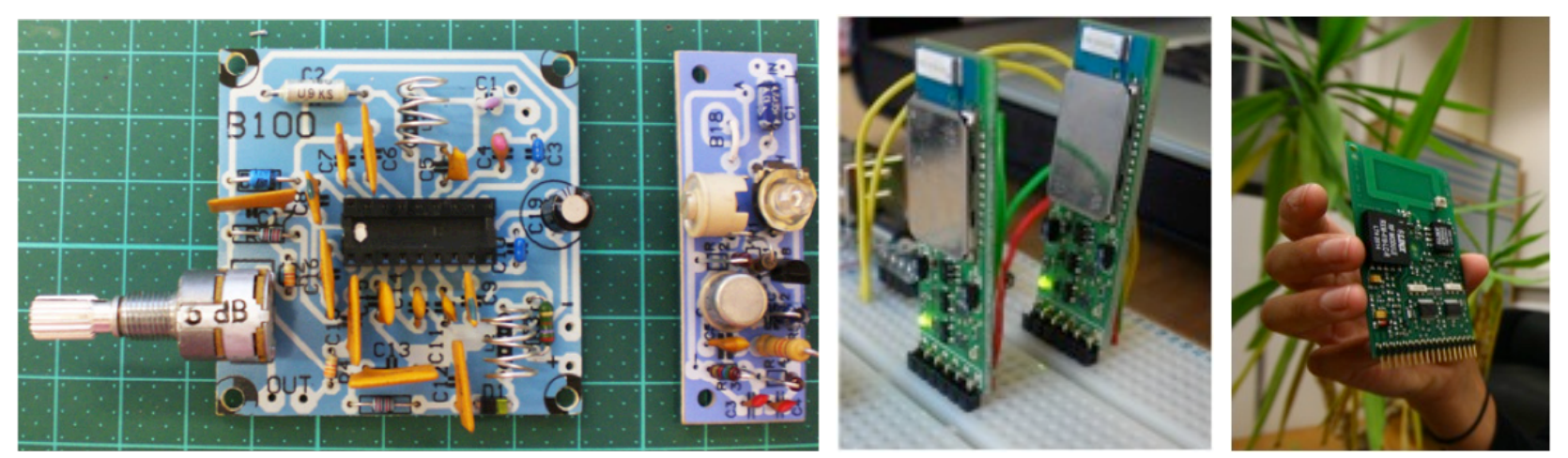

Fig. 95: Para a comunicação entre as peças, várias possibilidades foram testadas. Primeiro foi testado um emissor e receptor comum de rádio sendo que o resultado não foi satisfatório devido à instabilidade e baixa qualidade do módulo utilizado.

Fig. 96: Foram testados módulos blue tooth, cujo resultado foi satisfatório mas sua programação mostrou-se muito complexa.

Fig. 97: Por fim foi utilizado um módulo transceiver (transmissor + receptor) de rádio freqüência utilizado [400 mhz RF (Radio Frequence) Transceiver (Parallax)].O trasnceiver funciona como um botão que se conecta remotamente, o valor do output (ligado/desligado; 0/1) de um pino de um Arduino é transmitido para o pino de input do outro que é então processado pela placa. Fonte: Gabriela Carneiro, 2007. 

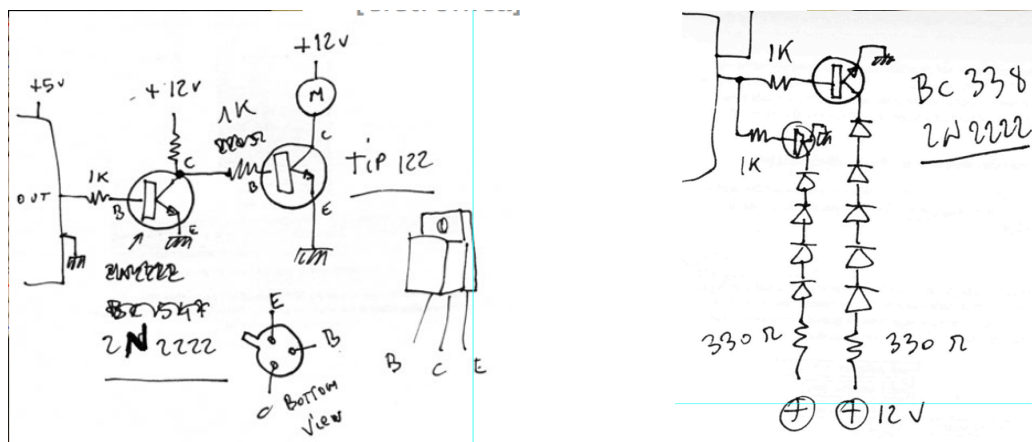

Fig. 98: O circuito compreende a parte elétrica responsável por unir os diferentes inputs e outputs com a placa microcontroladora. Ele é responsável por conduzir a energia e alterá-la quando necessário. Nele que se encontram os resistores, capacitores, transistores e diodos utilizados para manter o equilíbrio e comunicação do sistema. A figura ilustra a esquemática da ligação da placa microcontroladora com o motor.

Fig. 99: A figura ilustra a asquemática da ligação dos LED's com a placa microcontroladora e com a energia. Fonte: Gabriela Carneiro, 2007.
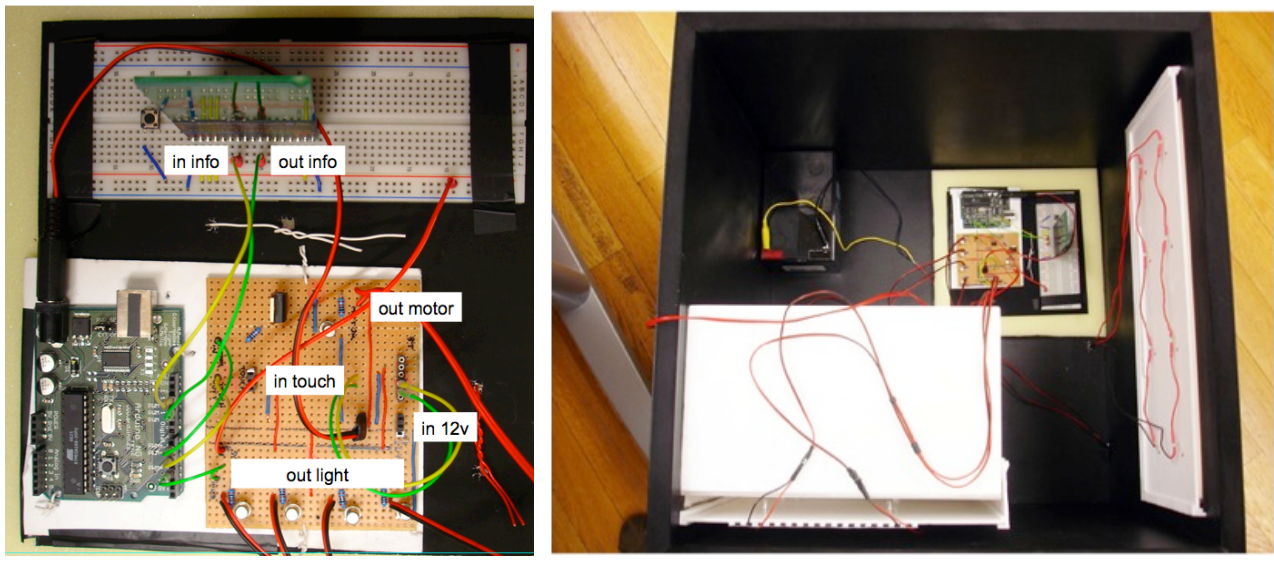

Fig. 100: Imagem da versão final do circuito, conectado com o Arduino e com o módulo transceiver. Fig. 101: Imagem do interior da peça com a bateria no canto superior esquerdo. Como fonte de energia foram utilizadas baterias de $12 \mathrm{~V}$ recarregáveis (uma em cada peça). A ausência de fios era essencial para a movimentação da peça. Durante a exposição a peça funcionava o dia inteiro e durante a noite era colocada para recarregar. Fonte: Gabriela Carneiro, 2007. 
Assim sendo, no processo de criação do projeto Affective Twins o aspecto analisado consiste na diligência das diferentes linguagens e lógicas que compõem o objeto. Uma análise do projeto PIX leva essa preocupação a um nível acima. A dimensão do projeto, sua complexidade e a variedade de pessoas envolvidas na sua execução faz com que a principal preocupação passe da pluralidade do objeto para o agenciamento dos conhecimentos individuais que cada pessoa traz consigo quando inserida no processo. Como aponta Ira Greenberg, normalmente:

“Para não-programadores, o código é uma construção misteriosa e intimidadora, agrupada na categoria de coisas muito complicadas, geeky126 ou consumidoras de muito tempo de aprendizado. No outro extremo, para alguns programadores profissionais, o código é visto apenas como uma ferramenta para resolver problemas técnicos; certamente não um meio criativo"127 (GREENBERG, 2007, p. xxii)

O grande desafio estabelecido no processo de criação do projeto PIX foi o de diminuir as distâncias entre os diferentes campos disciplinares e trazer os diversos agentes (profissionais) envolvidos para participar do processo como um todo. Esta idéia reafirma a consideração colocada por Malcolm McCullough ao dizer que "quando a tecnologia da informação se torna parte da infra-estrutura social, ela demanda uma reconsideração do design por um grande número de disciplinas"128 (McCULLOUGH, 2004, xiv). Essa reconsideração concerne tanto a sua recolocação no processo como também à abertura para o diálogo constante entre diferentes campos do conhecimento. Quanto mais as partes se ativerem a aprender a linguagem das outras disciplinas, maior será o ganho do processo.

${ }^{126}$ Geek é uma gíria do Inglês Norte-Americano para descrever pessoas aficcionadas por computadores.

127 Do Original: "For nonprogrammers, code is a mysterious and intimidating construct that gets grouped into the category of things too complicated, geeky, or time-consuming to be worth learning. At the other extreme, for some professional programmers, code is seen only as a tool to solve a technical problem - certainly not a creative medium" (GREENBERG, 2007, p. xxii)

${ }^{128}$ Do original: "When information technology becomes a part of the social infrastructure, it demands design consideration from a broad range of disciplines." (McCULLOUGH, 2004, xiv) 
A criação do projeto PIX consistiu na integração de três frentes de trabalho: uma responsável pela estrutura, outra pelo circuito e uma terceira pela sua interface web (Fig. 102-118). Neste processo, as fases clássicas de concepção, desenvolvimento e produção são integradas em um procedimento único, no qual ocorre a relação interdependente entre intencionalidade projetual, expectativas comunicacionais e participação dos envolvidos no processo.

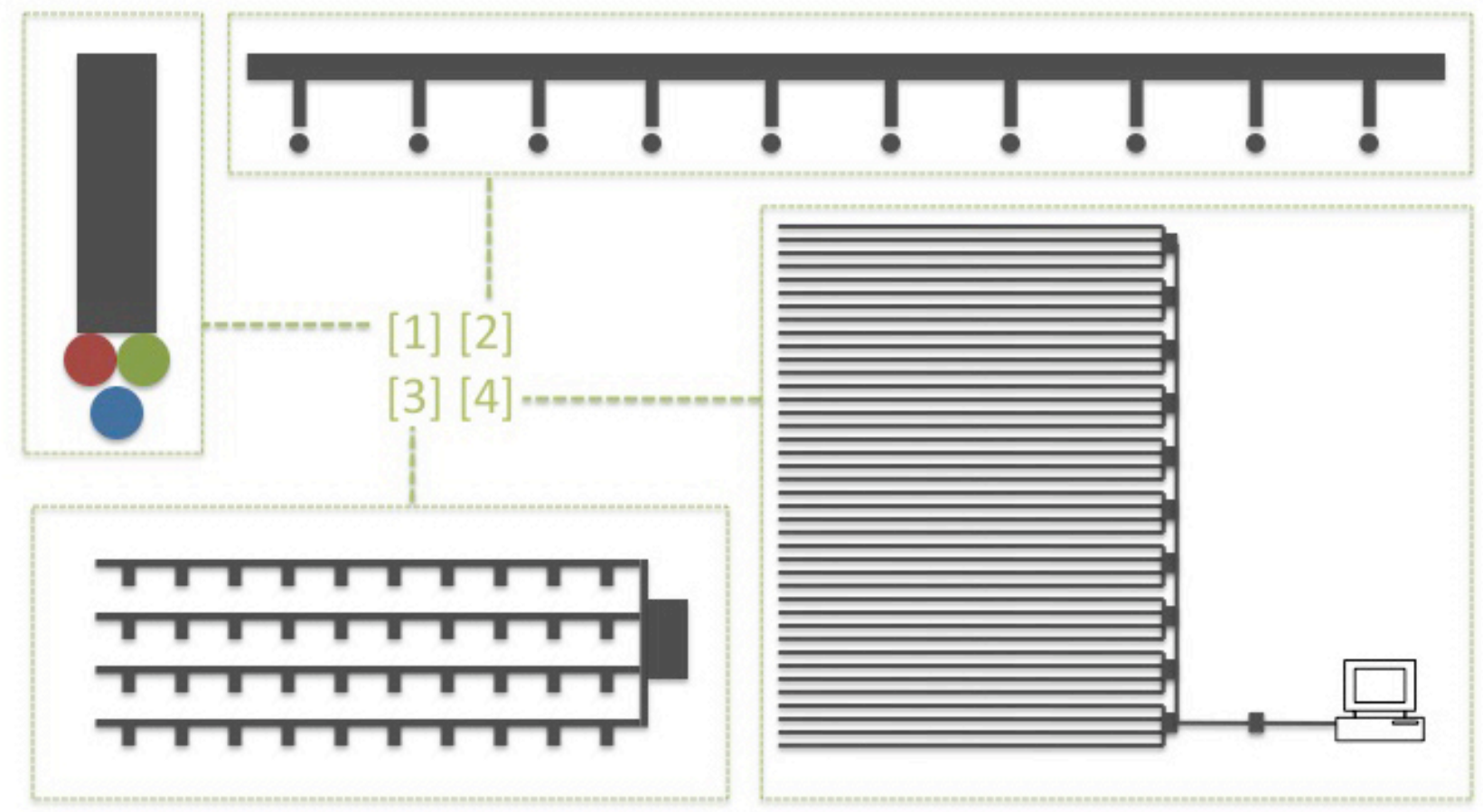

Fig. 102: Neste esquema é possível entender as partes que compõem o projeto PIX: [1] são 400 estruturas de suporte para os 1200 LEDs do projeto. [2] As estruturas são espalhadas nas 40 linhas da grelha. [3] Cada conjunto de quatro linhas é conectado a uma caixa que contém três placas nas quais conjuntos de 5 shift registers são os reponsáveis por comandar o acionamento ou não de cada LED. [4] Os dez conjuntos de quatro linhas são conectados a uma outra caixa na qual estão os multiplexadores e o microcontrolador. A caixa é então conectada a um computador que envia, periodicamente, os dados das animações.

Fonte: Nomads.usp, 2008. 
O desenvolvimento da estrutura compreendeu a construção de toda a parte física do projeto e sua instalação na fachada da casa. 0 circuito compreendeu a eletrônica, ou seja, é o cérebro de todo o projeto, responsável em traduzir as informações recebidas (input) no comando de acendimento ou não de cada LED da estrutura (output). A interface web possibilitou a criação e edição de pequenas animações de padrões luminosos para serem mostradas na grelha de LEDs.

Todo o trabalho foi realizado por uma equipe multidisciplinar que envolveu arquitetos, designers, cineasta, físico e cientistas da computação, permitindo uma constante revisão das idéias e de sua execução, enriquecendo o processo e o próprio objeto. A participação de diversos pesquisadores em equipe proporciona aprendizagem e diálogo, e promove um processo transdisciplinar, no qual as responsabilidades são coordenadas de forma horizontal. A horizontalidade pressupõe o reconhecimento de cada um dentro do processo, assim como de competências e de responsabilidades. Matthew Fuller e Usman Haque falam de um processo no qual "Isto não necessariamente confere responsabilidades similares para todos os participantes em um sistema, mas ao contrário, presume que enquanto hierarquias formadas pela experiência, capacidade e aptidão são inevitáveis, elas não são imutáveis."129 (FULLER; HAQUE, 2008, p.18)

No caso do projeto PIX, o arquiteto, responsável pelo gerenciamento dos saberes, esteve sempre ciente do andamento das diversas frentes de trabalho e promoveu o diálogo entre elas. Por mais que exista alguém responsável pelo gerenciamento do processo de criação, é importante colocar que, em uma perspectiva horizontal, este papel é tão importante e influente no resultado final, como todos os outros. No caso do projeto PIX, sua configuração final é conseqüência das pessoas específicas que foram aos poucos sendo incorporadas no projeto, sendo que as soluções foram modificadas de acordo com o conhecimento agregado por cada um ao

${ }^{129}$ Do original: "This does not necessarily confere equal responsibility to all participants in a system but instead presumes that while hierarchies formed by experience, skill and aptitude are inevitable, they are not immutable." (FULLER; HAQUE, 2008, p.18) 
participar do processo. Diferente de uma perspectiva linear de trabalho, na qual os pesquisadores trazem sua própria paisagem e estão pouco dispostos a desvios de caminhos, o processo colocado pelo projeto PIX pressupôs a troca constante e o agenciamento das intenções.
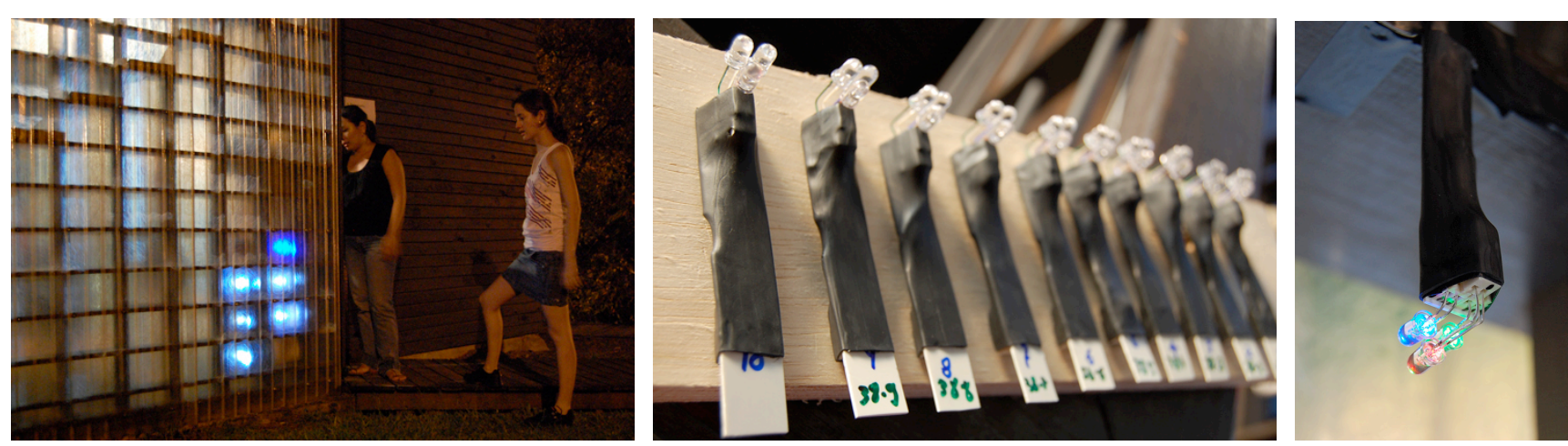

Fig. 103: Primeiros testes do efeito dos LEDs na fachada da casa.

Fig. 104: Estruturas de suporte dos LEDs prontas para serem instaladas.

Fig. 105: Estrutura instalada e funcionando. Fonte: Nomads.usp, 2008.

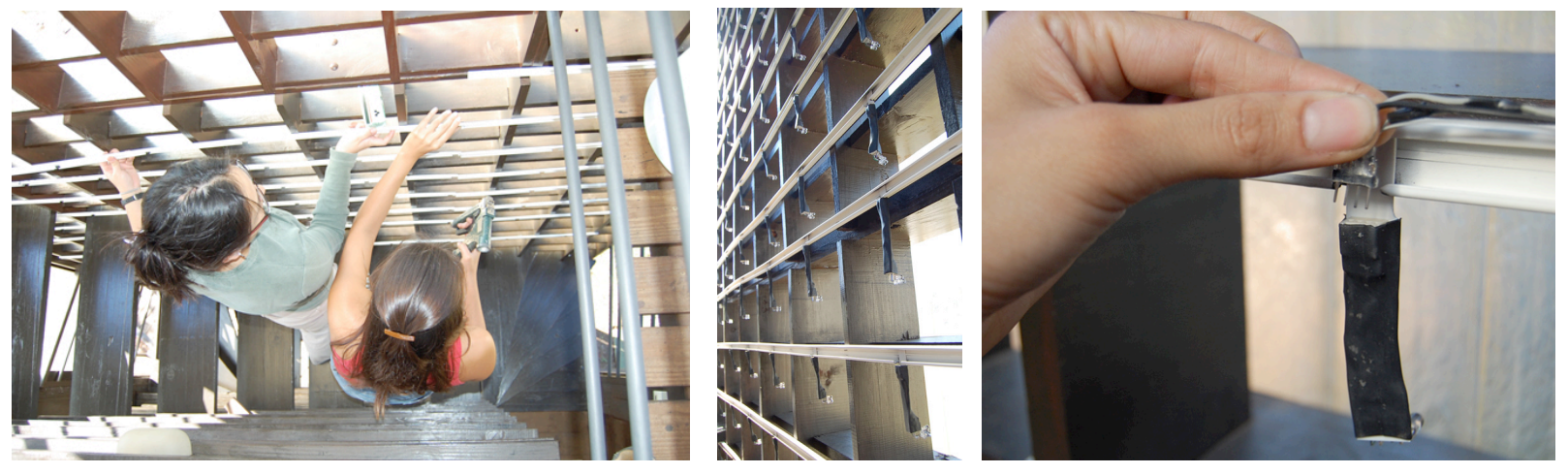

Fig. 106: Instalação das canaletas nas quais os suportes dos LEDs foram fixados.

Fig. 107: Canaletas e estruturas dos LEDs instalados.

Fig. 108: Instalação das linhas que ligam os LEDs às caixas controladoras. Fonte: Nomads.usp, 2008 


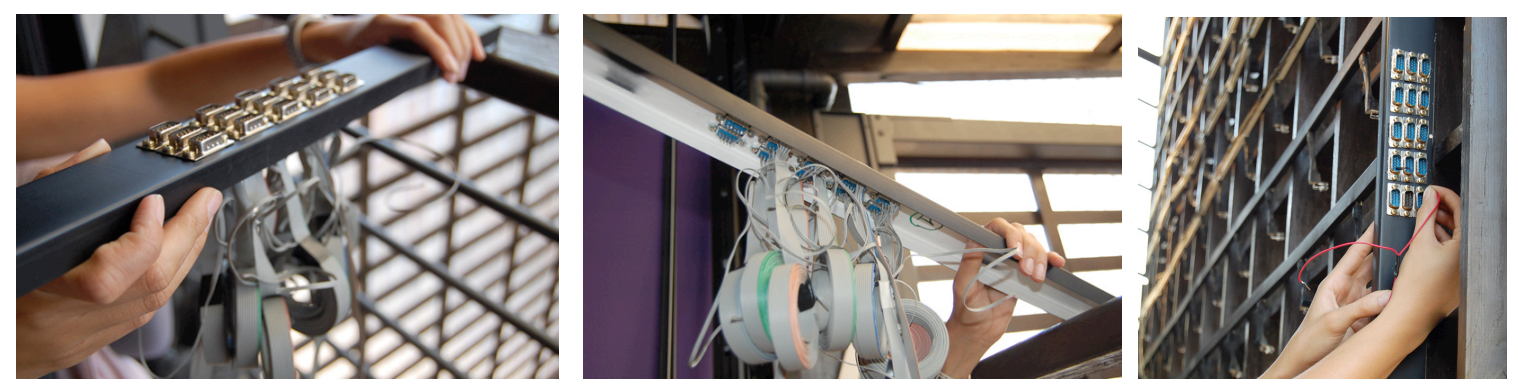

Fig. 109: Exterior da colunas que conectam as 40 linhas do projeto.

Fig. 110: Interior da coluna antes de seu fechamento. As linhas enroladas são as que conectam as estruturas dos LEDs. Fig. 111: Estrutura dos LEDs, linhas e coluna instalada. Testes individuais dos LEDs para verificar a conexão.

Fonte: Nomads.usp, 2008

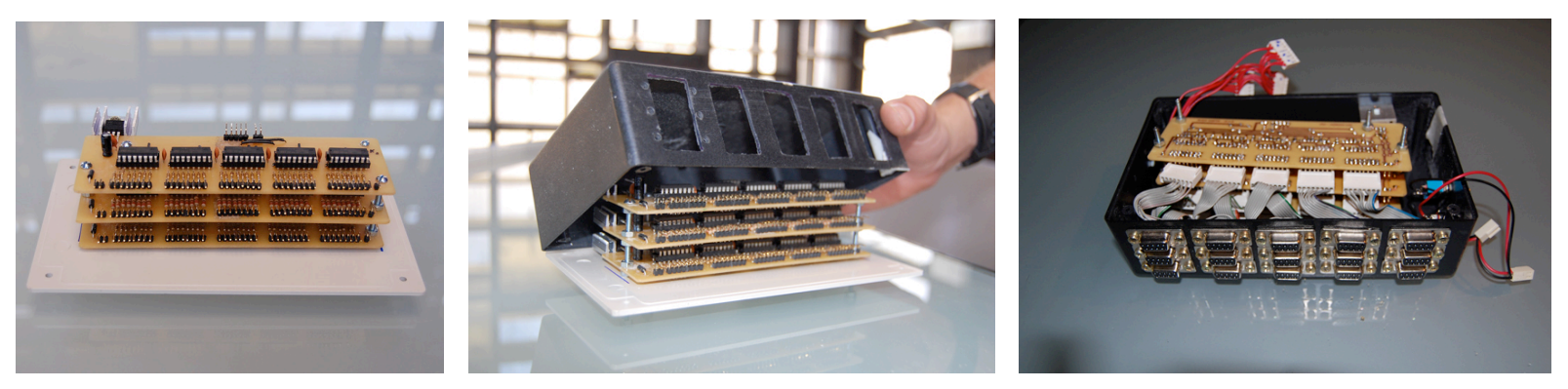

Fig. 112: Placas com os shift registers. Cada placa comanda 40 LEDs (uma das três cores de cada quatro linhas) Fig. 113-114: Fechamento da caixa, sem e com os conectores instalados. Fonte: Nomads.usp, 2008.
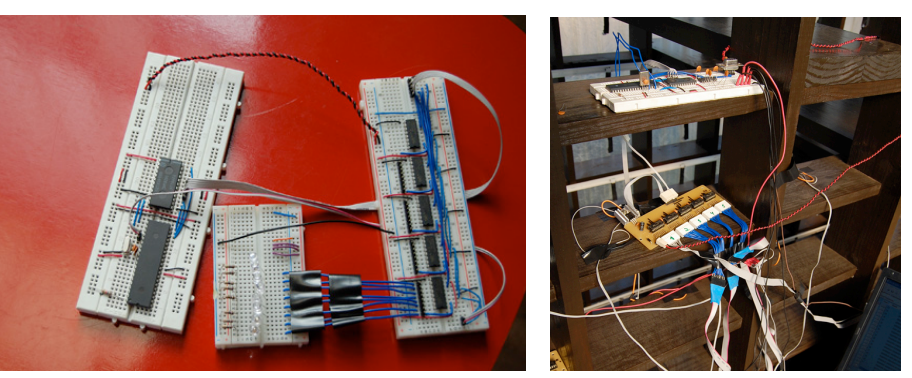

Fig. 115: Primeiro protótipo do circuito montado em protoboards com o PIC, multiplexador e shift registers.

Fig. 116: Testes individuais das placas com os shift registers (no total

são 30 placas). Fonte: Nomads.usp, 2008. 

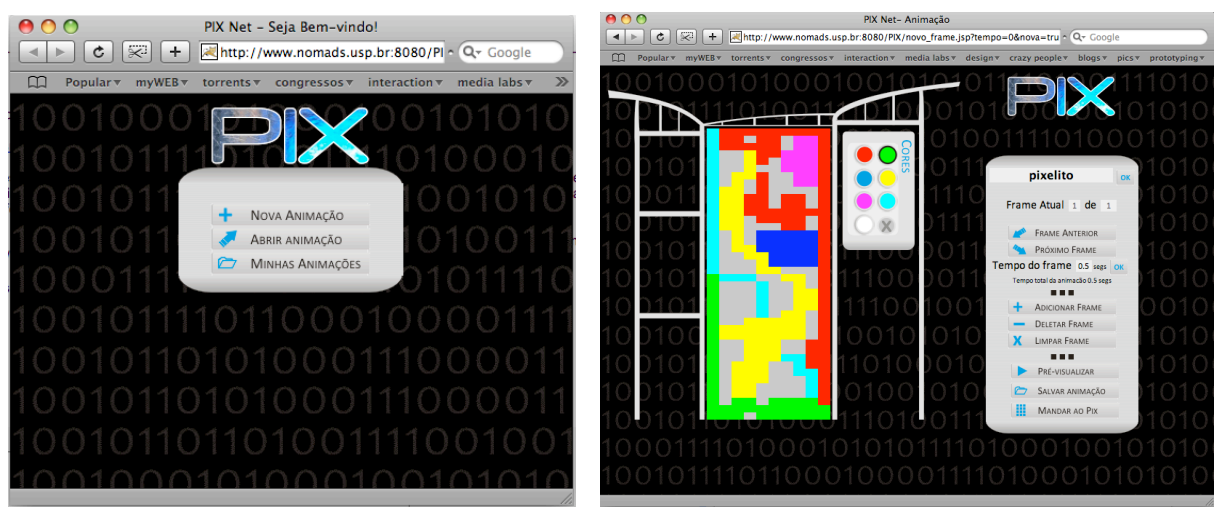

Fig. 117: Página inicial da interface gráfica para a edição de animações. Fig. 118: Editor de animação do projeto PIX. Fonte: Nomads.usp, 2008.

No item 1.2 , falou-se sobre a interação com os meios digitais. Especificamente foi esboçado um pouco das lógicas e do funcionamento desses meios, com o objetivo de elucidar o que está por trás da computação e da interação das pessoas com eles. Naquele momento, o foco foi colocado mais nos meios digitais do que na interação em si. Isso mostrou que a natureza das interações entre homem e computação difere tanto daquelas estabelecidas com objetos tradicionais (não-possuidores da capacidade de processamento de dados), quanto das interações entre as pessoas.

No caso da análise dos projetos Affective Twins e PIX, a partir do ponto de vista das interações mediadas por eles, o que está em jogo é a observação de dois sistemas distintos, homem e máquina, e das suas interações. Uma vez que não existem ferramentas métricas para medir os modos e níveis de interação, até porque a interação se configura como um processo dinâmico, serão utilizados conceitos e modelos para intensificar a percepção das relações colocadas por estes objetos.

As noções de sistema, observação e interação remetem à teoria da cibernética, que pode auxiliar a entender o conceito de interação e que classifica-se em cibernética de primeira ordem e de segunda ordem. Ambos utilizam 
a mesma linguagem e os mesmos elementos para descrever os sistemas e o que as diferencia é o ponto de vista. Segundo Heinz Von Foerster (1975), a cibernética de primeira ordem trata dos sistemas observados e a de segunda ordem trata da observação dos sistemas, ou seja, como eles agem e interagem com o ambiente e com os outros sistemas ao seu redor. Assim sendo, o fato de este trabalho abordar os modos de interação entre pessoas e máquinas pode ser entendido como a observação das possibilidades de trocas e conversação entre dois sistemas distintos, ou seja, trata de uma abordagem a partir da cibernética de segunda ordem.

Para isso, alguns elementos básicos precisam ser adicionados. Segundo Paul Pangaro (2005), o conceito fundamental da cibernética reside na noção de finalidade (goal) e circularidade (looping). Segundo esse ponto de vista, todo sistema tem um objetivo e suas ações são repetidas até seus objetivos serem alcançados. A cada ciclo, vários fatores interferem no comportamento do sistema e o desvia de seu caminho principal. A informação atualizada de sua situação é então retornada ao sistema que a compara com a condição desejada e age de forma a corrigir o caminho. Para que o controle ocorra, a alimentação do sistema com informações parciais de seu estado é fundamental, sendo que essa transmissão do resultado da ação é denominada feedback ou retro-alimentação.

Ranulph Glanville aponta que a "cibernética sempre se interessou na circularidade na qual o observador [usado como um termo geral para abranger o agenciador] observa o que acontece em alguns sistemas e age nesse sistema"130 (GLANVILLE, 2004, p. 1380) [grifo nosso]. O autor coloca que o que diferencia a abordagem da cibernética de primeira e segunda ordem, em referência à circularidade das relações que se colocam em um sistema, é que na versão clássica da cibernética essa questão é colocada por meio de uma "relação de poder. 0 observador é visto como agindo no observado, mas o observado não era entendido como agindo no

\footnotetext{
${ }^{130}$ Do original: "Cybernetics has always been interested in the circularity in which the observer (used as general term to cover agency) observes what is happening in some system and acts on that system" (GLANVILLE, 2004, p. 1380)
} 
observador"131. Há uma certa hierarquia e definição de papéis (observador, sistema e finalidade) que a cibernética de segunda ordem busca superar.

A análise colocada por Glanville (2004, p. 1381) do tradicional exemplo do termostato, a partir dos dois pontos de vista, ilustra a forma como se dá a dissolução dessas fronteiras. 0 termostato (sistema) é normalmente entendido como um interruptor que detecta a temperatura (input) e controla o funcionamento da caldeira (processamento) que distribui o calor no ambiente (output). A partir do ponto de vista da cibernética de primeira ordem temos um elemento (interruptor) que controla dois outros (a caldeira e a temperatura), de acordo com o feedback fornecido (temperatura atual). Uma análise em termos de cibernética de segunda ordem dificulta a definição das partes, neste caso a controladora e a controlada, e ainda inclui o sistema natural (fornecedora da temperatura) no sistema. Ao observá-lo como um todo, percebe-se que o controle é dividido: a temperatura ambiente controla o interruptor, que controla a caldeira, que, somado aos fatores naturais (clima), controla a temperatura, que controla o interruptor... e assim, o resultado da interpretação é um sistema cuja determinação dos papéis se confunde.

Os elementos até então colocados (primeira ordem, segunda ordem, observador, interator, input, output, processamento, feedback, loop, circularidade e finalidade) possibilitam inúmeras análises dos projetos desenvolvidos ao longo desta pesquisa. Eles permitem não apenas a elucidação das interações como também, tão importante quanto, a clarificação do ponto de vista a partir do qual a análise é feita. Em suma, o objetivo aqui é o de colocar algumas questões proeminentes dessas experimentações.

\footnotetext{
${ }^{131}$ Do original: "(In classical (first-order) Cybernetics this was presented through a) power relationship. The observer was seen as acting on the observed, but the observed was not understood to act on the observer." (GLANVILLE, 2004, p. 1381)
} 

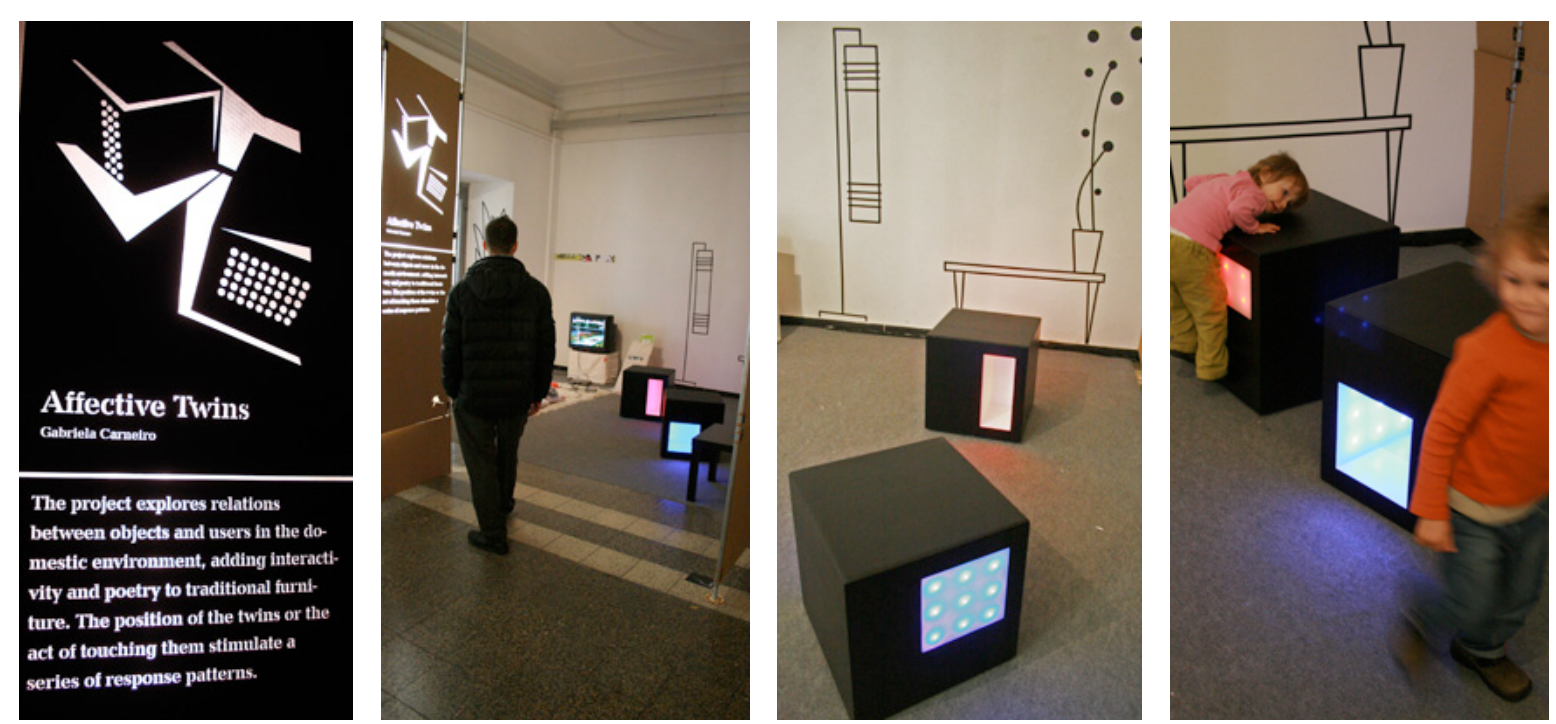

Fig. 119: Painel com descrição do projeto.

Fig. 120 e 121: Imagens do projeto exposto.

Fig. 122: crianças experimentando a interação da peça.

Fonte: Gabriela Carneiro, 2007.
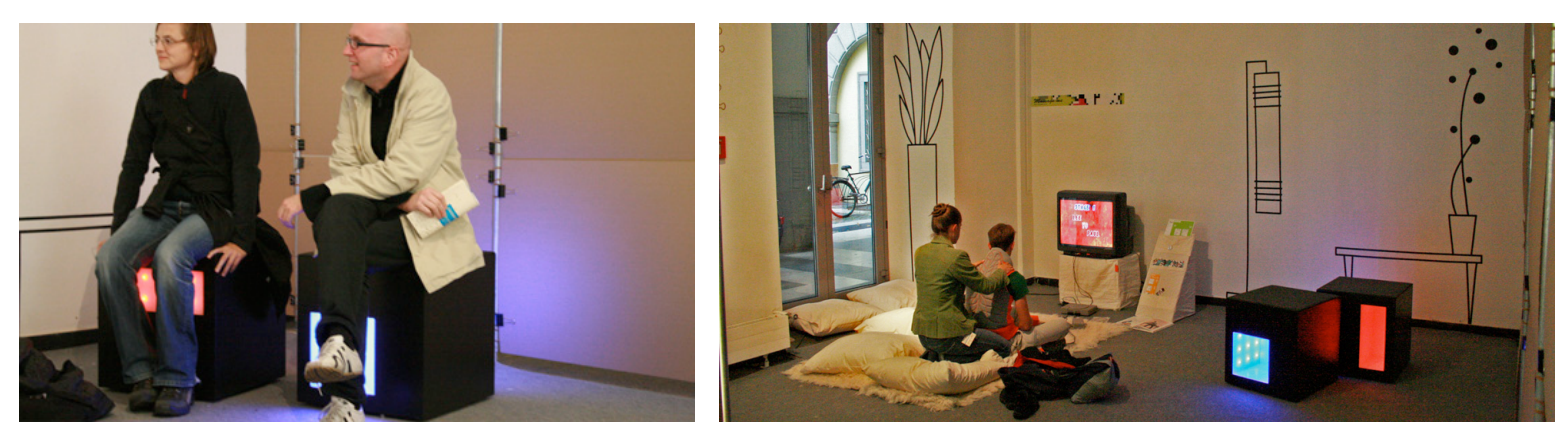

Fig. 123: a peça em uso por participantes do festival.

Fig. 124: Projetos Affective Twins e Massage Me (Hannah-Perner Wilson e Mika Satomi). Uma ambiência única foi pensada para os dois projetos para enfatizar o caráter doméstico das propostas.

Fonte: Gabriela Carneiro, 2007. 
O projeto Affective Twins foi concluído e exposto ao público na ocasião de uma exposição de arte interativa (Fig. 119-124). Essa exposição foi de extrema importância para a avaliação da receptividade da proposta. Uma ressalva deve ser feita, uma vez que o evento em questão foi um festival de arte, o que claramente influenciou a interpretação que as pessoas deram para a peça. Apesar de o contexto de uma exposição de artes não corresponder exatamente ao cenário imaginado para este, ainda assim se configurou como um momento de interação (percepção, diálogo e avaliação da proposta) com possíveis usuários e críticos deste campo do conhecimento. Estas respostas se mostraram essenciais para a continuidade da pesquisa e foram utilizadas para a avaliação do processo como um todo e estabelecimento de possíveis caminhos a serem seguidos por essa experiência.

Entre algumas reações observadas, notou-se uma grande receptividade da peça por parte das crianças, que encontraram na proposta um tipo de interação bastante aberta e intuitiva. A simplicidade do desenho e da interação promoveu uma livre apropriação do objeto por esse público, uma vez que não havia limites impostos para seu uso, ou seja, não haviam cuidados especiais a serem tomados por se tratar de um sistema eletrônico. Para elas, a peça atuou como um estímulo para várias brincadeiras através das sensações provocadas. A justaposição dos dois módulos era utilizada pelas pessoas como uma superfície de relaxamento e a vibração alternada entre as peças (reação de quando as duas eram tocadas) era recebida como uma massagem pelo corpo inteiro.

Ao observar e interagir com a peça, houve também quem a imaginasse como parte de uma série de peças de mobiliário que auxiliasse ubiquamente o dia a dia de deficientes físicos. Para alguém com problemas auditivos as luzes e a vibração poderiam ser trabalhados de forma a codificar as informações não-passíveis de serem percebidas. 0 mobiliário poderia, por exemplo, reagir ao toque da campainha ou ao tocar do telefone. 
Além dos possíveis usuários, a proposta foi também experimentada por pesquisadores de diversas áreas. Um musicologista, professor de um curso de arquitetura, percebeu no objeto um exemplo significativo para a idéia que trabalha nas suas disciplinas. Para ele, o som deve ser abordado não apenas a partir do conforto acústico dos ambientes mas também de forma a estimular os sentidos de quem experiencia o espaço. 0 som emitido pela vibração dos gêmeos suscita esta idéia na qual a sonoridade faz parte do conjunto de sensações estimuladas pela peça.

Um outro aspecto interessante foi que a observação do comportamento das pessoas em relação ao objeto incitou várias outras possibilidades a serem exploradas como continuidade desse experimento. Por exemplo, algumas pessoas pegavam os dois módulos e justapunham suas superfícies laterais em diversas posições. Isso se mostrou como algo interessante a ser trabalhado: que a justaposição das diferentes superfícies dos módulos alterassem o comportamento da peça.

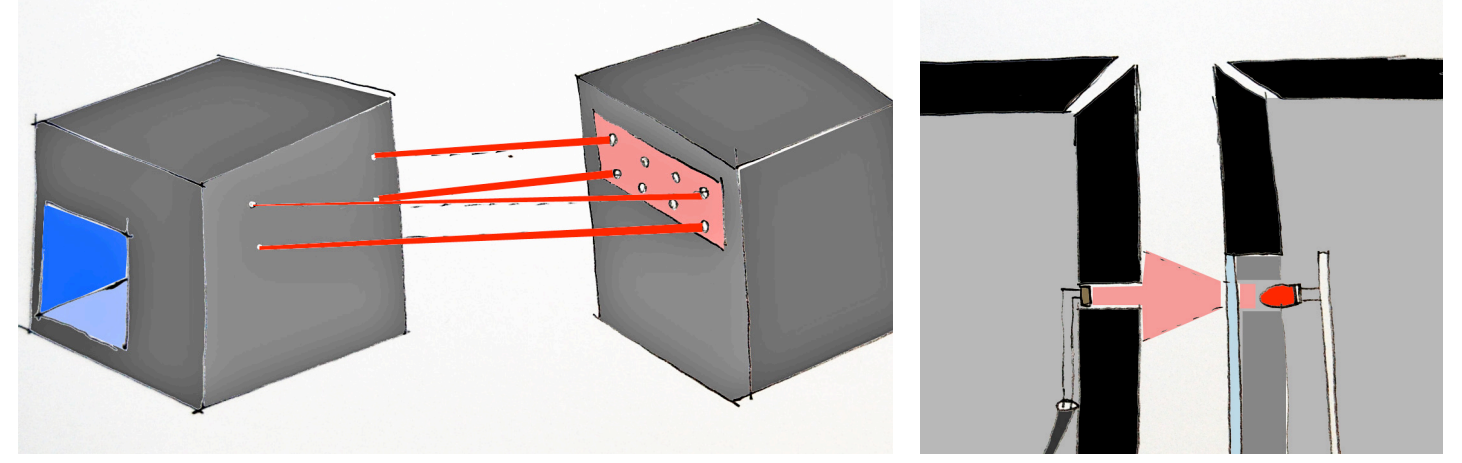

Fig. 125: Ilustração de possibilidades pensadas a partir da observação dos interatores com a peça.

Aproveitamento da luz já emitida pela peça como input para os fotossensores localizados estrategicamente. As linhas vermelhas marcam a relação da posição do LED com o fotossensor.

Fig. 126: Detalhe da introdução do fotossensor na estrutura do objeto. Eles seriam colocados no fundo de pequenos furos para que captassem apenas a luz direta do LED, assim a luz ambiente interferiria menos na interação. Fonte: Gabriela Carneiro, 2008. 
Uma idéia seria utilizar fotossensores (sensores que variam de acordo com a intensidade de luz) posicionados estrategicamente que utilizassem a luz já emitida pelo objeto como input; isso faria a luz passar então a atuar também como parte do sensor. A captação dos padrões luminosos poderia então retroalimentar o sistema e assim aumentar o grau de complexidade da interação. Essa e várias outras idéias foram suscitadas ao se observar as pessoas interagirem com a peça. Esse momento de observação é algo importante quando se trata de um objeto interativo pois, muitas vezes, durante o processo de criação, o envolvimento com questões específicas limita a visualização de possibilidades simples e interessantes que agregam valor ao conceito trabalhado.

Sobre o projeto PIX, a análise parte de um ponto de vista distinto. Uma vez que o projeto ainda não foi concluído, o exame colocado aqui compreende a observação da interação das pessoas com o objeto em construção, nesse caso, aquelas que não participaram diretamente do projeto. A relevância dessas interações advém de um dos objetivos colocados pelo projeto: o de atuar como plataforma a ser apropriada por outras experimentações. 0 termo plataforma é aqui colocado a partir do entendimento do projeto como um elemento a ser utilizado como suporte e apoio para a implementação de diferentes proposições.

A observação aqui colocada se refere à interação com um objeto ainda em processo de criação. A importância dessa análise reside na constatação de que a maneira como o projeto é apropriado pela imaginação de pessoas que não participam, diretamente, do seu processo de criação gera fortes influências na determinação e avaliação dos caminhos a serem seguidos. Entre as diversas idéias, um ponto importante de ser observado é que, na sua maioria, a fachada ainda é vista como um display que responde diretamente a comandos (input), sejam eles locais (por meio de sensores instalados na casa) ou remotos (por meio da interface web).

A primeira proposta de interação implementada, composta pela produção de animações para serem exibidas na fachada, é uma ilustração dessa perspectiva do comando. As animações são produzidas e a fachada apenas as reproduz, reagindo ao comando conforme instruções inseridas pela programação. Porém, cabe colocar que esta 
experimentação foi elaborada para possibilitar um primeiro contato das pessoas com os efeitos alcançados através da exibição de padrões luminosos na fachada em questão. Com a utilização da interface web, qualquer pessoa poderá fazer experimentações desses efeitos, mesmo que não tenha conhecimentos específicos de programação.

Acredita-se que, com o tempo, à medida que as pessoas se tornarem mais familiares com o funcionamento da fachada e que diferentes experimentações forem exploradas, a tendência será a elevação da complexidade da interatividade do objeto. Por elevação da complexidade da interação entende-se a passagem de um objeto que apenas responde às ações, para um outro que possibilite o estabelecimento de uma relação não-hierárquica, ou seja, no qual as pessoas possam se engajar em um tipo de diálogo não-previsível com o objeto.

Muito dessa perspectiva advém da Teoria da Conversação de Gordon Pask, um dos primeiros propositores e praticantes da cibernética, em especial da cibernética de segunda ordem, que observa sistemas interagindo. Essa teoria merece uma visão mais aprofundada, uma vez que auxilia na compreensão do que pode significar o aumento de complexidade na interação entre pessoas e objetos interativos. Segundo Usman Haque, arquiteto interessado pela exploração da interação em suas obras, essa teoria vem, cada dia mais, despertando a atenção de artistas, arquitetos e designers que trabalham com a ubiqüidade da informação no ambiente. Segundo o autor:

“Agora, no início do século XXI, a 'Teoria da Conversação de Pask' parece particularmente importante porque sugere como, no campo crescente da computação ubíqua, os seres humanos, objetos e dispositivos, assim como seu ambiente compartilhado podem coexistir em uma relação mutuamente construtiva." 132 (HAQUE, 2003, p. 55)

${ }^{132}$ Do original: "Now, at the beginning of the 21st century, Pask's Conversation Theory seems particularly importante because it suggests how, in
the growing field of ubiquitous computing, humans, devices and their shared environemt might coexist in mutually constructive relationship." (HAQUE, 2003, p. 55) 
Ainda nos anos 1950, Pask desenvolveu máquinas que, com a utilização de elementos mecânicos e eletromecânicos (antes do surgimento dos circuitos integrados e microcontroladores), "demonstram autênticos sistemas interativos que desenvolvem perfis de interação únicos com cada participante humano"133 (HAQUE, 2003, p. 55). Trata-se de experimentos que oferecem uma estrutura conceitual para "construir artefatos interativos que lidam com a complexidade dinâmica natural que os ambientes precisam ter sem se tornarem prescritivos, restritivos e autocráticos."134(HAQUE, 2003, p. 55)

Segundo Paul Pangaro (2005), participar de uma conversação significa se engajar em uma relação nas quais as partes são percebidas como equivalentes, não em sua composição material e sim no seu comportamento e engajamento na conversa. Isso requer, entre outras coisas, que ambas as partes variem seu comportamento, imprevisivelmente e de acordo com as respostas (feedbacks) que recebe. Na computação, essa abordagem significaria trabalhar com diversos objetivos (goals) e diferentes formas de alterar estes objetivos. Pangaro coloca que uma interação mais interessante acontece quando o sistema computacional varia de acordo com o uso, ou seja, nele é previsto um aumento na capacidade de ponderação entre possíveis respostas na medida em que é estimulado (recebe os inputs).

No caso de ambos os projetos analisados neste capítulo, observa-se que seus processos de criação se nutriram bastante dessa perspectiva não-hierárquica, porém, nota-se que as interações implementadas até o momento são caracteristicamente reativas. Nos objetos em questão, a idéia da relação a ser estabelecida é abstraída e, então, as possibilidades são delimitadas, convertidas em etapas e programadas, sem espaço para alterações no sistema de

${ }^{133}$ Do original: "demonstrate authentically interactive systems that develop unique interaction profiles with each human participant" (HAQUE, 2003, p. 55).

${ }^{134}$ Do original: "(Pask's early experiments with mechanical and electromechanical systems provide a conceptual framework for) building interactive artefacts that deal with the natural dynamic complexity that environments must have without becoming prescriptive, restrictive and autocratic."(HAQUE, 2003, p. 55) 
acordo com o uso. Isso não torna os projetos desinteressantes e não diminui sua importância no contexto da pesquisa, até porque esse entendimento, assim como muitos outros, foi alcançado apenas a partir da experimentação prática. 0 que o ponto de vista colocado pela teoria da conversação faz é abrir caminhos e mostrar possibilidades para a exploração de outros níveis de interação, aqueles que, a partir de regras simples, fazem despontar comportamentos complexos.

Colocadas estas análises, fica claro que a atividade prática de criação de objetos interativos aprofunda, ao mesmo tempo que simplifica, o entendimento dos aspectos que regem a interação das pessoas com o meio digital. No atual contexto, início do século XXI, esse tipo de atividade é facilitado pela quantidade de informação sobre o tema, pelo barateamento dos componentes necessários e diminuição de seu tamanho. Somado a isso, existe um grande número de comunidades online e iniciativas cujo objetivo é desenvolver e divulgar técnicas de prototipagem e linguagens de programação mais acessíveis a pessoas não especialistas no assunto, ou que nunca se aproximaram com o tema. Algumas iniciativas, tal como o Pure Data ${ }^{135}$, Processing ${ }^{136}$, Arduino ${ }^{137}$, Wiring ${ }^{138}$, Open Frameworks ${ }^{139}$, Fritzing ${ }^{140}$, e Instructables ${ }^{141}$ são importantes de serem destacadas pois baseiam-se em código aberto e são gratuitas, o que auxilia no seu crescimento e no desenvolvimento de grandes comunidades cuja principal característica é a constante troca de informações e possibilidades entre seus usuários. Nesse

135 Pure Data é um ambiente gráfico de programação para o processamento em tempo real de áudio, vídeo e gráficos. Disponível em: $<$ http://puredata.info>. (Acesso em 10/11/2008)

${ }^{136}$ Processing é uma linguagem e um ambiente de programação destinado a pessoas que queiram programar imagens, animações e interações com o meio digital. Disponível em: <http://processing.org>. (Acesso em 10/11/2008)

${ }^{137}$ Arduino é uma plataforma de prototipagem de eletrônica, ou seja, de controle de sensores e atuadores. Sua linguagem é baseada na no Wiring e seu ambiente no Processing. Disponível em: <http://arduino.cc>. (Acesso em 10/11/2008)

${ }^{138}$ Wiring é uma plataforma de prototipagem de eletrônica para o desenvolvimento de projetos de arte eletrônica, mídias tangíveis, e também para o ensino da programação e da prototipagem com meios eletrônicos. Disponível em: <http://www.wiring.org.co>. (Acesso em 10/11/2008)

${ }^{139}$ Open Frameworks é um repositório de códigos em C++ para serem utilizados em instalações artísticas. Disponível em: $<$ http://www.openframeworks.cc>. (Acesso em 10/11/2008)

${ }^{140}$ Fritzing é um software que auxilia na criação de esquemas para a manufatura de circuitos impressos. Disponível em: $<$ http://www.fritzing.org>. (Acesso em 10/11/2008)

${ }^{141}$ Instructable, baseado na filosofia DIY (Do It Yourself ou faça você mesmo) é uma comunidade na qual as pessoas depositam manuais passo-apassos de como fazer diversos tipos de projetos. Disponível em: <http://www.instructables.com>. (Acesso em 10/11/2008) 
sentido, o mais importante é ter abertura para a experiência prática e ter consciência que o que separa a teoria da prática da criação de objetos interativos, é apenas a vontade de ir além. Segundo Usman Haque e Adam Somlai-Fisher:

““Artistas das novas mídias e arquitetos não necessariamente precisam da precisão e exatidão, normalmente necessárias para os cientistas, a fim de explorar as poesias da interação. Freqüentemente não necessitam de equipamentos tão sofisticados para o desenvolvimento de projetos interativos verdadeiramente interessantes." 142 (HAQUE; SOMLAI-FISHER, 2005, p. 4)

As experiências descritas neste capítulo reforçam a idéia colocada pelos autores. Não são projetos cujo objetivo é desenvolver novas tecnologias e, sim, de partir do que se tem acesso, propor novas idéias e agenciamentos e colocar questões (ruídos) para se extrair de soluções simples e acessíveis, interações ricas e complexas.

\footnotetext{
${ }^{142}$ Do original: "New media artists and architects don't necessarily need the precision and accuracy that scientists usually do in order to explore the poetries of interaction. They often do not require such sophisticated equipment in order to develop truly interesting interactive projects." (HAQUE; SOMLAI-FISHER, 2005, p. 4)
} 

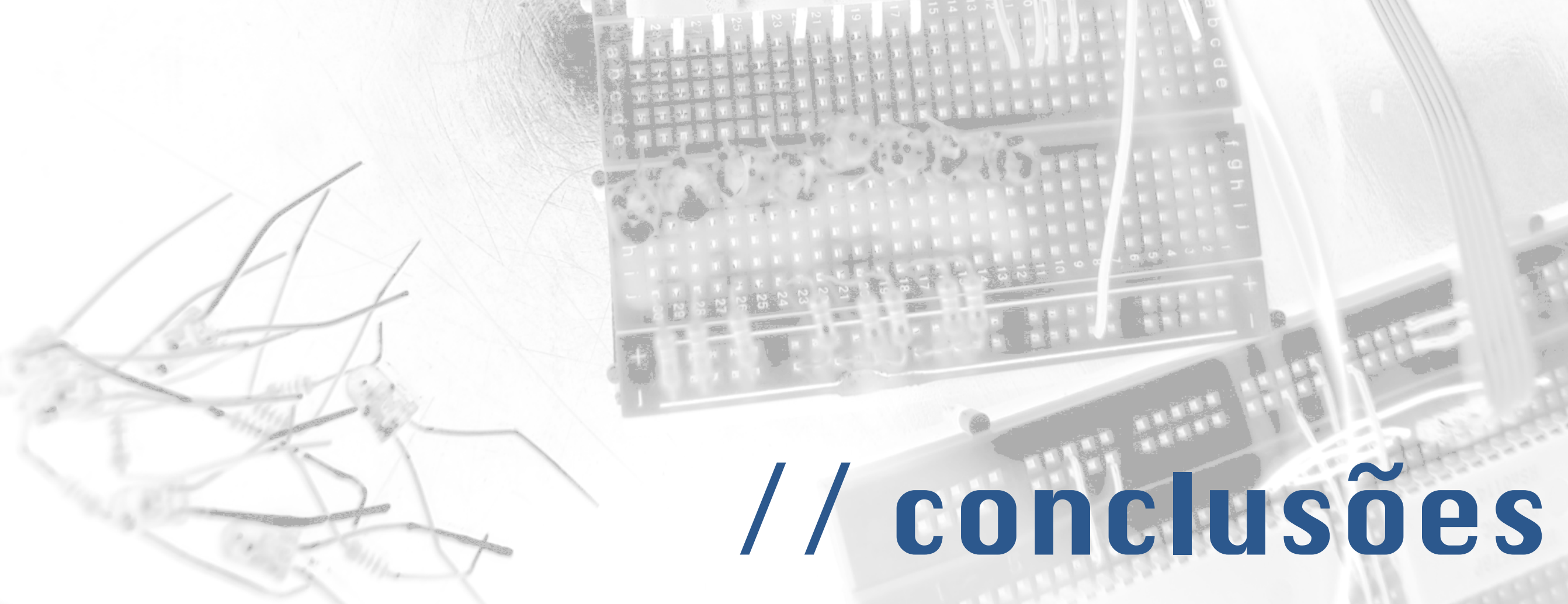
Com o intuito de fornecer impressões relevantes dos resultados alcançados por esta pesquisa, alguns aspectos são ressaltados. Em primeiro lugar, considerações sobre a aproximação com o tema são recuperadas da introdução, com o objetivo de elucidar ganhos obtidos e dificuldades enfrentadas no processo de pesquisa. A seguir, fala-se sobre o ponto para o qual convergem as análises empreendidas ao longo deste estudo, o processo de criação de objetos interativos. Sobre ele faz-se importante a seleção e ênfase dos principais entendimentos alcançados e a indicação de princípios para esse tipo de projeto. Para completar, são delineados caminhos passíveis de serem seguidos por pesquisas futuras.

\section{// Aproximações com o tema}

A perspectiva da complexidade, a alternância entre teoria e prática e os contextos nos quais a pesquisa foi desenvolvida caracterizam o caminho percorrido. 0 modo de lidar com o tema influenciou diretamente os resultados obtidos, além do mais, coloca abordagens que podem ser aproveitadas por outros estudos.

Mais do que descrições detalhadas e visões totalizadoras, o ponto de vista da complexidade valoriza o estabelecimento de relações entre essas percepções. Para o fim de elucidar relações possíveis entre diferentes campos do conhecimento, essa aproximação mostrou-se de grande valia. Nessa abordagem, o risco de produzir um trabalho que não aprofunde as questões tratadas é grande. Para evitá-lo, fez-se um esforço de entender idéias específicas das diferentes áreas, cuidando-se na utilização de suas linguagens. 
Nesse sentido, a combinação entre exploração teórica, pesquisa de aplicações e atividades práticas mostrou-se fundamental. Um tipo de ação estimula, no outro tipo, considerações que o primeiro, por si só, não engloba, o que contribui significativamente para a consolidação de entendimentos externos aos dois. Essas instâncias percorreram toda a pesquisa de forma que uma nutriu-se constantemente do conhecimento produzido pela outra. Os produtos obtidos e as questões levantadas são conseqüência desse processo híbrido de fazer pesquisa que, apesar da dificuldade de gestão do tempo, curto para uma pesquisa que se propõe a tanto, alcançou um resultado, para nós, muito positivo.

Outra instância diretamente ligada às já mencionadas concerne os contextos nos quais a pesquisa foi desenvolvida. Tanto o grupo de pesquisa Nomads.usp, quanto o Departamento de Cultura da Interface da Kunstuniversität, baseiam-se na presença de pessoas de diferentes formações. Dessa forma, tornam-se ambientes nos quais as discussões, reflexões e atividades que ocorrem no seu cotidiano obrigam os pesquisadores que ali desenvolvem seus estudos a engajarem-se em diálogos nos quais o agenciamento entre diversos temas, linguagens, colocações e idéias de áreas distintas é necessário.

Diante desse quadro, o que pode ser observado é que a interlocução com diferentes áreas mostra-se como um caminho fundamental para que resultados inovadores sejam alcançados. Neste sentido, para que essa aproximação seja otimizada, é necessária uma abertura para a incorporação e entendimento de diferentes perspectivas da realidade. Se desta interlocução resultarem proposições práticas, os resultados podem ser ainda mais ampliados, uma vez que as criações se configuram como um dos importantes momentos de diálogo. Por último, conclui-se que, uma vez que o engajamento deve ser mútuo, o desenvolvimento da pesquisa em lugares que estimulem essas trocas é essencial. 


\section{// Processos de criação de objetos interativos}

Este caminho gerou esclarecimentos, almejados por esta pesquisa, referentes ao processo de criação de objetos dotados de interatividade digital. Em processos convencionais, o desenvolvimento das partes de um objeto se faz por pessoas diferentes, em momentos específicos, de forma hierarquizada, na qual, muitas vezes, nem todos os envolvidos encontram-se preparados para diálogos mais efetivos entre os diversos saberes. De certa maneira, isso é compreensível pois os fundamentos que regem, por exemplo, a definição de características formais e materiais de um objeto diferem completamente das lógicas por trás da programação de sistemas comunicativos digitais.

O que este estudo apresenta são possibilidades de criação de objetos de tal maneira que a definição de como estes processos comunicativos ocorrem passa equivaler em importância à delimitação de qualquer outra das suas características. Faz-se necessária a abertura tanto para o aprendizado e a incorporação de outros processos de raciocínio, quanto para o estabelecimento de diálogos com linguagens que em um primeiro momento pode causar grande estranhamento. Nesse, como em outros tipos de abordagem das mídias digitais, os profissionais não trabalham sozinhos. Suas ações se dão de forma colaborativa, com um caráter mais horizontal no qual, junto com outras pessoas, fazem parte de uma rede. Assim, na medida em que os membros dessa rede passam a ter mais clareza sobre seu papel e o papel dos outros, eles tendem a se tornam mais abertos para esse tipo de experiência, ou seja, por meio da percepção das potencialidades de cada um dentro do processo, uma outra visão de trabalho é instaurada, mais favorável a equipes mistas.

A investigação das soluções e relações comunicativas instaura um processo que se alimenta constantemente dos conhecimentos individuais e das interações entre as pessoas envolvidas. Nesta dinâmica, reconhece-se o constante confronto entre diferentes métodos para a aproximação e solução dos problemas colocados. As 
pessoas trazem consigo metodologias de trabalho específicas das áreas das quais derivam, sendo que, na medida em que se sucedem os diálogos, constata-se a necessidade de avaliações conjuntas das pertinências de cada uma Sendo assim, este tipo de processo pressupõe-se o agenciamento coletivo das metodologias individuais de forma não-hierarquizada, sendo que, cada projeto demanda processos específicos. A partir deste ponto de vista, não se chega a metodologias padronizadas que ditem caminhos a ser seguidos, porém, como resultado do estudo empreendido, pode-se esboçar algumas estratégias.

\section{// Princípios para a criação}

Sobre as motivações iniciais, destaca-se a importância de partir de fundamentos bem estruturados para escapar de um dos principais riscos que se corre ao utilizar as mídias digitais, que é o de se perder na ampla gama de soluções tecnológicas disponíveis. 0 que se vê, com freqüência, é o foco em "usar a tecnologia", o que é, de certa forma, natural pois muitas possibilidades colocadas por ela são atraentes. É importante evitar o excesso e, para que isso ocorra, é necessária uma idéia bem definida que guie de maneira consistente todas as decisões tomadas ao longo do processo de criação dos objetos. Uma estruturação consistente da motivação inicial auxilia na proposição de soluções criativas, simples e de melhor qualidade.

Pode-se afirmar que conhecimentos básicos de eletrônica e programação de micro-controladores são fundamentais. Uma vez que permeiam todo o trabalho concernente à computação física, noções dos aspectos elementares das lógicas encontradas em circuitos integrados e das linguagens de programação direcionadas ao controle de inputs e outputs por micro-controladores são essenciais. Só assim um diálogo construtivo pode ser efetivado e soluções inovadoras alcançadas. 
Sobre o nível de conhecimento técnico necessário, constata-se que há uma grande diferença entre os casos nos quais o trabalho é desenvolvido individualmente daqueles que envolvem uma equipe multidisciplinar. Em projetos individuais é imprescindível o aprendizado e domínio de todas as questões envolvidas. Neste caso, exige-se um esforço de uma única mente em manusear entendimentos fundamentalmente distintos, sendo que as soluções acabam se restringindo à capacidade e ao conhecimento individual. Quando o processo é coletivo, os conhecimentos são necessários de forma a viabilizar os diálogos. Fica claro que quanto mais as pessoas se esforçam neste sentido, maior a probabilidade de soluções surpreendentes aparecerem.

Para a ampliação das possibilidades de desenvolvimento de uma idéia, uma equipe deve ser montada com o cuidado de agregar pessoas interessadas no desenvolvimento colaborativo de projetos. Isso pressupõe um perfil específico caracterizado pela abertura de cada um às trocas de saberes. Não basta resolver problemas, é também necessário estar aberto para ensinar e aprender durante o processo. Pode-se afirmar que os resultados alcançados neste tipo de aproximação dependem diretamente das particularidades das pessoas envolvidas.

Por se tratar de um processo aberto que valoriza a participação individual, desvios devem ser previstos de forma que a substituição, adição ou subtração de membros da equipe pode significar alterações dos caminhos previamente imaginados. Isto deve ser encarado como algo positivo. Se o processo de desenvolvimento do projeto depende dos conhecimentos individuais, a revisão de seu andamento de acordo com eventuais alterações da composição da equipe prevalece como condição básica na sua criação.

Dito isso, algumas pessoas ainda dão preferência para processos hierárquicos. De certa maneira, em uma relação na qual um manda e outro obedece não há tanta necessidade de diálogo sendo que, muitas vezes, ele pode se tornar trabalhoso e exaustivo. A partir dos resultados alcançados por este estudo, percebeu-se que um processo de criação centrado nas interações entre as partes possui maiores probabilidades de superar as expectativas 
iniciais em termos de resultados alcançados. E, para que isso aconteça, abertura e diálogo no processo como um todo são elementos essenciais.

\section{// Perspectivas de pesquisas}

A abrangência multidisciplinar da pesquisa, indica vários caminhos que podem ser explorados, entre muitos possíveis. Alguns deles são esboçados aqui com o intuito de destacar questões incitadas ao longo deste estudo. Primeiramente, aponta-se a possibilidade de análises mais minuciosas sobre as diferentes escalas de intervenção. Uma vez que nesta pesquisa foram delineadas apenas algumas idéias gerais, investigações que explorem a interatividade nas escalas apresentadas, com uma abordagem das peculiaridades que escaparam ao olhar aqui empreendido, configuram-se como interessantes possibilidades de continuidade.

Sugerem-se também investigações mais focadas no desenvolvimento de interfaces interativas cujas relações baseiam-se na idéia de conversação entre as partes. As análises feitas neste estudo somente introduzem esta perspectiva, mas acredita-se na necessidade de estudos exclusivos sobre processos de criação e proposições de interfaces cujo mote seja a exploração desse tipo de relação.

A continuidade do estabelecimento de aproximações inter-áreas é necessária. Arquitetura, design e computação, enquanto áreas percebidas como essenciais para o desenvolvimento de objetos interativos, deveriam também ser tratadas a partir da introdução de outros pontos de vista. Como uma entre as diversas possibilidades, podese pensar na sua relação com diferentes áreas da biologia, deste diálogo pode originar trabalhos interessantes relacionados com o corpo ou com fenômenos da natureza. Da mesma maneira, questões oriundas das ciências políticas podem acrescentar preocupações de maiores abrangências sociais. Também pode ser interessante a 
introdução de conceitos da experiência advindos da psicologia e a psicanálise, no sentido de explorar entendimentos mais profundos das experiências interativas das pessoas com estes objetos.

Para completar esta conclusão, duas observações devem ser empreendidas sobre a formação dos profissionais com vistas a prepará-lo para enfrentar e ser propositivo no tipo de abordagem proposto por esta pesquisa. Em primeiro lugar, acredita-se que para o aproveitamento efetivo de processos de trabalho multidisciplinares, deve ser incluída a preparação para a participação em equipes múltiplas de forma que as partes tenham consciência da importância do diálogo e do manuseio das diferenças. Neste sentido, com o objetivo de estimular o entendimento das áreas do conhecimento como um sistema inter-relacionado. Somado a isso, se os objetos interativos parecem ser cada dia mais uma demanda real da sociedade, é necessária a inclusão nos cursos de um conjunto de saberes que expandam o entendimento das possibilidades colocadas pela computação digital. Entender suas lógicas é essencial no esforço de se tornar propositivo em processos de criação de objetos e arquiteturas interativas.

Espera-se assim que esta pesquisa tenha contribuído para a contextualização dos processos de criação de objetos interativos na contemporaneidade. Em especial, deseja-se que ela estimule a formação de um olhar que priorize as possibilidades colocadas pela abertura ao diálogo, de maneira que o pensamento criativo transcenda as capacidades individuais em direção à algo múltiplo, novo e inusitado. 


\section{$\{$ referências $\}$}

ASHBY, Ross, (1957), An introduction do cybernetics. London: Chapman \& Hall. Internet (1999), disponível em: <http://pcp.vub.ac.be/books/IntroCyb.pdf>. (Acesso em 04/11/2008)

ANSHUMAN, Sachin; KUMAR, Bimal, (2004), Architecture and HCI: a review of trends towards an integrative approach to designing responsive space. In International Journal of IT in Architecture, Engineering and Construction, vol. 2, issue 4, december. Milpress, p. 273-283.

BAUDRILLARD, Jean, (2004), 0 sistema dos objetos. 1a Ed.: 1968. São Paulo: Perspectiva.

BONSIEPE, Gui, (1997), Design: do material ao digital. 1a Ed.: 1994. Florianópolis: FIESC/IEL.

BRIGGS, Asa; BURKE, Peter, (2004), Uma história social da mídia: de Gutenberg à Internet. 1a Ed.: 2002. Rio de Janeiro: Jorge Zahar Ed.

COUCHOT, Edmond, (2003), A tecnologia na arte: da fotografia à realidade virtual. Porto Alegre: Editora da UFRGS.

CSIKSZENTMIHALY, Mihaly, (1981), The meaning of things: domestic symbols and the self. Cambridge: Cambridge University Press.

DOURISH, Paul, (2004), Where the action is: the foundations of embodied interaction. Cambridge, MA: The MIT Press.

DUNNE, Anthony; RABY, Fiona, (2001), Design noir: the secret life of electronic objects. Basel; Boston; Berlin: Birkhauser.

DUNNE, Anthony, (2005), Hertzian tales: electronic products, aesthetic experience, and critical design. Cambridge, MA: The MIT Press. 
DUNNE, Anthony; GAVER, William, (1997), The pillow: artistdesigners in the digital age. CHI Extended Abstracts, p. 361-362.

FAULKNER, Christine, (1998), The essence of humancomputer interaction. London: Prentice Hall.

FIEDLER-FERRARA, Nelson, (2005), Quando o todo é mais sagaz do que a soma de suas partes. In, São Paulo: scientiæ studia, v. 3, n. 2, p. 323-37.

FLAKE, Gary William, (1998), The computational beauty of nature: computer explorations of fractals, chaos, complex systems and adaptation. Cambridge, MA: The MIT Press.

FULLER, Matthew; HAQUE, Usman, (2008), Situated technologies pamphlets 2: Urban versioning system 1.0. New York: The Architectural League of New York.

GLANVILLE, Ranulph, (2004), The purpose of secondorder cybernetics. In Kybernetes, Vol. 33 No.9/10, Emerald. p. 1379-1386.

GAVER, William et al. (2004). The drift table: designing for ludic engagement. Proceedings of CHI'04, Vienna, Austria: ACM.

GAVER, William et al. (2003). Ambiguity as a resource for design. Proceedings of CHI'03.

GREENBERG, Ira, (2007), Processing: creative coding and computational art. USA: Friendsoft.

GREENFIELD, Adam, (2006), Everyware: the dawning age of ubiquitous computing. Berkeley, CA: New Riders.

HAQUE, Usman, (2007), The architectural relevance of Gordon Pask. In: 4d Social - Interactive Design Environments, Wiley \& Sons. p. 54-61.

HAQUE, Usman; SOMLAI-FISHER, Adam, (2005), Low tech sensors and actuators: for artists and architects. Relatório de atividades disponível em: <http://lowtech.propositions.org.uk/>. (Acesso em 30/10/2008)

ISHII, Hiroshi; ULLMER, Brygg, (1997), Tangible bits: towards seamless interfaces between people, bits and atoms. Proceedings of CHI '97. ACM 1: March 22-27. 
ISHII, Hiroshi, (2008), Tangible bits: beyond pixels. Bonn, Germany: Proceedings of the Second International Conference on Tangible and Embedded Interaction (TEI'08), Feb 18- 20.

ISHII, Hiroshi; MAZALEK, Ali; LEE, Jay, (2001), Bottles as a minimal interface to access digital information. In CHI'01 Extended Abstracts, ACM Press, p. 187-188

JOHNSON, Peter, (1992), Human computer interaction: psychology, task analysis and software engineering. England: McGraw-Hill Book Company Europe.

JOHNSON, Steven, (2001), Cultura da interface: como o computador transforma nossa maneira de criar e comunicar. RJ: Jorge Zahar Ed.

KRUEGER, Myron, (1977), Responsive environments. In: WARDRIP-FRUIN, Noah; MONTFORT, Nick (ed.). The New Media Reader. Cambridge, MA: The MIT Press: 2003. p. 379- 398. Do original: AFIPS 46 National Computer Conference Proceedings, 423-433. Montvale, N.J.: AFIPS Press.

LOZANO-HEMMER, Rafael, (2002), Alien relationships form public space. In: Transurbanism. Rotterdam: V2_Publishing/NAI Publishers, p. 138-159.

MARGOLIN, Viktor, (2000), Expanding the boundaries of design: the product environment and the new user. 1988. In: MARGOLIN, V.; BUCHANAN, R. (edited by). The Idea of design. 1a Ed.: 1995. Cambridge, MA: The MIT Press, p. 275-280.

McCUllOUGH, Malcolm, (2004), Digital ground: architecture, pervasive computing and environmental knowing. Cambridge, MA: MIT Press.

MOGGRIDGE, Bill, (2007), Designing interactions. Cambridge, MA: The MIT Press.

MITCHELL, Tom, (1988), The product as illusion. In: THACKARA, John. Design After Modernism: Beyond the Object. Thames and Hudson: London.

MITCHELL, William, (2003), ME++ The cyborg self and the networked city. Cambridge, MA: MIT Press. NORMAN, Donald A , (1993), Things that make us smart: defending human attributes in the age of the machine. Cambridge, MA: Perseus Book. 
WARDRIP-FRUIN, Noah; MONTFORT, Nick (ed.), (2003), The new media reader. Cambridge, MA: The MIT Press.

O'SULLIVAN, Dan; IGOE, Tom, (2005), Physical computing: sensing and controlling the physical world with computers. Boston: Thomson.

PANGARO, Paul, (1991-2006), Cybernetics (Definition), Disponível em: http://www.pangaro.com/published/cyber-macmillan.html

PANGARO, Paul, (2005), media-interaction-cybernetics. Palestra proferida no Digital Arts \& New Media Program, UC Santa Cruz, April-25. Disponível em:

<http://www.cyberneticians.com/video/Paul_Pangaro_DANM2005.mov>. (Acesso em 02/11/2008)

PASK, Gordon, (1968), The colloquy of mobiles. In: REICHART, Jasia. Cybernetic Serendipity. The Computers and the Arts, Studio International Special Issue, London/New York, pp. 34-35.

PICARD, Rosalind, (1998), Affective Computing. Cambridge, MA: The MIT Press.

RYOKAI, Kimiko, (2007), I/O Brush: beyond static collages. Proceedings of CHI'07 - Interaction , CA, USA: April 28-May 3.

SIMON, Herbet, (1999) The sciences of the artificial. Cambridge, MA: The MIT Press.

SHARP, Helen; ROGERS, Yvonne; PREECE, Jenny, (2007), Interaction design: beyond humancomputer interaction. 2a Ed. England: John Wiley \& Sons.

SMITH, Courtenay; TOPHAN, Sean, (2002), Xtreme houses. Berlin: Prestel.

TEI'2008. International Conference on Tangible and Embdded Interaction. Disponível em: $<$ http://tei-conf.org/07/cfp.html>. (Acesso em: 30/10/2008)

THACKARA, John, (2005), In the bubble: designing in a complex world. Cambridge, MA: MIT Press.

TRAMONTANO, Marcelo, (2007), Habitares interactivos; 12 notas preliminares. In: Troyano (ed.) Installing: art and digital culture. Santiago: Lom. von FOERSTER, Heinz, (1975), The cybernetics of cybernetics. Minnearpolis, MN: Future Systems Inc.

WEISER, Mark, (1991), The computer for the 21st century. In: Scientific American, 265:66-75. 


\section{\{Índice remissivo\}}

Aegis Hyposurface, dECOi [92]

Affective Twins $[10,12,101,102,106,107,111,113,115,122,127,130,131]$

affective computing [83]

algoritmos [28, 29, 41]

ambientes virtuais (VE, Virtual Environments) [42]

arquitetura $[3,5,9,15,18,22,23,42,54,79,87,89,90,91,93,94,97,115$,

$132,146]$

Ars Electronica [10]

arte $[29,66,68,70,89,131]$

arte computacional [68]

arte interativa [89, 131]

atuadores $[74,87,104,105,106,108,115]$

bit $[27,39,61,62,113,114]$

bitmaps [39]

$\mathrm{BIX}$, realites:united $[89,90]$

BOOLE, George [29] 
Brainball, Interactive Institute [71, 72]

cartões perfurados [34]

Casa Consciente, A. Georgia Institute of Technology [79, 80]

CAVE (Cave Automatic Virtual Environment) [42]

cibernética [6, 7, 102, 127, 128, 129, 134]

complexidade $[4,6,7,46,49,71,102,122,133,134,135,141]$

computação digital $[15,31,101,103,105,147]$

computação física [102, 144]

computação ubíqua $[58,59,60,61,62,66,79,134]$

computação vestível (wearable computing) $[72,76]$

computador analógico [30]

computador digital $[30,31]$

computador pessoal $[15,33,35,36,44,58,62,114]$

design conceitual [16]

design crítico [51]

design centrado no usuário (user-centered design) [46]

D.O.S. - Designers On Spot [10]

Drift Table, Equator [83-86]

EDVAC - Electronic Discrete Variable Automatic Calculator [31]

Engelbart, Doug [36]

espaço hertziano (hertzian space) [94]

feedback [97, 102, 128, 129, 135]

3-D [42, 91]

H2O Pavillion, NOX e Edwin van der Heide [90, 92]

hipertextos [42] 
hardware [32, 37, 45, 119]

iBand, Media Lab Europe [74, 75]

interfaces tangíveis $[11,58,61,62,63,64,111,112,113,114,115]$

interfaces gráficas - GUI, Graphical User Interface [35-41, 61,110, 115, 127]

interfaces físicas [33, 35, 36]

interfaces textuais [36, 38]

Internet $[10,11,78,89,97,110,119]$

intranet [78]

input $[38,64,97,102,103,104,105,108,110,111,113,114,120,124$

$129,132,133,135,144]$

I/O Brush, Tangible Media Group [65, 66]

Key Table, Equator [83-85]

Kunsthausgraz, Peter Cook e Colin Fournier [88-90]

lógica binária $[27,28]$

loop [38, 128, 129]

Mann , Steve [73]

microprocessador $[28,34,36,37]$

multimídia [37, 41, 42]

MusicBottles, Tangible Media Group [17, 18, 24, 25]

narrativas $[15,54,79,108,116]$

Nebula, Philips Design Center [82]

objetos interativos $[3,8,11,12,54,102,105,134,136,137,141,143,146$, 147]

output $[88,102,103,104,105,109,110,111,113,114,120,121,124,129$, 144] 


\section{PASK, Gordon [134, 135]}

PeekaDrawer, Georgia Institute of Technology [80]

PIX [10, 12, 101, 102, 109, 111, 113, 114, 115, 122 - 125, 127, 133]

pixel [29, 39, 63, 113, 114, 115]

Placebo, Anthony Dunne \& Fiona Raby [52, 53, 96]

primeira ordem (cibernética) [127-129]

programação $[25,26,29,32,38,46,64,105,115,117,119,120,133,134$,

$136,143,144]$

realidade virtual (Virtual Reality, VR) [37, 38, 42, 43, 44]

Reconfigurable House, Usman Haque e Adam Somlai-Fischer [87, 88]

Remote Home, Tobi Schneidler [81]

segunda ordem (cibernética) [127, 128, 129, 134]

sensores [ 17, 43, 53, 54, 59, 74, 78, 82, 83, 87, 97, 103, 104, 105, 106,

$108,115,132,133]$

Sky Ear, Usman Haque [95]

smart houses [78]

software [31, 37, 45, 46, 50, 60, 91, 115, 119]

SonicFabric, Alyce Santoro [76, 77]

Tablecloth, Equator [83, 84]

tecidos inteligentes [77]

tecnologias da informação e comunicação (TIC) $[7,49,53,57,62,69,70$,

$87,96,98]$

The Hug Shirt, Cute CIrcuit [74]

transistores [28, 29, 30, 121]

Turn-on, AWG-Alles Wird Gut [23, 24] 
Under Scan, Rafael Lozano-Hemmer [96, 97]

Vectorial Elevation, Rafael Lozano-Hemmer [97, 98]

vídeo-arte [67]

Videoplace, Myron Krueger [68, 69]

Von Neumann, John [31, 32]

WIMP - Windows, Icons, Menus and Pointers [37, 40] 

